Modelos assimétricos inflacionados de zeros

Mariana Ferreira Dias

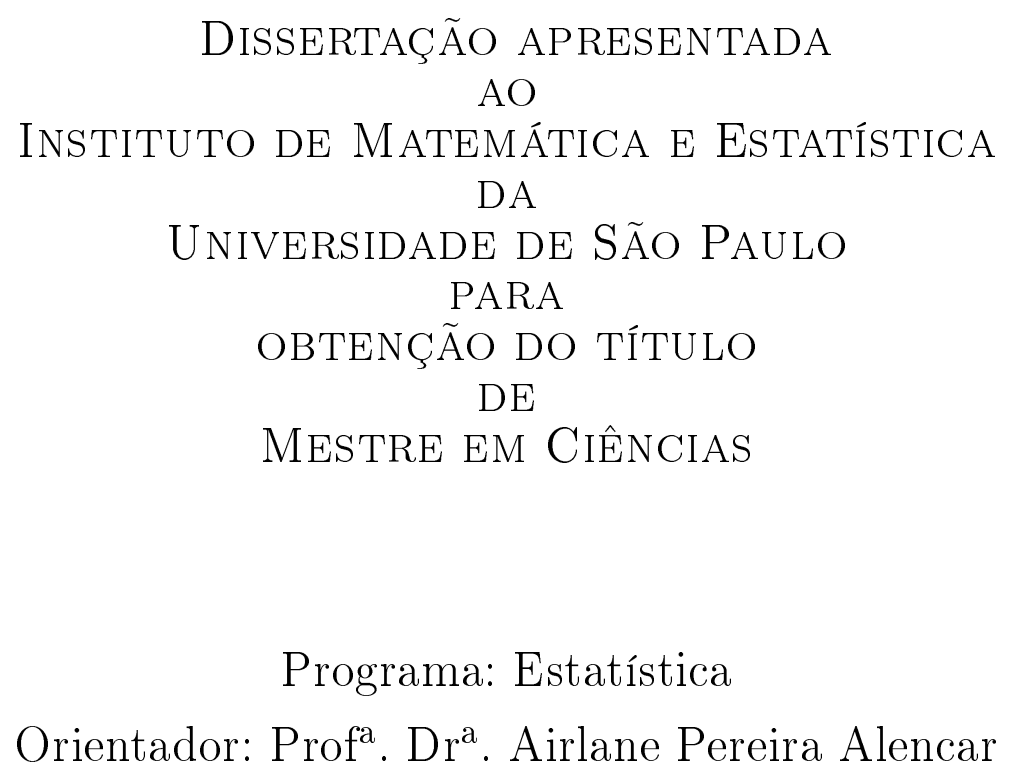

São Paulo, novembro de 2014 


\section{Modelos assimétricos inflacionados de zeros}

Esta versão da dissertação contém as correções e alterações sugeridas pela Comissão Julgadora durante a defesa da versão original do trabalho, realizada em 28/11/2014. Uma cópia da versão original está disponível no

Instituto de Matemática e Estatística da Universidade de São Paulo.

Comissão Julgadora:

- Prof ${ }^{\mathrm{a}}$. Dr ${ }^{\mathrm{a}}$. Airlane Pereira Alencar - IME-USP

- Prof ${ }^{a}$. Dra ${ }^{a}$. Silvia Lopes de Paula Ferrari - IME-USP

- Prof ${ }^{\mathrm{a}}$. Dr ${ }^{\mathrm{a}}$. Ana Luiza de Souza Bierrenbach - UFG 


\section{Agradecimentos}

Agradeço primeiramente a Deus por ter guiado meu caminho ao longo desta jornada. Se não fosse por Sua vontade eu não teria cumprido as longas e difíceis etapas do curso. Agradeço também às pessoas que Ele colocou em meu caminho e que sempre me ajudaram de alguma forma.

À Prof. Airlane por toda a orientação, compreensão e companheirismo ao longo deste trabalho. Mesmo tendo que trabalhar a distância, você nunca deixou de me orientar em todas as etapas. Além disso, seu incentivo para que meu trabalho fosse de grande contribuição para a área aplicada sempre me motivaram muito. Obrigada por ter acreditado em mim e por todo o conhecimento acadêmico (e cultural) que adquiri no decorrer do trabalho.

Aos meus pais, pelas maiores heranças que alguém pode receber em sua vida: o amor e o estudo. Vocês sempre nos fizeram querer ser alguém, e ser alguém que ama o que faz pois consequentemente o fará da melhor forma possível.

À minha querida irmã, especialmente pelo período em que moramos juntas enquanto eu fazia as matérias e que sempre me deu um suporte emocional muito grande, seja em forma de palavras ou em uma taça de vinho.

Ao meu marido, que pacientemente esperou dois anos a mais para casarmos pois eu escolhi aprimorar minha carreira. Obrigada pelos tantos finais de semana que passamos estudando e pelas inúmeras vezes que fiz você ler esta dissertação.

Às minhas amigas Ana Paula e Maria Cecília, que tanto me ajudaram e incentivaram desde os tempos de graduação, a jornada com certeza foi muito mais fácil com a ajuda de vocês. 


\section{Resumo}

DIAS, M. F. Modelos assimétricos inflacionados de zeros. 2014. 74 f. Dissertação (Mestrado) - Instituto de Matemática e Estatística, Universidade de São Paulo, São Paulo, 2014.

A principal motivação desse estudo é a análise da quantidade de sangue recebido em transfusão (padronizada pelo peso) por crianças com problemas hepáticos. Essa quantidade apresenta distribuição assimétrica, além de valores iguais a zero para as crianças que não receberam transfusão. Os modelos lineares generalizados, usuais para variáveis positivas, não permitem a inclusão de zeros. Para os dados positivos, foram ajustados tais modelos com distribuição gama e normal inversa. Também foi considerado o modelo log-normal. A análise de resíduos padronizados indicou heterocedasticidade, e portanto a variabilidade extra foi modelada utilizando a classe de modelos GAMLSS. A terceira abordagem consiste em modelos baseados na mistura de zeros e distribuições para valores positivos, incluídos recentemente na família dos modelos GAMLSS. Estes aliam a distribuição assimétrica para os dados positivos e a probabilidade da ocorrência de zeros. Na análise dos dados de transfusão, observa-se que a distribuição normal inversa apresentou melhor ajuste por acomodar dados com forte assimetria em relação às demais distribuições consideradas. Foram significativos os efeitos das variáveis explicativas Kasai (ocorrência de operação prévia) e PELD (nível de uma medida da gravidade do paciente com 4 níveis) assim como os efeitos de interação sobre a média e variabilidade da quantidade de sangue recebida. A possibilidade de acrescentar efeitos de variáveis explicativas para modelar o parâmetro de dispersão, permite que a variabilidade extra, além de sua dependência da média, seja melhor explicada e melhore o ajuste do modelo. A probabilidade de não receber transfusão depende de modo significativo somente de PELD. A proposta de um só modelo que alia a presença de zeros e diversas distribuições assimétricas facilita o ajuste dos dados e a análise de resíduos. Seus resultados são equivalentes à abordagem em que a ocorrência ou não de transfusão é analisada por meio de modelo logístico independente da modelagem dos dados positivos com distribuições assimétricas.

Palavras-chave: Modelos inflacionados de zeros, GAMLSS, Normal inversa, Gama. 


\section{Abstract}

DIAS, M. F. Zero-inflated asymmetric models. 2014. 74 f. Dissertação (Mestrado) - Instituto de Matemática e Estatística, Universidade de São Paulo, São Paulo, 2014.

The main motivation of this study is to analyze the amount of blood transfusions received (by weight) of children with liver problems. This amount shows asymmetric distribution as well as present zero values for children who did not receive transfusions. The usual generalized linear models for positive variables do not allow the inclusion of zeros. For positive data, such models with gamma and inverse normal distributions were fitted in this study. Log-normal distribution was also considered. Analysis of the standardized residuals indicated heterocedasticity and therefore the extra variability was modelled using GAMLSS. The third approach consists of models based on a mixture of zeros and distributions for positive values, also recently included in the family of GAMLSS models. These models combine the asymmetric distribution of positive data and the probability of occurrence of zeros. In the data analysis of transfusion, the inverse normal distribution showed better goodness of fit to allow adjustment of data with greater asymmetry than the other distributions considered. The effects of the explanatory variables Kasai (occurrence of previous operation) and PELD level (a measure of the severity of the patient with 4 levels) and interaction effects on the mean and variability of the amount of blood received were significant. The inclusion of explanatory variables to model the dispersion parameter, allows to model the extra variability, beyond its dependence on the average, and improves fitness of the model. The probability of not receiving transfusion depends significantly only PELD. The proposal of a unified model that combines the presence of zeros and several asymmetric distributions greatly facilitates the fitness of the model and the evaluation of fitness. An advantage is the equivalence between this model and a separate logistic model to for the probability of the occurrence of transfusion and a model for the positive skewed data.

Keywords: Zero-adjusted models, GAMLSS, Inverse Gaussian, Gamma. 


\section{Sumário}

$\begin{array}{ll}\text { Lista de Figuras } & \text { ix }\end{array}$

Lista de Tabelas $\quad$ xi

1 Introdução $\quad \mathbf{1}$

1.1 Considerações Preliminares . . . . . . . . . . . . . . . . . . . . 1

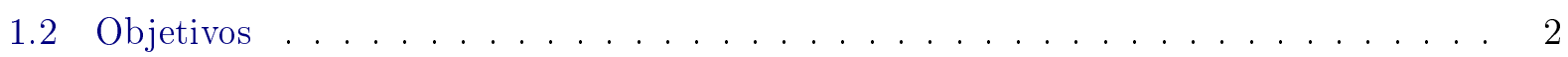

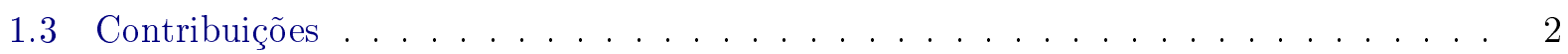

1.4 Organização do Trabalho . . . . . . . . . . . . . . . . . . 3

2 Conceitos 5

2.1 Distribuição Gama . . . . . . . . . . . . . . . . . . . . . . . 5

2.1 .1 Distribuição Gama zero ajustada . . . . . . . . . . . . . . . 5

2.2 Distribuição Log-Normal . . . . . . . . . . . . . . . . . . . . . . . . . . . 6

2.3 Distribuição Normal Inversa . . . . . . . . . . . . . . . . . . . . 7

2.3.1 Distribuição Normal Inversa zero ajustada . . . . . . . . . . . . . . . . . . 7

2.4 Comparação entre as distribuições . . . . . . . . . . . . . . . . . 9

3 Modelos de Regressão $\quad 11$

3.1 Modelos Lineares Generalizados . . . . . . . . . . . . . . . . . . . . . . . 12

3.1 .1 Definição . . . . . . . . . . . . . . . . . . . . . 12

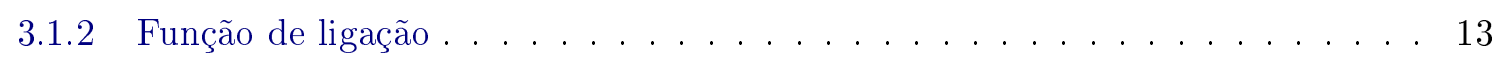

3.1.3 Estimação dos parâmetros do modelo . . . . . . . . . . . . . . . . 14

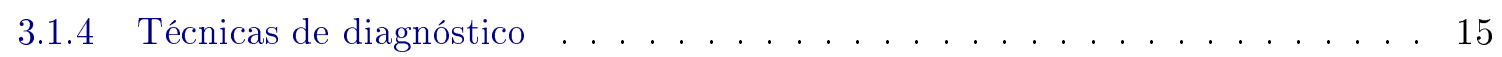

3.1.5 Seleção do modelo . . . . . . . . . . . . . . . . . . 15

3.1.6 Intervalo de confiança para o indivíduo . . . . . . . . . . . . . . . 17

3.2 Modelos Aditivos Generalizados para Posição, Escala e Forma . . . . . . . . . . . . 17

3.2 .1 Definição . . . . . . . . . . . . . . . . . . . . . . 17

3.2 .2 Função de ligação . . . . . . . . . . . . . . . . . . . . . . . . . . . 19

3.2.3 Estimação dos parâmetros do modelo . . . . . . . . . . . . . . . . . 19

3.2 .4 Técnicas de diagnóstico . . . . . . . . . . . . . . . . . 20

3.2 .5 Seleção do modelo . . . . . . . . . . . . . . . . . . . 21

3.2 .6 Intervalo de confiança para o indivíduo . . . . . . . . . . . . 22 
4.1 Análise descritiva . . . . . . . . . . . . . . . . . . . . 23

4.1 .1 Base de dados $\mathrm{A} \ldots \ldots \ldots \ldots \ldots \ldots$

4.1 .2 Base de dados B . . . . . . . . . . . . . . . 27

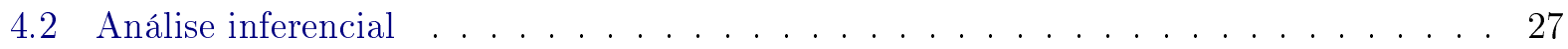

4.2.1 GLM com distribuições gama, log-normal e normal inversa . . . . . . . . . 28

4.2.2 GAMLSS com distribuições gama, log-normal e normal inversa . . . . . . . . 31

4.2.3 GAMLSS com distribuições gama zero ajustada e normal inversa zero ajustada 35

4.3 Seleção do Modelo . . . . . . . . . . . . . . . . . . . . . 38

5 Estudo bootstrap $\quad 45$

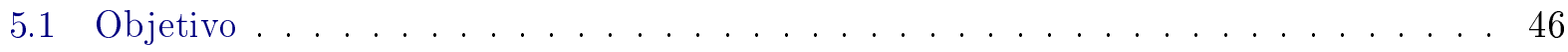

5.2 Resultados . . . . . . . . . . . . . . . . . . . 46

6 Conclusões e sugestões $\quad 55$

Referências Bibliográficas . . . . . . . . . . . . . . . . . 59 


\section{Lista de Figuras}

2.1 Funções densidade da distribuição gama para diversos valores do parâmetro $\sigma$. . . . 6

2.2 Funções densidade da distribuição ZAGA para diversos valores do parâmetro $\sigma$. . . . 7

2.3 Funções densidade da distribuição log-normal para diversos valores do parâmetro $\sigma$. 8

2.4 Funções densidade da distribuição normal inversa para diversos valores do parâmetro

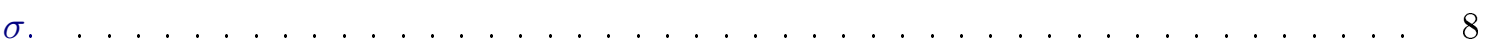

2.5 Funções densidade da distribuição ZAIG para diversos valores do parâmetro $\sigma$. . . . 9

3.1 Gráficos de diagnóstico para um modelo ajustado a dados com resposta normal inversa. 16

3.2 Gráfico normal de probabilidades para um modelo ajustado a dados com resposta normal inversa. . . . . . . . . . . . . . . . . . . . . . 16

4.1 Histograma da variável de transfusão de sangue por peso do paciente. . . . . . . . . . 24

4.2 Boxplot da transfusão de sangue por peso do paciente segundo Kasai. . . . . . . . . 25

4.3 Boxplot da transfusão de sangue por peso segundo PELD. . . . . . . . . . . . . . . . 26

4.4 Perfis médios da transfusão de sangue por peso segundo Kasai e PELD. . . . . . . . 26

4.5 Gráfico de envelope para os modelos GLM. . . . . . . . . . . . . . . . . . . . . . 30

4.6 Gráficos de resíduos padronizados para os modelos GLM. . . . . . . . . . . . . . . . 30

4.7 Gráficos para diagnóstico do ajuste do modelo considerando a distribuição gama para os dados. . . . . . . . . . . . . . . . . . . . . . . . . . . 33

4.8 Gráficos para diagnóstico do ajuste do modelo considerando a distribuição log-normal para os dados. . . . . . . . . . . . . . . . . . . . . . . . 34

4.9 Gráficos para diagnóstico do ajuste do modelo considerando a distribuição normal inversa para os dados. . . . . . . . . . . . . . . . . . . . . . . . . 34

4.10 Gráficos para diagnóstico do ajuste do modelo considerando a distribuição ZAGA para os dados. . . . . . . . . . . . . . . . . . . . . . . . 37

4.11 Gráficos para diagnóstico do ajuste do modelo considerando a distribuição ZAIG para os dados. . . . . . . . . . . . . . . . . . . . . . . . . . 38

4.12 Gráficos para diagnóstico do ajuste do modelo selecionado. . . . . . . . . . . . . . . . 41

4.13 Gráficos para diagnóstico dos resíduos do modelo selecionado. . . . . . . . . . . . . . 42

4.14 Perfis médios estimados pelo modelo final da transfusão de sangue por peso segundo Kasai e PELD. . . . . . . . . . . . . . . . . . . . . . . . . . . 43

5.1 Histograma das estimativas para cada $\hat{\beta}_{j}^{*}$ derivados do ajuste do parâmetro $\mu$. . . . . 47

5.2 Gráfico quantil-quantil das estimativas para cada $\hat{\beta}_{j}^{*}$ derivados do ajuste do parâme-

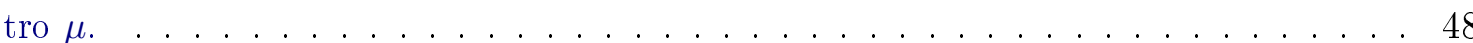


5.3 Histograma das estimativas para cada $\hat{\alpha}_{j}^{*}$ derivados do ajuste do parâmetro $\sigma . \ldots \quad$. 49

5.4 Gráfico quantil-quantil das estimativas para cada $\hat{\alpha}_{j}^{*}$ derivados do ajuste do parâme-

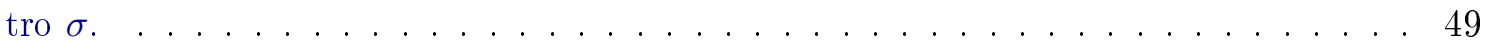

5.5 Histograma das estimativas para cada $\hat{\gamma}_{j}^{*}$ derivados do ajuste do parâmetro $\nu$. . . . 50

5.6 Gráfico quantil-quantil das estimativas para cada $\hat{\gamma}_{j}^{*}$ derivados do ajuste do parâme-

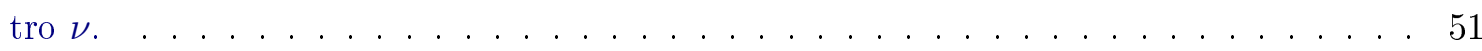

5.7 Histograma das estimativas para cada $\hat{\gamma}_{j}^{*}$ derivados do ajuste do parâmetro $\nu$ no

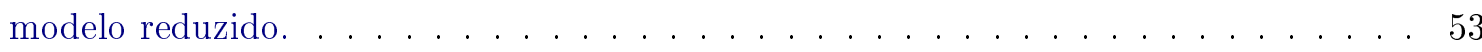

5.8 Gráfico quantil-quantil das estimativas para cada $\hat{\gamma}_{j}^{*}$ derivados do ajuste do parâmetro $\nu$ no modelo reduzido. . . . . . . . . . . . . . . . . . 54 


\section{Lista de Tabelas}

3.1 Funções de ligação utilizadas nos modelos GAMLSS. . . . . . . . . . . . . . . . . 19

4.1 Medidas descritivas da transfusão de sangue por peso segundo Kasai. . . . . . . . . . 25

4.2 Medidas descritivas da transfusão de sangue por peso segundo PELD . . . . . . . . . 25

4.3 Coeficiente de variação de transfpeso segundo Kasai e PELD. . . . . . . . . . . . . 27

4.4 Frequência da ocorrência de transfusão segundo Kasai. . . . . . . . . . . . . . . . 27

4.5 Frequência da ocorrência de transfusão segundo PELD . . . . . . . . . . . . . . . . 27

4.6 Estimativas dos modelos GLM . . . . . . . . . . . . . . . . . . 29

4.7 Estimativas dos modelos GAMLSS para o parâmetro de posição $\mu$. . . . . . . . . 32

4.8 Estimativas dos modelos GAMLSS para o parâmetro de escala $\sigma \ldots \ldots$. . . . . . . 32

4.9 Medidas resumo do resíduo quantílico para os modelos GAMLSS. . . . . . . . . . . . 33

4.10 Estimativas dos modelos GAMLSS para o parâmetro de posição $\mu$. . . . . . . . 36

4.11 Estimativas dos modelos GAMLSS para o parâmetro de escala $\sigma \ldots \ldots$. . . . . . . 36

4.12 Estimativas dos modelos GAMLSS para a probabilidade de não receber transfusão $\nu .37$

4.13 Medidas do resíduo quantílico aleatorizado para os modelos com distribuição ZAGA

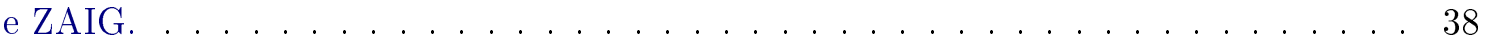

4.14 Valores do critério GAIC para seleção de variáveis nos ajustes dos parâmetros da distribuição. . . . . . . . . . . . . . . . . . . . . . 39

4.15 Estimativas do modelo selecionado. . . . . . . . . . . . . . . . . . . . . 41

4.16 Medidas do resíduo quantílico aleatorizado para o modelo selecionado. . . . . . . . . 41

4.17 Efeitos estimados com intervalo de confiança e valor-p para o ajuste do parâmetro $\mu .42$

4.18 Intervalo de confiança para a transfusão de sangue por peso. . . . . . . . . . . . . . . 43

5.1 Medidas descritivas dos coeficientes $\hat{\beta}_{j}^{*}$ para as amostras bootstrap do modelo ZAIG. 50

5.2 Medidas descritivas dos coeficientes $\hat{\alpha}_{j}^{*}$ para as amostras bootstrap do modelo ZAIG. 51

5.3 Medidas descritivas dos coeficientes $\hat{\gamma}_{j}^{*}$ para as amostras bootstrap do modelo ZAIG. $\quad 52$

5.4 Medidas descritivas dos coeficientes $\hat{\gamma}_{j}^{*}$ para as amostras bootstrap do modelo ZAIG

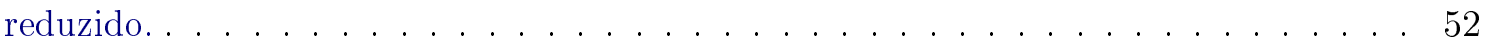




\section{Capítulo 1}

\section{Introdução}

\subsection{Considerações Preliminares}

$\mathrm{Na}$ área da saúde, uma infinidade de medidas podem ser avaliadas em pacientes que sofrem de algum tipo de doença. É de grande interesse para a população que estas medidas possam ser utilizadas em seu próprio proveito, na forma de avaliação da eficácia de um certo tratamento, ou ainda, para o desenvolvimento de um novo.

Estas medidas podem se apresentar em diferentes formatos: de forma binária, por exemplo, definindo a presença ou não de uma característica do indivíduo, em forma de contagem, como o número de vezes que o indivíduo foi internado, ou ainda, o alvo deste trabalho, o volume de sangue em relação ao peso do paciente recebido em uma transfusão.

A motivação para o estudo partiu dos dados de pacientes com atresia biliar (AB), uma doença hepática rara, identificada geralmente durante o período neonatal. Esta doença é a principal responsável pela necessidade de transplante de fígado na faixa etária pediátrica. Após sua identificação, o procedimento de portoenterostomia de Kasai, que consiste na drenagem da bílis, é recomendado para o paciente, possibilitando um adiamento da cirurgia de transplante. Ainda que isto seja um grande benefício por proporcionar um tempo maior para encontrar um órgão compatível, além de permitir um tempo de desenvolvimento para o recém-nascido, notam-se maiores riscos para o paciente no momento da cirurgia de transplante. Entre estes riscos, um sangramento excessivo, que evidentemente não pode ser mensurável, e portanto é representado pelo volume de transfusão de sangue recebido, padronizado pelo peso do indivíduo.

Esse volume de sangue, assim como algumas medidas mencionadas, não apresentam um comportamento condizente com a distribuição normal, que poderiam ser ajustadas em modelos de regressão linear, a abordagem mais comum para modelagem de dados. Assim, outros tipos de distribuição devem ser avaliadas como alternativa, juntamente com suas metodologias para ajuste de modelos de regressão. $\mathrm{O}$ volume de sangue seria condizente com distribuições que tratam de dados positivos assimétricos, dado que a maior parte dos pacientes recebeu um volume de até $5 \%$ de seu peso, mas uma quantidade considerável ainda se distribuiu até o máximo de $20 \%$. Por este motivo, o estudo irá testar a adequação das distribuições gama, log-normal e normal inversa para modelagem dos dados.

Distribuições usuais para modelagem de dados assimétricos não compreendem o valor zero em seu domínio, situação das distribuições supracitadas. Não obstante, em alguns casos este valor está presente na variável em estudo, representando neste caso os pacientes que não precisaram receber transfusão de sangue. Desta forma, o ajuste de um modelo de regressão com as referentes distribuições seria impróprio, visto que as observações iguais a zero teriam que ser descartadas. Estes pacientes ainda assim presumivelmente sofreram sangramentos durante a cirurgia e portanto suas informações são importantes.

Com isso, a distribuição precisaria ser adequada para cobrir os valores nulos da variável. Ou, de forma alternativa, o modelo de regressão se adaptar para a modelagem dos dados. Assim, o ajuste dos dados inicia-se pelos modelos lineares generalizados (Generalized Linear Models - GLM), pro- 
postos por Nelder e Wedderburn (1972) e que, por suportarem distribuições pertencentes à família exponencial linear, permitem a suposição de distribuições assimétricas para os dados. Por vezes, os dados apresentam ainda uma variabilidade distinta para diferentes unidades amostrais, de forma não proporcional a uma função da média, levando à necessidade de modelagem do parâmetro de escala do modelo. Este tipo de abordagem pode ser realizada por meio dos modelos lineares generalizados duplos (Double Generalized Linear Models - DGLM) introduzidos por Smyth (1989), que além da modelagem da média, ajusta simultaneamente um modelo para o parâmetro de escala, ou de forma equivalente, pelos modelos aditivos generalizados para locação, escala e forma (Generalized Additive Models for Location, Scale and Shape - GAMLSS) desenvolvidos por Rigby e Stasinopoulos (2001, 2005) e Akantziliotou et al. (2002).

Estes modelos consideram apenas as observações positivas, e portanto, a base de dados é reduzida na modelagem. Uma solução para a adequação da distribuição baseia-se em misturas de distribuições, como por exemplo quando a variável é zero com uma certa probabilidade $p$ e é maior que zero, seguindo uma distribuição como a normal inversa, com probabilidade $1-p$. Atualmente, os modelos GAMLSS englobaram essas distribuições como a distribuição normal inversa zero ajustada (zero adjusted inverse gaussian - ZAIG), e gama zero ajustada (zero adjusted gamma - ZAGA).

Ao fazer um paralelo com a técnica utilizada para adaptação da distribuição, investiga-se a possibilidade da modelagem dos dados sob distribuição ZAIG ser análoga ao ajuste de um modelo GLM para os dados positivos considerando a distribuição normal inversa e outro, independente, para a probabilidade de não receber transfusão de sangue, definida pela codificação da variável resposta de forma binária, classificando a ocorrência ou não de transfusão de sangue.

\subsection{Objetivos}

O principal objetivo desta dissertação é avaliar comparativamente as metodologias disponíveis para o ajuste de dados de característica assimétrica inflacionados de zeros e que ainda apresentam heterogeneidade extra entre unidades amostrais. De forma secundária, as distribuições sugeridas pela literatura para esta categoria de dados também são avaliadas, buscando a compreensão de suas particularidades.

As comparações entre as classes de modelos propostos foram realizadas basicamente em termos de:

- Estimativas, erros padrões e significância de efeitos de variáveis explicativas;

- Análise de resíduos;

- Critérios de seleção de variáveis;

- Adequabilidade às características dos dados: assimetria, heterocedasticidade, valores nulos.

\subsection{Contribuições}

As principais contribuições desta dissertação são definidas pelos seguintes itens:

- Confrontamento entre as distribuições gama, log-normal e normal inversa, amplamente aplicadas a dados de características assimétricas. Foi possível ressaltar suas diferenças, em particular, o poder de adaptação da distribuição normal inversa a dados altamente assimétricos;

- Evolução e comparação entre diferentes metodologias de modelagem de dados que suportam as distribuições citadas, acentuando suas vantagens e deficiências para ajuste dos dados;

- Averiguação da possibilidade do ajuste de um modelo inflacionado de zeros para diversas distribuições, dada a equivalência do ajuste do modelo GAMLSS com distribuição ZAIG em relação ao modelo com ajuste somente para os dados positivos paralelamente a um modelo logístico para a probabilidade de ocorrência de zeros na variável resposta. 
- Definição do intervalo de confiança para a resposta do indivíduo, baseando-se nos resultados do modelo escolhido;

- Estudo bootstrap para os estimadores dos coeficientes dos parâmetros da distribuição modelados. Teoricamente, estes seguem uma distribuição normal assintoticamente, porém o estudo mostrou que especificamente para os parâmetros de escala e forma (nesta dissertação caracterizando a probabilidade de ocorrência de uma observação nula) esta hipótese é violada. Não obstante, a construção de intervalos de confiança bootstrap homologaram os resultados da metodologia selecionada para o modelo final aplicado aos dados, mostrando a importância desta técnica computacional.

\subsection{Organização do Trabalho}

A presente dissertação está organizada em seis capítulos. No Capítulo 1 uma descrição do contexto motivacional do estudo e os objetivos do trabalho são apresentados. No Capítulo 2 as distribuições que podem ser atribuídas aos dados são apresentadas de forma detalhada, assim como suas propriedades e comparações são discutidas. O Capítulo 3 consiste na apresentação das classes de modelos de regressão utilizadas para ajuste dos dados, considerando as etapas aplicadas neste trabalho. As aplicações das metodologias exploradas nos Capítulos 2 e 3 encontram-se no Capítulo 4 , juntamente com a discussão sobre a abordagem mais adequada para os dados que motivaram o estudo. No Capítulo 5 a técnica de bootstrap é aplicada ao modelo selecionado para verificação dos resultados obtidos. Finalizando, o Capítulo 6 apresenta as conclusões e sugestões a respeito de todo o conteúdo desenvolvido ao longo da dissertação. 


\section{Capítulo 2}

\section{Conceitos}

Neste capítulo serão apresentadas as propriedades e particularidades das distribuições consideradas neste trabalho: Gama, Log-Normal e Normal Inversa. Estas pertencem à classe de distribuições assimétricas positivas e são geralmente utilizadas em dados de tempo de sobrevivência, taxas e medidas comuns em áreas médicas, conforme citado por Paula (2013), como por exemplo o percentual de sangue recebido por um indivíduo em relação ao seu peso, medida deste trabalho.

Ao final do capítulo serão discutidas suas diferenças e semelhanças.

\subsection{Distribuição Gama}

A distribuição gama possui diferentes parametrizações para sua função densidade de probabilidade e neste trabalho será apresentada a mesma forma adotada por Stasinopoulos et al. (2014).

Uma variável aleatória $Y$ com distribuição gama, parâmetros de locação $\mu$ e escala $\sigma$, tem sua função densidade expressa da seguinte forma

$$
f_{Y}(y \mid \mu, \sigma)=\frac{1}{\left(\sigma^{2} \mu\right)^{\frac{1}{\sigma^{2}}}} \frac{y^{\frac{1}{\sigma^{2}}-1} e^{-y /\left(\sigma^{2} \mu\right)}}{\Gamma\left(1 / \sigma^{2}\right)},
$$

em que $y>0, \mu>0$ e $\sigma>0$. Sua média e variância são dadas respectivamente por $E(Y)=\mu$ e $\operatorname{Var}(Y)=\sigma^{2} \mu^{2}$.

Com grande versatilidade, alterando os parâmetros da distribuição gama é possível obter diversas formas para sua função densidade. A Figura 2.1 apresenta o comportamento desta função para diversos valores de $\sigma$. É possível notar que para valores menores do parâmetro de escala a distribuição se aproxima da simetria em torno da média.

\subsubsection{Distribuição Gama zero ajustada}

Sendo uma extensão da distribuição gama, esta permite que a ocorrência de zeros seja incorporada à analise da base de dados que contém valores da variável resposta iguais a zero. Neste caso, considera-se que as observações são geradas por dois processos: um de natureza discreta, referente à probabilidade de ocorrência da observação igual a zero, e um de distribuição contínua, que caracteriza as observações positivas.

Assim sendo, a distribuição da variável aleatória $Y$ pode ser escrita como uma função de probabilidade discreta-contínua mista, conforme Heller et al. (2006)

$$
f(y)=\left\{\begin{array}{l}
1-\pi, y=0 \\
\pi g(y), y>0
\end{array}\right.
$$

em que $g(y)$ é a densidade da distribuição gama e $\pi$ a probabilidade de ocorrência da observação. 
Gamma, GA

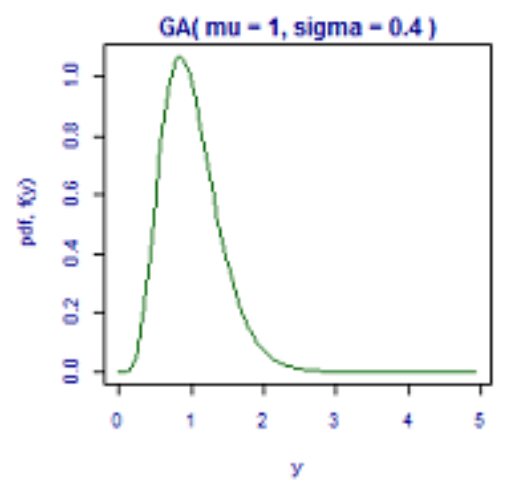

Gamma, GA

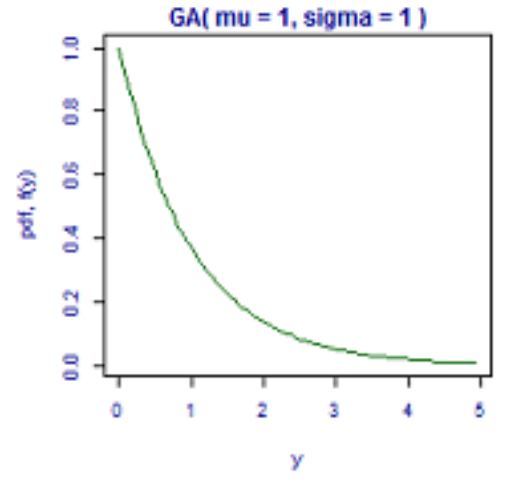

Gamma, GA

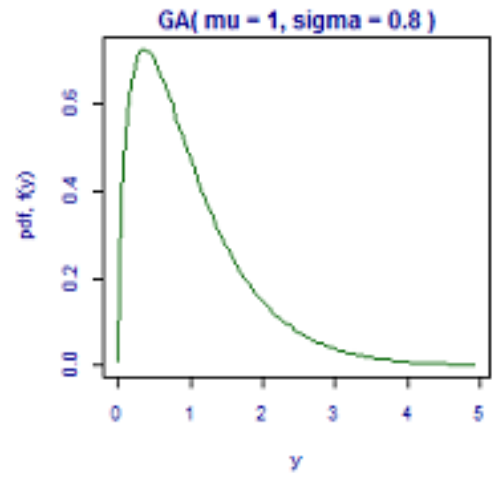

Gamma, GA

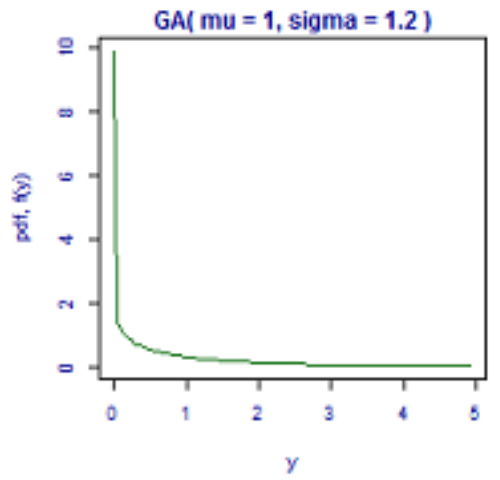

Figura 2.1: Funções densidade da distribuição gama para diversos valores do parâmetro $\sigma$.

A distribuição do modelo zero adjusted gamma (ZAGA) definida por Stasinopoulos et al. (2014) apresenta uma pequena modificação na parametrização, sendo o parâmetro $\nu$ correspondente à probabilidade da observação ser igual a zero. Assim, a função densidade de probabilidade é dada por

$$
f_{Y}(y \mid \mu, \sigma, \nu)=\left\{\begin{array}{l}
\nu, y=0 \\
(1-\nu)\left\{\frac{1}{\left(\sigma^{2} \mu\right)^{1 / \sigma^{2}}} \frac{y^{\frac{1}{\sigma^{2}}-1} e^{-y /\left(\sigma^{2} \mu\right)}}{\Gamma\left(1 / \sigma^{2}\right)}\right\}, y>0,
\end{array}\right.
$$

em que $\mu>0, \sigma>0$ e $0<\nu<1 \operatorname{com} E(Y)=(1-\nu) \mu$ e $\operatorname{Var}(Y)=(1-\nu) \mu^{2}\left(\nu+\sigma^{2}\right)$.

Os gráficos na Figura 2.2 mostram comportamento similar em relação aos da Figura $2.1 \mathrm{com}$ exceção à massa presente no ponto $y=0$, correspondente à parte discreta do modelo. Nas densidades apresentadas nessa figura, a probabilidade de ocorrência de zero é de $20 \%$ e, de forma complementar, a probabilidade de valores positivos da variável aleatória $Y$ é igual a $80 \%$.

\subsection{Distribuição Log-Normal}

Uma variável aleatória $Y$ tem distribuição log-normal se a variável $X$ resultante da transformação $X=\log (Y)$ seguir a distribuição normal com média $\mu$ e variância $\sigma^{2}$. A transformação logarítmica permite que operações com esta variável retornem sempre valores positivos. A função densidade de probabilidade é dada por (Stasinopoulos et al., 2014)

$$
f_{Y}(y \mid \mu, \sigma)=\frac{1}{y \sqrt{2 \pi \sigma^{2}}} \exp \left\{-\frac{[\log (y)-\mu]^{2}}{2 \sigma^{2}}\right\}
$$

para $y>0, \mu=(-\infty, \infty)$ e $\sigma>0$. A média de $Y$ será $E(Y)=w^{1 / 2} e^{\mu}$ e a variância $\operatorname{Var}(Y)=$ 

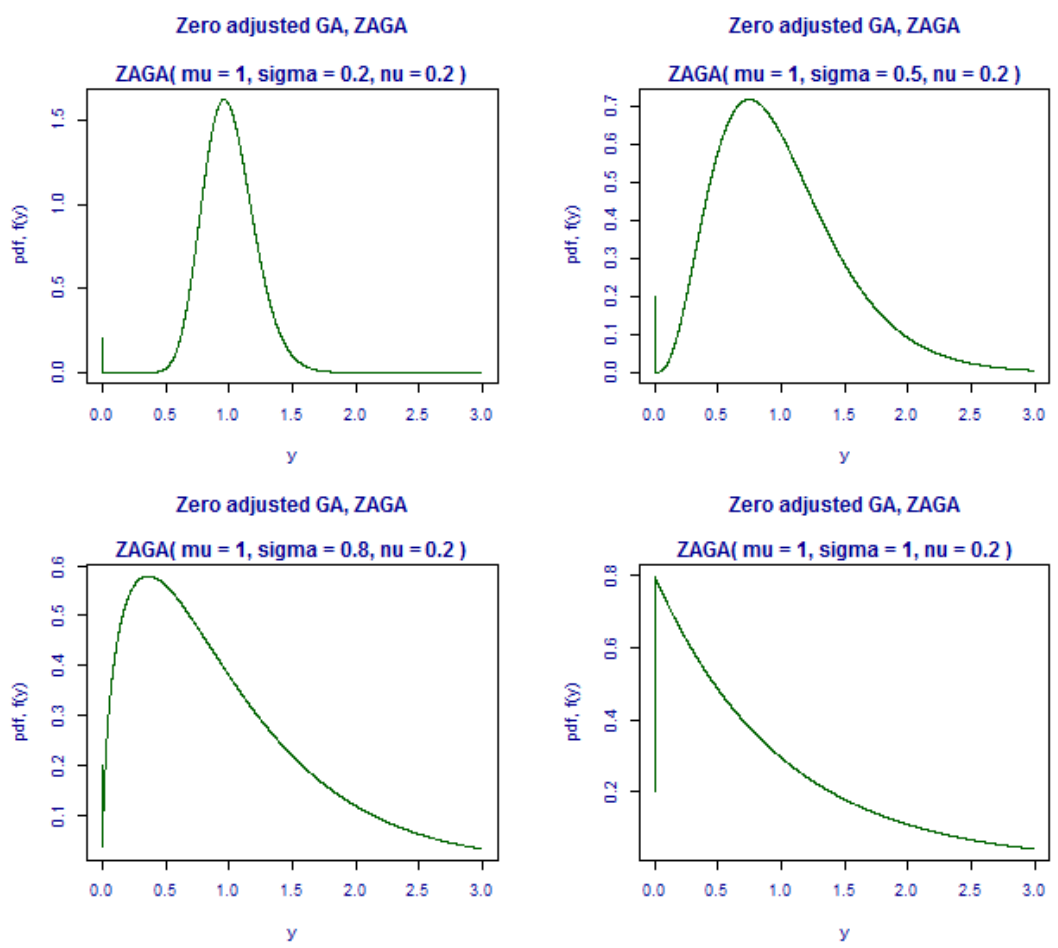

Figura 2.2: Funções densidade da distribuição ZAGA para diversos valores do parâmetro $\sigma$.

$w(w-1) e^{2 \mu}$ em que $w=\exp \left(\sigma^{2}\right)$.

Assim como a distribuição gama, a função densidade de probabilidade da log-normal assume diferentes formatos, aproximando-se da simetria para valores baixos do parâmetro de escala, $\sigma$. Este padrão de comportamento pode ser observado na Figura 2.3 onde estão presentes os gráficos das densidades fixando $\mu=0.1$.

\subsection{Distribuição Normal Inversa}

Uma variável aleatória $Y$ com distribuição normal inversa tem sua função densidade de probabilidade definida da seguinte forma, conforme Stasinopoulos et al. (2014)

$$
f_{Y}(y \mid \mu, \sigma)=\frac{1}{\sqrt{2 \pi \sigma^{2} y^{3}}} \exp \left\{-\frac{1}{2 \mu^{2} \sigma^{2} y}(y-\mu)^{2}\right\},
$$

para $y>0, \mu>0$ e $\sigma>0$. A média de $Y$ é dada por $E(Y)=\mu$ e sua variância $\operatorname{Var}(Y)=\sigma^{2} \mu^{3}$.

Seguindo o mesmo padrão em relação às distribuições apresentadas anteriormente, ao considerar diversos valores para o parâmetro de escala, a distribuição normal inversa também se adapta à dados com comportamento simétrico para valores menores de $\sigma$. Na Figura 2.4 estão presentes os resultados destes diferentes valores de $\sigma$ considerando $\mu=1$.

\subsubsection{Distribuição Normal Inversa zero ajustada}

De forma similar à apresentada na Seção 2.1.1, esta extensão da distribuição normal inversa possibilita a análise de variáveis que seguem uma distribuição positiva assimétrica com ocorrência de zeros.

A distribuição do modelo zero adjusted inverse gaussian (ZAIG) definida por Stasinopoulos et al. (2014) é dada por 


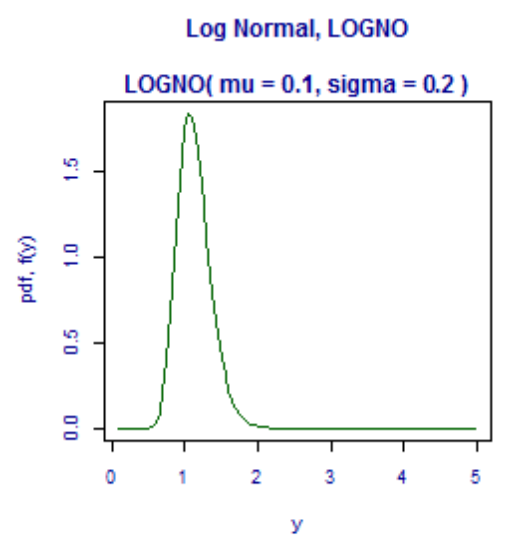

Log Normal, LOGNO

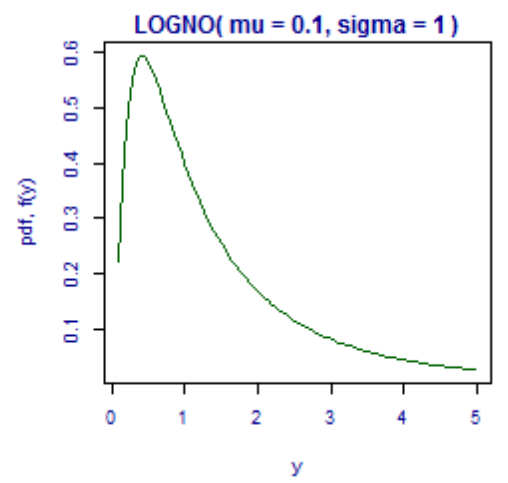

Log Normal, LOGNO

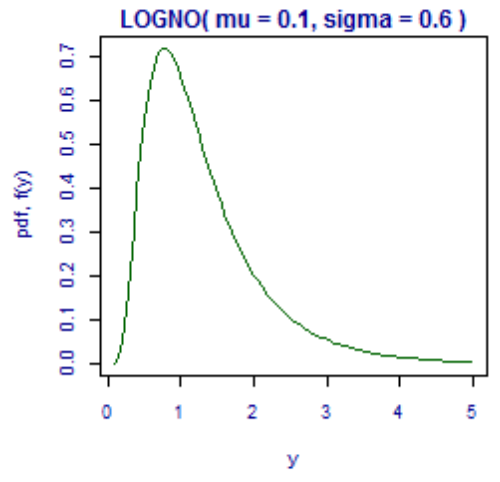

Log Normal, LOGNO

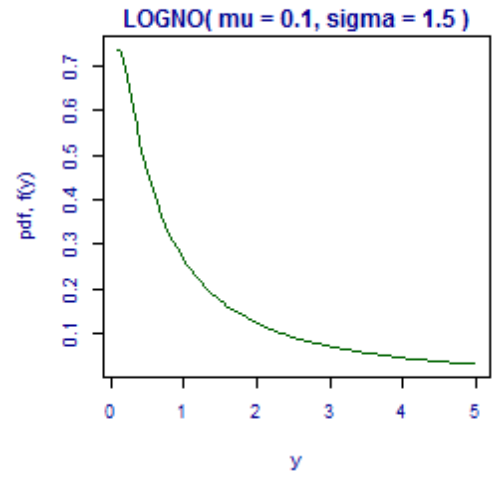

Figura 2.3: Funções densidade da distribuição log-normal para diversos valores do parâmetro $\sigma$.
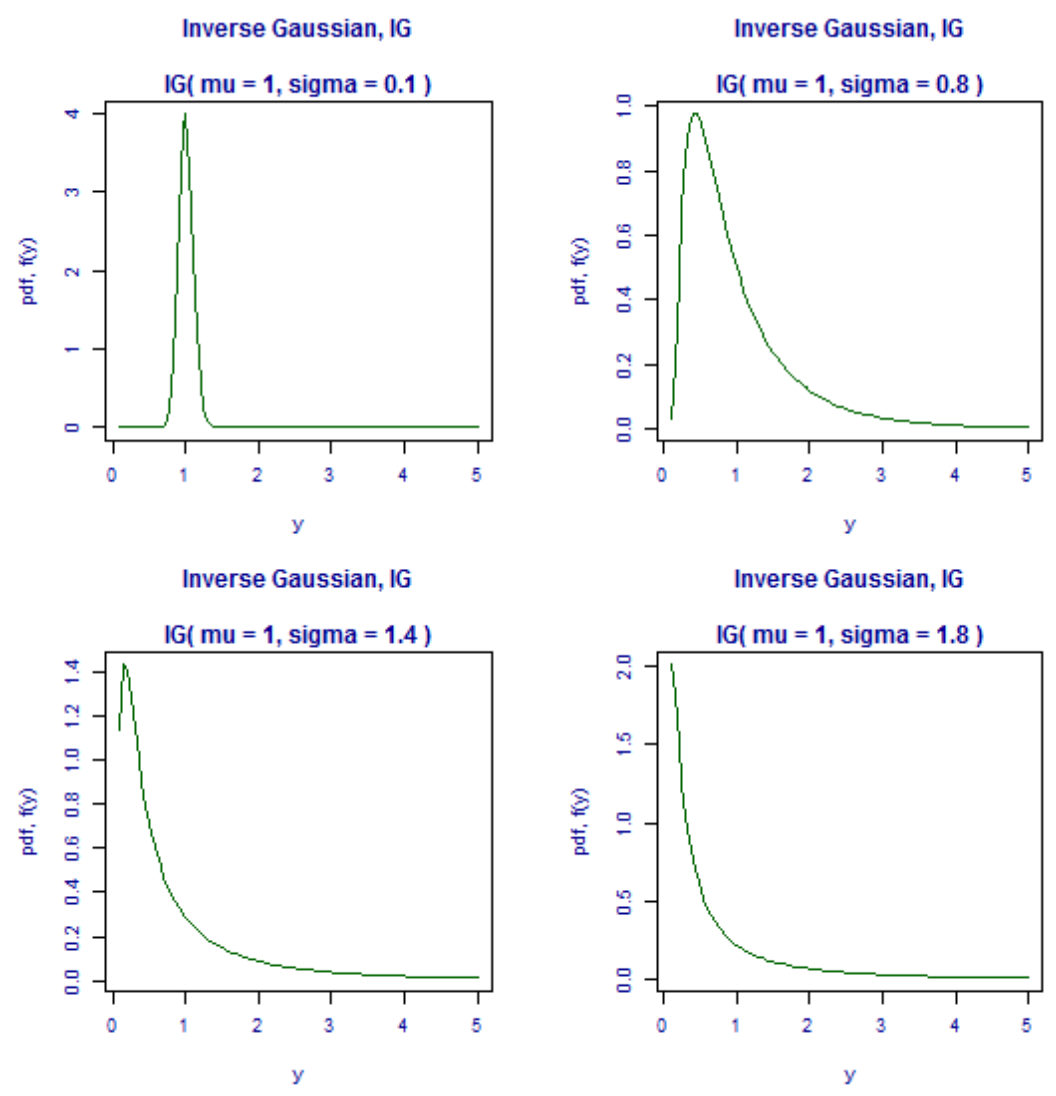

Figura 2.4: Funções densidade da distribuição normal inversa para diversos valores do parâmetro $\sigma$. 


$$
f_{Y}(y \mid \mu, \sigma, \nu)=\left\{\begin{array}{l}
\nu, y=0 \\
(1-\nu)\left\{\frac{1}{\sqrt{2 \pi \sigma^{2} y^{3}}} \exp \left[-\frac{(y-\mu)^{2}}{2 \mu^{2} \sigma^{2} y}\right]\right\}, y>0,
\end{array}\right.
$$

em que $\mu>0, \sigma>0$ e $0<\nu<1 \operatorname{com} E(Y)=(1-\nu) \mu$ e $\operatorname{Var}(Y)=(1-\nu) \mu^{2}\left(\nu+\mu \sigma^{2}\right)$.

Novamente, os gráficos na Figura 2.5 são similares ao gráfico da distribuição original presentes na Figura 2.4 porém com o acréscimo de uma probabilidade de $20 \%$ de ocorrência $y=0$, correspondente à parte discreta do modelo.
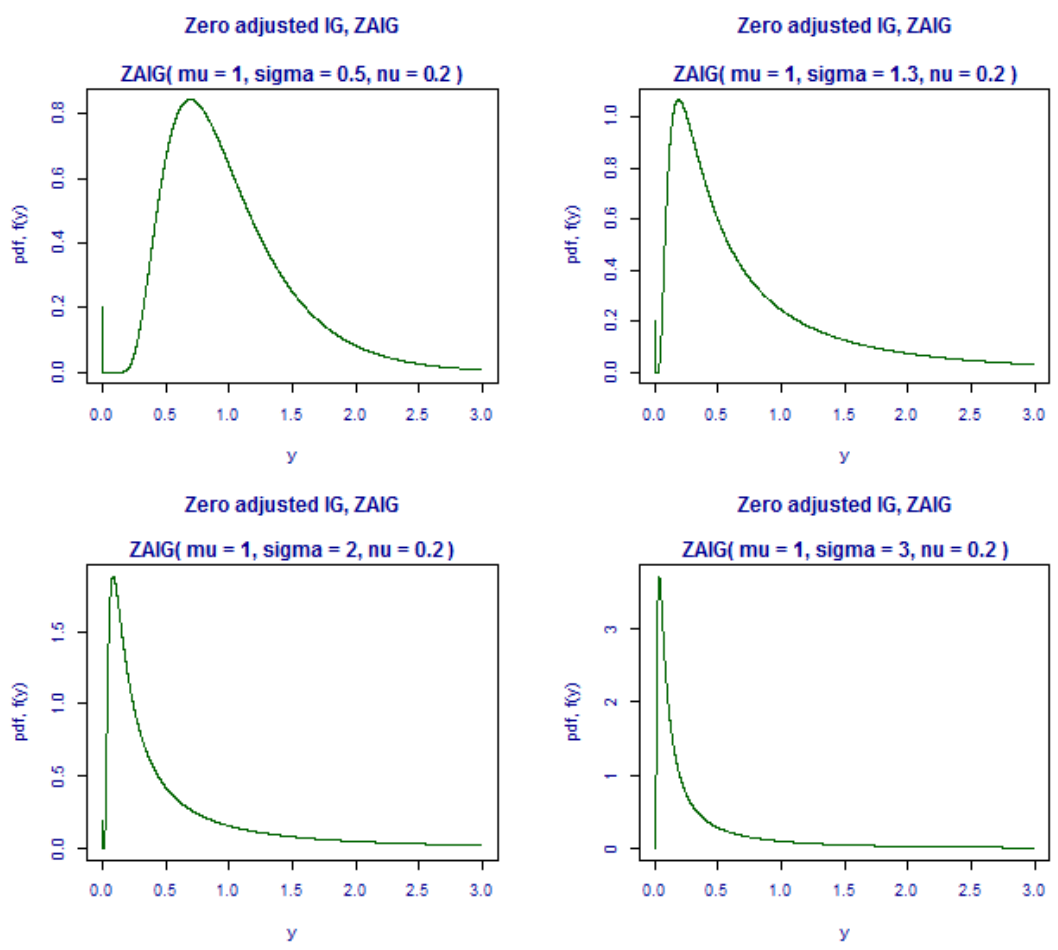

Figura 2.5: Funções densidade da distribuição ZAIG para diversos valores do parâmetro $\sigma$.

\subsection{Comparação entre as distribuições}

É usual adotar o modelo gama para variáveis assumindo valores positivos, principalmente porque essa distribuição pertence à família exponencial e está incluída na classe dos modelos lineares generalizados, como discutido na próxima seção. É interessante notar que o parâmetro de escala nessa parametrização proposta por Stasinopoulos et al. (2014), corresponde ao inverso do parâmetro de dispersão apresentado ao se escrever densidades de distribuições pertencentes à família exponencial, como em Paula (2013). Para membros da família exponencial, observa-se que se o parâmetro de dispersão cresce, a distribuição da variável de interesse se aproxima para a distribuição normal como apresentado em Jorgensen (1987).

$\mathrm{Na}$ avaliação dos gráficos da função de densidade de probabilidade das três distribuições, foi possível verificar esse comportamento de que para valores menores do parâmetro $\sigma$, as densidades de probabilidade se aproximam da simetria. Dessa forma, as distribuições tornam-se atrativas para o estudo de variáveis assimétricas e também simétricas em que a variância depende da média (Paula, 2013).

O ajuste de modelos estatísticos considerando que os dados seguem distribuição gama ou lognormal apresenta uma característica interessante, já que assume que o coeficiente de variação é constante, ou seja, a razão entre o desvio padrão e a média da variável resposta não varia. Isso 
indica que quanto maior a média da variável, maior seu desvio padrão. Geralmente a análise de dados a partir destas duas distribuições produzem resultados similares que levam à mesma inferência nos modelos produzidos (McCullagh e Nelder, 1989).

Uma diferença entre estas distribuições é o momento em que se utiliza a transformação da variável, pois ao trabalhar com a distribuição log-normal, toda a análise pode ser realizada para a variável transformada $(\log (Y))$, enquanto ao adotar a distribuição gama, basta modelar o logaritmo de sua média. Sendo assim, as estimativas dos parâmetros do modelo log-normal são baseadas em médias geométricas, enquanto para o modelo gama com função de ligação logarítmica, as estimativas são obtidas por meio de médias aritméticas (Wiens, 1999). Por este motivo, para McCullagh e Nelder (1989) a escolha do modelo adequado depende ainda da interpretação dos parâmetros. Nos casos em que os dados são provenientes de uma distribuição log-normal mas são ajustados como gama, Firth (1988) demonstrou que esta especificação incorreta pode ser mais eficiente do que a recíproca.

Para análises de dados altamente assimétricos à direita, a distribuição normal inversa demonstra superioridade na qualidade do ajuste, conforme mostrado no trabalho de Heller et al. (2006) para dados de sinistros de seguros. Isso ocorre pelo fato da variância depender de forma cúbica da média, enquanto na distribuição gama esta dependência ocorre de forma quadrática. 


\section{Capítulo 3}

\section{Modelos de Regressão}

Diversas classes de modelos estão disponíveis na literatura e vem sendo amplamente exploradas e aprimoradas. A complexidade e diversidade de dados disponíveis hoje em dia impulsionam essa melhoria pela necessidade de se obter respostas mais precisas e de possíveis interpretações dos parâmetros estimados.

As siglas dos modelos apresentados será consoante à nomenclatura em inglês a fim de facilitar a correspondência com programas computacionais e literatura de referência.

O modelo de regressão linear consiste em uma técnica estatística para a análise da relação entre variáveis, sendo uma das mais utilizadas por ser de grande aplicação em diversas áreas (Montgomery e Peck, 1992). Para esta classe de modelos, assume-se que os erros são provenientes da distribuição normal, possibilitando a realização de testes estatísticos para os parâmetros estimados. Entretanto esta suposição muitas vezes é violada por dados que apresentam um comportamento distinto desta distribuição, como assimetria ou repostas categóricas.

A equação do modelo é representada por

$$
\boldsymbol{y}=X \boldsymbol{\beta}+\boldsymbol{e}
$$

em que:

- $\boldsymbol{y}$ é um vetor de dimensão $n \times 1$ de observações;

- $X$ é uma matriz de dimensão $n \times(p+1)$ com $p$ variáveis regressoras de $n$ observações cada $(p<n)$ e uma coluna de valor constante um;

- $\boldsymbol{\beta}$ é um vetor de dimensão $(p+1) \times 1$ dos coeficientes da regressão;

- $\boldsymbol{e}$ é um vetor de dimensão $n \times 1$ de erros aleatórios.

Em geral, assume-se que o vetor de erros $\boldsymbol{e}$ tenha média zero e variância $\sigma^{2} \boldsymbol{I}_{n}$, assim todos os erros têm média zero, são não correlacionados (em geral assume-se independentes) e variância $\sigma^{2}$. Desse modo, os estimadores de mínimos quadrados ordinários são não viesados e os melhores estimadores dentre todos os lineares não viesados. Quando há heterocedasticidade, é possível utilizar os estimadores de mínimos quadrados ponderados e, em casos de alguma dependência, os estimadores de mínimos quadrados generalizados obtendo-se estimadores ótimos, no sentido de terem a menor variância possível.

Usualmente assume-se que os erros têm distribuição normal e, a partir disso, são obtidas distribuições dos estimadores utilizados. Assim é possível construir intervalos de confiança e testes de hipóteses envolvendo os parâmetros do modelo. Quando não são válidas algumas suposições do modelo, era usual recorrer a transformação das variáveis para propor modelos homocedásticos e sob normalidade, como discutido em Paula (2013).

A partir da década de 70, uma nova classe foi proposta por Nelder e Wedderburn (1972): modelos lineares generalizados (Generalized Linear Models - GLM). Estes são considerados uma generalização dos modelos lineares. Sua maior contribuição é a ampliação das distribuições que 
podem ser atribuídas à variável resposta. Além disso, permitem maior flexibilidade para a relação funcional entre a média da variável resposta e o preditor linear $\eta$ (Paula, 2013). Assim, muitas vezes os dados não apresentam distribuição normal e homocedástica em torno da média, mas mesmo assim não é preciso recorrer a transformações da variável resposta. Basta propor modelos em que uma função da média segue modelo linear dos parâmetros, incluindo variáveis explicativas. Assim, a interpretação dos efeitos das variáveis explicativas afetam a média da variável de interesse. Além disso, comportamentos heterocedásticos, em que a variância varia em função da média podem ser facilmente considerados na análise.

Seu modelo é representado pela seguinte equação (3.2) e será discutido de forma detalhada na Seção 3.1

$$
\boldsymbol{\eta}=g(\boldsymbol{\mu})=X \boldsymbol{\beta} .
$$

A análise descritiva de dados com comportamento assimétrico, propósito deste projeto, geralmente leva em consideração o coeficiente de variação, que indica se a razão entre o desvio padrão e a média da variável é constante. Quando este apresenta variação entre grupos de observações, torna-se necessária a modelagem conjunta da média e do parâmetro de dispersão. Smyth (1989) introduziu os modelos lineares generalizados duplos (Double Generalized Linear Models - DGLM); uma extensão do GLM com um processo de estimação dos parâmetros baseado no método de máxima verossimilhança. Com isto, possíveis problemas de heterocedasticidade extra dos dados, ou seja, além do desvio padrão proporcional à média como no caso da distribuição gama, podem ser resolvidos, resultando em um modelo de ajuste adequado aos dados.

Em diversos estudos da área médica, como por exemplo dados de sobrevivência, o comportamento de algumas covariáveis pode ser considerado não linear e para isso Hastie e Tibshirani (1990) apresentaram os modelos aditivos generalizados (Generalized Additive Models - GAM). Estes são uma extensão do GLM pois substituem o termo linear $X \boldsymbol{\beta}$ por uma soma de funções de suavização que são não paramétricas e podem ser estimadas por curvas de alisamento.

Os modelos GAM e GLM representaram grandes avanços para a técnica de modelagem. Entretanto, ainda não supriam necessidades como o ajuste de outros parâmetros da distribuição da variável resposta. Para isso, Rigby e Stasinopoulos (2001, 2005) e Akantziliotou et al. (2002) desenvolveram os modelos aditivos generalizados para posição, escala e forma (Generalized Additive Models for Location, Scale and Shape - GAMLSS) que passaram a considerar uma família de distribuições mais geral, que inclui assimetrias extremas e/ou caudas pesadas, entre outras características. Este modelo será aprofundado na Seção 3.2.

Os modelos DGLM e GAMLSS se mostram equivalentes no caso de modelagem simultânea dos parâmetros de média e dispersão em uma mesma distribuição. Entretanto, suas parametrizações e técnicas de diagnóstico são distintas. Considerando o intento desta dissertação em comparar diferentes classes de modelos e distribuições, optou-se por trabalhar os ajustes que considerem apenas estes dois parâmetros através dos modelos GAMLSS.

As aplicações dos modelos foram realizadas no programa R Core Team (2014). Para os modelos GLM foi utilizada a função $g l m$, pertencente ao pacote desenvolvido por Venables e Ripley (2002). No caso dos modelos GAMLSS, a função para ajuste foi a gamlss considerando os pacotes desenvolvidos por Stasinopoulos et al. (2014) e Rigby e Stasinopoulos (2005). Para as análises inferenciais realizadas no Capítulo 4 considerou-se o nível de significância de 5\%.

\subsection{Modelos Lineares Generalizados}

\subsubsection{Definição}

A generalização dos modelos lineares proposta por Nelder e Wedderburn (1972) consiste na utilização de distribuições que pertençam a família exponencial. Diversos resultados e aplicações são apresentados em Paula (2013) e sua parametrização será utilizada nesta seção. 
Na família exponencial todas as funções de densidade ou de probabilidades podem ser escritas no seguinte formato

$$
f\left(y_{i} ; \theta_{i}, \phi\right)=\exp \left[\phi\left\{y_{i} \theta_{i}-b\left(\theta_{i}\right)\right\}+c\left(y_{i}, \phi\right)\right],
$$

em que:

- $Y_{1}, Y_{2}, \ldots, Y_{n}$ são variáveis aleatórias independentes com função densidade dada por (3.3);

- $\theta_{i}$ é o parâmetro canônico;

- $\phi$ é o parâmetro de precisão, ou de forma equivalente $\phi^{-1}$, parâmetro de dispersão;

- $b($.$) e c($.$) funções específicas que definem a distribuição.$

Considerando a função de $\log$-verossimilhança como $L(\boldsymbol{\beta})=\log f\left(y_{i} ; \theta_{i}, \phi\right)$ e as condições usuais de regularidade definidas por

$$
\begin{aligned}
E\left(\frac{\partial L(\boldsymbol{\beta})}{\partial \theta_{i}}\right) & =0 \\
E\left(\frac{\partial^{2} L(\boldsymbol{\beta})}{\partial \theta_{i}{ }^{2}}\right) & =-E\left[\left(\frac{\partial L(\boldsymbol{\beta})}{\partial \theta_{i}}\right)^{2}\right]
\end{aligned}
$$

para $\forall i$, obtém-se a média e variância da variável $Y_{i}$ pelos seguintes resultados

$$
E\left(Y_{i}\right)=\mu_{i}=b^{\prime}\left(\theta_{i}\right), \quad \operatorname{Var}\left(Y_{i}\right)=\phi^{-1} V\left(\mu_{i}\right),
$$

em que $V\left(\mu_{i}\right)=\partial \mu_{i} / \partial \theta_{i}$ é a função de variância. Esta é de grande importância para os modelos pois caracteriza a classe de distribuições a qual a função pertence. Com isso, é possível realizar comparações entre as distribuições comparando-se as funções de variância.

A equação do GLM apresentada em (3.2), com média em (3.5), tem sua parte sistemática definida pela transformação $\eta_{i}=g\left(\mu_{i}\right)$, em que $g($.$) é denominada função de ligação, com propriedade de$ ser monótona e diferenciável. Essa função de ligação relaciona a média às variáveis explicativas.

Para ilustrar a funcionalidade da família exponencial, considerou-se uma variável aleatória com distribuição normal inversa conforme definido na Seção 2.3. Para ajustes de parametrização, tem-se que: $\sigma=\phi^{-\frac{1}{2}}$. A função densidade de probabilidade pode ser escrita como

$$
\begin{aligned}
f(y ; \mu, \phi) & =\frac{\phi^{1 / 2}}{\sqrt{2 \pi y^{3}}} \exp \left\{-\frac{\phi(y-\mu)^{2}}{2 \mu^{2} y}\right\} \\
& =\exp \left[\phi\left\{-\frac{y}{2 \mu^{2}}+\frac{1}{\mu}\right\}-\frac{1}{2}\left\{\log \left(2 \pi y^{3} / \phi\right)+\frac{\phi}{y}\right\}\right],
\end{aligned}
$$

sendo que $y>0$ e $\mu>0$. A equivalência para a equação (3.3) será obtida para $\theta=-\frac{1}{2 \mu^{2}}$, $b(\theta)=-(-2 \theta)^{1 / 2}$ e $c(y, \phi)=\frac{1}{2} \log \left\{\phi /\left(2 \pi y^{3}\right)\right\}-\frac{\phi}{2 y}$. A função de variância será dada por $V(\mu)=\mu^{3}$.

\subsubsection{Função de ligação}

A função de ligação estabelece a relação entre o preditor linear $\eta=X \boldsymbol{\beta}$, que é função das variáveis explicativas e a média $\mu$. Para os modelos lineares, esta ligação é sempre a identidade, ou seja, $\eta=\mu$. Entretanto, para os modelos lineares generalizados algumas distribuições demandam 
que a média das observações seja sempre um valor positivo, tornando esta ligação inviável pois pode resultar em valores negativos para o preditor da média.

Entre as funções de ligação, existe um tipo especial: a função de ligação canônica. Esta consiste na ligação natural entre o preditor e a média, sendo encontrado através de um vetor de estatísticas suficientes para o vetor de parâmetros $\boldsymbol{\beta}$, ambos de mesma dimensão. Ao trabalhar com este tipo de ligação, garante-se a concavidade de $L(\boldsymbol{\beta})$ e consequentemente resultados assintóticos para os estimadores dos parâmetros $\boldsymbol{\beta}$, como por exemplo a unicidade da estimativa de máxima verossimilhança de $\boldsymbol{\beta}$, quando essa existir.

A ligação canônica existe quando $\eta=\theta$, onde $\theta$ é o parâmetro canônico definido em (3.3). Para as distribuições consideradas neste trabalho, gama e normal inversa, este tipo de ligação seria dada respectivamente por $\eta=\mu^{-1}$ e $\eta=\mu^{-2}$. A distribuição log-normal tem sua variável transformada previamente à construção do modelo, conforme Subseção 2.2, sendo então esta nova variável ajustada por um modelo normal com ligação identidade, que por sua vez é a ligação canônica da distribuição normal.

Neste trabalho, quando aplicada aos dados as distribuições gama ou normal inversa, tornou-se necessária a utilização de uma ligação não canônica para o parâmetro de média, o logaritmo, em razão da necessidade de garantir resultados positivos. Portanto, a resposta média será dada por $\mu=e^{\eta}=e^{(\boldsymbol{X} \boldsymbol{\beta})}$ e os efeitos das variáveis explicativas serão multiplicativos.

\subsubsection{Estimação dos parâmetros do modelo}

$\mathrm{O}$ vetor de parâmetros $\boldsymbol{\beta}$ do modelo proposto e o parâmetro de precisão $\phi$ são estimados pelo método de máxima verossimilhança (EMV). Conforme demonstrado por Mood (1950), as vantagens do uso deste tipo de estimador são suas propriedades de suficiência, invariância e não ser viesado assintoticamente, entre outras.

O processo consiste em encontrar a solução de $\mathbf{U}_{\beta}(\theta)=0$ e $\mathbf{U}_{\phi}(\theta)=0$, que são funções escore presentes na equação $(3.7)$

$$
\mathbf{U}_{\beta}(\theta)=\frac{\partial L(\boldsymbol{\theta})}{\partial \beta}, \quad \mathbf{U}_{\phi}(\theta)=\frac{\partial L(\boldsymbol{\theta})}{\partial \phi} .
$$

Como estas equações não possuem uma solução explícita para o vetor de parâmetros $\boldsymbol{\beta}$, fazse necessária a utilização de métodos iterativos para chegar às estimativas dos parâmetros. Ao considerar o método de otimização iterativo de Newton-Raphson para a obtenção das estimativas de máxima verossimilhança, dado pela equação (3.8)

$$
\boldsymbol{U}_{\beta}{ }^{(i)} \cong \boldsymbol{U}_{\beta}{ }^{(i-1)}+\boldsymbol{U}_{\beta}{ }^{\prime(i-1)}\left(\boldsymbol{\beta}^{(i)}-\boldsymbol{\beta}^{(i-1)}\right),
$$

para a iteração $i$, existe a possibilidade do sistema não resultar em uma solução pois a matriz $-\mathbf{U}_{\beta}^{\prime}$ pode não ser definida positiva.

Para isso, aplica-se o método escore de Fisher que substitui essa matriz pelo valor da informação de Fisher, apresentado na equação (3.9)

$$
\boldsymbol{K}_{\beta \beta}(\boldsymbol{\theta})=E\left\{-\frac{\partial^{2} L(\boldsymbol{\theta})}{\partial \beta \partial \beta^{T}}\right\} .
$$

Considerando o vetor $\boldsymbol{\theta}=\left(\boldsymbol{\beta}^{T}, \phi\right)^{T}$, a ortogonalidade entre $\boldsymbol{\beta}$ e $\phi$ pode ser verificada em (3.10). Isso implica uma matriz de informação de Fisher bloco diagonal dada por $\boldsymbol{K}_{\theta \theta}=\operatorname{diag}\left\{\boldsymbol{K}_{\beta \beta}, \boldsymbol{K}_{\phi \phi}\right\}$, com 


$$
\boldsymbol{K}_{\beta \phi}(\boldsymbol{\theta})=E\left\{-\frac{\partial^{2} L(\boldsymbol{\theta})}{\partial \boldsymbol{\beta} \partial \phi}\right\}=\mathbf{0} .
$$

A função escore do vetor $\boldsymbol{\theta}$ é dada por $\boldsymbol{U}_{\theta}=\left(\boldsymbol{U}_{\beta}{ }^{T}, U_{\phi}\right)^{T}$, definidos anteriormente.

A partir destas quantidades é possível demonstrar que $\hat{\boldsymbol{\beta}}$ e $\hat{\phi}$ serão assintoticamente distribuídos conforme (3.11)

$$
\hat{\boldsymbol{\beta}} \sim N_{p}\left(\boldsymbol{\beta}, \boldsymbol{K}_{\boldsymbol{\beta} \boldsymbol{\beta}}^{-\mathbf{1}}\right), \quad \hat{\phi} \sim N_{p}\left(0, \boldsymbol{K}_{\boldsymbol{\phi} \phi}^{-\mathbf{1}}\right),
$$

além de serem independentes.

\subsubsection{Técnicas de diagnóstico}

As técnicas de diagnósticos propostas para os modelos GLM consistem essencialmente em gráficos construídos a partir dos resíduos do modelo e valores ajustados, entre outras variáveis, além da função desvio. As técnicas descritas a seguir são recomendadas por Paula (2013) para modelos de dados assimétricos.

A função desvio mensura a distância entre o logaritmo da função de verossimilhança do modelo saturado (com $n$ parâmetros) e do modelo em estudo (com $p$ parâmetros, $p<n$ ) considerando as estimativas de máxima verossimilhança para o vetor $\boldsymbol{\beta}$. O ajuste será considerado satisfatório para um valor pequeno da função desvio, indicando que o modelo, mesmo com uma quantidade reduzida de parâmetros, produz um ajuste quase tão bom quanto o modelo saturado.

Para identificar pontos de alavanca, utiliza-se o gráfico da medida $\hat{h}_{i i}$ contra os valores ajustados do modelo. Esta medida corresponde à variação do valor ajustado $\hat{y}_{i}$ quando $y_{i}$ é acrescido de um infinitésimo. Os pontos a serem estudados são aqueles que apresentam valores maiores que $2 p / n$, para um modelo de $p$ parâmetros, de acordo com Paula (2013). Após sua identificação, recomenda-se a investigação das características da observação e a realização de um novo ajuste do modelo, excluindo-a para verificar possíveis mudanças inferenciais nos resultados. Na Figura 3.1a está ilustrado um exemplo deste gráfico.

A Distância de Cook consiste em uma medida que verifica a influência da retirada de uma observação nos parâmetros estimados do modelo. O gráfico desta medida é construído contra um índice ou os valores ajustados $\hat{y}_{i}$, sendo que os pontos destoantes no gráfico são considerados para análise. Na Figura 3.1b é possível verificar um ponto destoante do grupo. Após a identificação destes pontos, são adotados os mesmos procedimentos do gráfico citado anteriormente.

A validação da função de ligação utilizada no modelo é feita pelo gráfico dos valores de uma variável dependente ajustada $\hat{z}_{i}$ versus o preditor linear estimado $\hat{\eta}_{i}$, que pode ser visualizado na Figura 3.1d. O comportamento de tendência linear indica que a função de ligação é adequada.

O resíduo mais utilizado para diagnóstico nos modelos lineares generalizados é o chamado componente do desvio e é denominado dessa forma por ser definido a partir dos componentes da função desvio. Este resíduo é avaliado em dois tipos de gráficos: contra os valores ajustados no modelo (Figura 3.1c) e em relação aos percentis da distribuição normal padrão. No primeiro, verifica-se indícios de heterocedasticidade e pontos aberrantes. O segundo, um gráfico normal de probabilidades, é ainda chamado de gráfico de envelope pois ajusta bandas de confiança aos resíduos. Caso sejam observados pontos fora destas bandas, considera-se que a distribuição atribuída aos dados não é adequada. Este gráfico pode ser visualizado na Figura 3.2.

\subsubsection{Seleção do modelo}

Entre as diferentes técnicas de seleção de um modelo, Paula (2013) descreve quatro: métodos forward, backward e stepwise e o critério de informação de Akaike (Akaike Information Criterion AIC). Esta dissertação aborda apenas o método AIC para seleção das variáveis explicativas. 

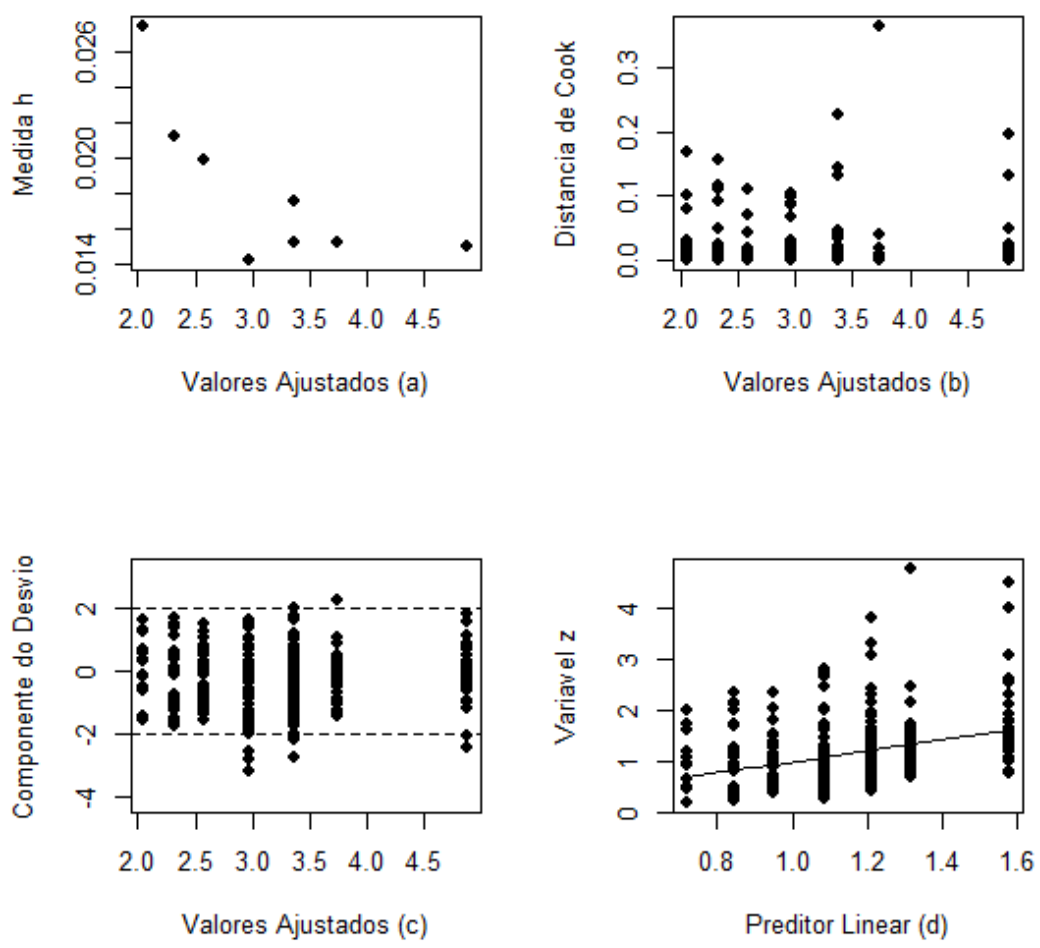

Figura 3.1: Gráficos de diagnóstico para um modelo ajustado a dados com resposta normal inversa.

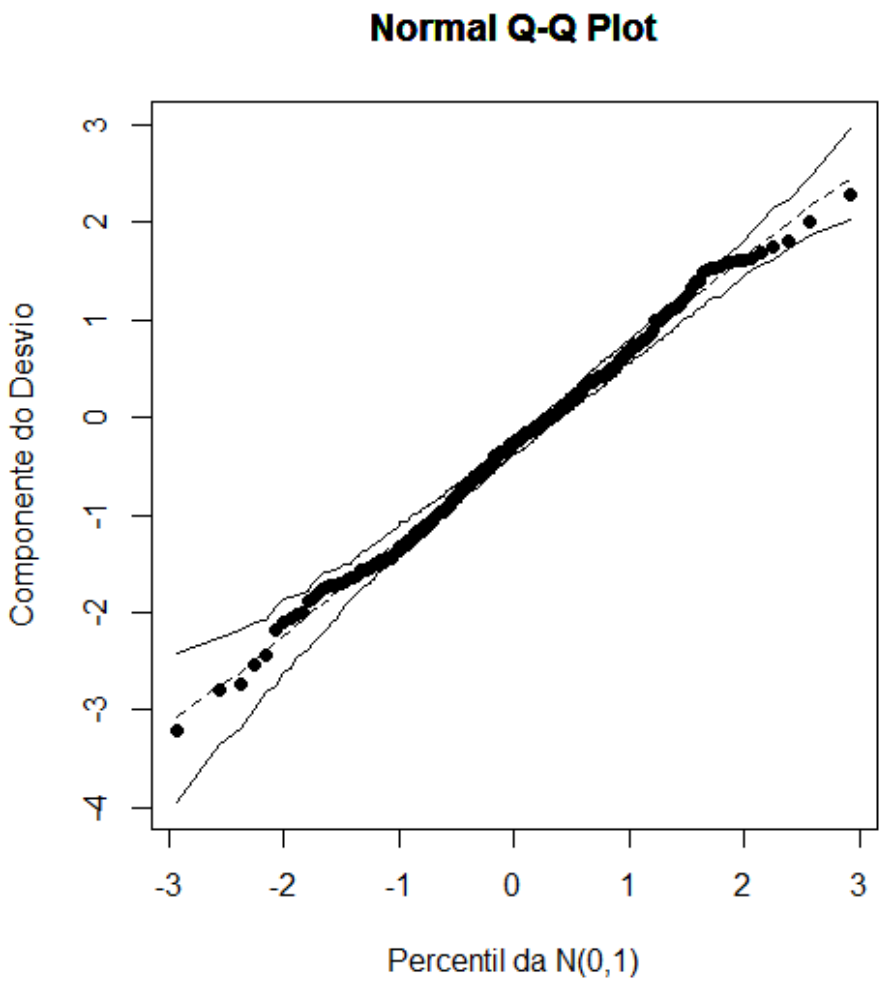

Figura 3.2: Gráfico normal de probabilidades para um modelo ajustado a dados com resposta normal inversa. 
O critério consiste em encontrar um modelo com um número de parâmetros reduzido que esteja bem ajustado. Por esta propriedade, este critério é considerado parcimonioso. A quantidade a ser minimizada é dada por

$$
A I C=D^{*}(\boldsymbol{y} ; \hat{\boldsymbol{\mu}})+2 p,
$$

em que $D^{*}(\boldsymbol{y} ; \hat{\boldsymbol{\mu}})=\phi D(\boldsymbol{y} ; \hat{\boldsymbol{\mu}})=2\{L(\boldsymbol{y} ; \boldsymbol{y})-L(\hat{\boldsymbol{\mu}} ; \boldsymbol{y})\}$ é a função desvio, citada na seção anterior, e $p$ é o número de parâmetros do modelo.

No pacote $M A S S$, utilizado para ajuste dos modelos, está implementada uma função para a seleção do modelo com menor valor para o critério AIC. A partir do modelo completo, aplica-se o método backward que subtrai gradativamente as variáveis explicativas até encontrar o modelo com menor AIC. Também é aconselhável que a retirada de variáveis explicativas seja acompanhada por testes de significância dos parâmetros correspondentes a essas variáveis, e que no modelo final apresente efeitos significativos.

\subsubsection{Intervalo de confiança para o indivíduo}

A determinação de um intervalo de confiança (IC) da variável resposta esperada para cada tipo de unidade experimental permite a avaliação da variabilidade do comportamento de diferentes unidades em um estudo.

A partir das estimativas do vetor de parâmetros $\boldsymbol{\beta}$ e considerando a propriedade de invariância que os estimadores de máxima verossimilhança possuem, a estimativa para a variável resposta de uma certa unidade experimental, com variáveis explicativas $x_{i}$, será dada por:

$$
\hat{Y}_{i}=\hat{\mu}_{i}=g^{-1}\left(\hat{\eta}_{i}\right)=g^{-1}\left(x_{i}^{T} \hat{\boldsymbol{\beta}}\right)
$$

Os limites do intervalo de confiança podem ser obtidos por meio dos quantis da distribuição determinada no modelo. Por exemplo, para um intervalo com coeficiente de confiança de $95 \%$ calculam-se os quantis de 2,5\% e 97,5\% da distribuição escolhida, de modo que os parâmetros $\left(\mu_{i}, \phi\right)$ sejam substituídos pelas respectivas estimativas obtidas no ajuste do modelo.

O trabalho de Giner e Smyth (2014) apresenta uma metodologia de computação numérica de quantis para distribuições unimodais, dado que esta medida geralmente não apresenta uma expressão fechada. O quantil $q$ será determinado através da solução da equação:

$$
q=F^{-1}(p)
$$

em que $F^{-1}(p)$ é o inverso da função de distribuição acumulada para um dado percentil $p$.

\subsection{Modelos Aditivos Generalizados para Posição, Escala e Forma}

\subsubsection{Definição}

A classe de modelos GAMLSS exposta de forma detalhada no trabalho de Rigby e Stasinopoulos (2005) proporcionou uma ampla gama de opções para a modelagem de bases de dados, a começar pelo fato da variável resposta não precisar pertencer à família exponencial. Os modelos podem ser construídos de forma paramétrica ou não-paramétrica, dependo da necessidade da média assumir uma determinada função paramétrica das variáveis explicativas ou considerando apenas funções não-paramétricas de suavização. Para o modelo não paramétrico, o efeito das variáveis explicativas podem por exemplo variar de acordo com o valor de $x$, assumindo que o efeito seja representado por exemplo por funções splines da variável explicativa. 
Outra grande contribuição do GAMLSS é a possibilidade de expandir a parte sistemática do modelo para ajuste de outros parâmetros da distribuição da variável resposta, além da média. Nesta classe, o parâmetros de escala e forma também podem ser modelados com efeitos aleatórios e/ou termos paramétricos e/ou não-paramétricos, além de funções lineares/não lineares das variáveis explicativas.

A possibilidade de modelar outros parâmetros além da média permite que o GAMLSS seja adequado especialmente para a modelagem de dados com características leptocúrticas, assimetrias positivas ou negativas e heterogeneidade, entre outros. Estes parâmetros ainda podem se comportar de forma distinta de acordo com a variabilidade de variáveis explicativas. Esta propriedade é a principal justificativa para a utilização desta classe de modelos na dissertação, pois a partir deste modelo é possível considerar as observações nulas da variável resposta - pacientes que não receberam transfusão de sangue - devido à atribuição de um parâmetro para a probabilidade da observação ser igual a zero.

A equação do modelo GAMLSS é composta por observações independentes $y_{i}$ para $i=1,2, \ldots, n$ com função densidade de probabilidade dada por $f\left(y_{i} \mid \theta^{i}\right)$, condicionada a $\theta^{i}=\left(\theta_{1 i}, \theta_{2 i}, \theta_{3 i}, \theta_{4 i}\right)=$ $\left(\mu_{i}, \sigma_{i}, \nu_{i}, \tau_{i}\right)$, um vetor de quatro parâmetros para a distribuição atribuída à variável resposta. Geralmente, a dupla $\left(\mu_{i}, \sigma_{i}\right)$ caracteriza os parâmetros de locação e escala, respectivamente. Os últimos dois se referem à forma da distribuição, quando necessário, podendo ainda caracterizar qualquer outro parâmetro de uma distribuição populacional. Para cada um dos parâmetros citados considerase $g_{i}($.$) uma função de ligação monótona conhecida que os relaciona com as variáveis explicativas.$ Assim, as equações de um modelo GAMLSS para modelos paramétricos são apresentadas por

$$
\begin{aligned}
& g_{1}(\boldsymbol{\mu})=\boldsymbol{\eta}_{1}=\boldsymbol{X}_{1} \boldsymbol{\beta}_{1}+\sum_{j=1}^{J_{1}} \boldsymbol{Z}_{j 1} \gamma_{j 1}, \\
& g_{2}(\boldsymbol{\sigma})=\boldsymbol{\eta}_{2}=\boldsymbol{X}_{2} \boldsymbol{\beta}_{2}+\sum_{j=1}^{J_{2}} \boldsymbol{Z}_{j 2} \gamma_{j 2}, \\
& g_{3}(\boldsymbol{\nu})=\boldsymbol{\eta}_{3}=\boldsymbol{X}_{3} \boldsymbol{\beta}_{3}+\sum_{j=1}^{J_{3}} \boldsymbol{Z}_{j 3} \gamma_{j 3}, \\
& g_{4}(\boldsymbol{\tau})=\boldsymbol{\eta}_{4}=\boldsymbol{X}_{4} \boldsymbol{\beta}_{4}+\sum_{j=1}^{J_{4}} \boldsymbol{Z}_{j 4} \gamma_{j 4},
\end{aligned}
$$

em que:

- $\boldsymbol{\mu}, \boldsymbol{\sigma}, \boldsymbol{\nu}, \boldsymbol{\tau}$ e $\boldsymbol{\eta}_{k}$, para $k=1,2,3,4$ são vetores de dimensão $n$;

- $\boldsymbol{\beta}_{k}^{T}=\left(\beta_{1 k}, \beta_{2 k}, \ldots, \beta_{J_{k}^{\prime} k}\right)$ é um vetor de parâmetros de dimensão $J_{k}^{\prime}$;

- $\boldsymbol{X}_{k}$ é uma matriz de planejamento fixa de dimensão $n \times J_{k}^{\prime}$;

- $\boldsymbol{Z}_{j k}$ é uma matriz de planejamento fixa de dimensão $n \times q_{j k}$;

- $\gamma_{j k}$ é uma variável aleatória de dimensão $q_{j k}$ correspondente a efeitos aleatórios.

A matriz $\boldsymbol{X}_{k}$ não necessariamente será a mesma para $k=1,2,3,4$, sendo assim, cada parâmetro da distribuição pode ser caracterizado por um grupo distinto de variáveis explicativas. Assim como o índice $k$ pode ser menor, como por exemplo nas distribuições ZAGA e ZAIG que contém apenas três parâmetros: $(\boldsymbol{\mu}, \boldsymbol{\sigma}, \boldsymbol{\nu})$.

Para modelos que não contém efeitos aleatórios em qualquer dos parâmetros da distribuição o último termo da equação será desconsiderado, e estes passam a se apresentar na forma paramétrica linear, similar à equação do GLM, dada por 


$$
g_{k}\left(\boldsymbol{\theta}_{k}\right)=\boldsymbol{\eta}_{k}=\boldsymbol{X}_{k} \boldsymbol{\beta}_{k}
$$

Neste trabalho foi utilizado o modelo paramétrico (3.16) por produzir resultados de forma satisfatória, além de facilitar a interpretação dos parâmetros estimados.

\subsubsection{Função de ligação}

Devido à abordagem paramétrica do estudo, as funções de ligação terão as mesmas propriedades apresentadas na Subseção 3.1.2 para os modelos GLM.

Entretanto, como o GAMLSS permite a modelagem de todos os parâmetros da distribuição atribuída aos dados, cada um destes poderá receber uma função de ligação distinta, de acordo com suas características.

Para todas as distribuições implementadas na biblioteca gamlss.dist (Stasinopoulos et al., 2014) estão atribuídas funções de ligação padrão para cada parâmetro, porém, o programa disponibiliza outras ligações que podem ser utilizadas, de acordo com a necessidade dos dados. Na Tabela 3.1 estão presentes as funções de ligação utilizadas neste trabalho para cada parâmetro das distribuições consideradas nos modelos GAMLSS.

\begin{tabular}{rccc}
\hline & $\mu$ & $\sigma$ & $\nu$ \\
\hline Gama & $\log$ & $\log$ & - \\
Log-Normal & identidade & $\log$ & - \\
Normal Inversa & $\log$ & $\log$ & - \\
Gama zero ajustada & $\log$ & $\log$ & $\operatorname{logito}$ \\
Normal Inversa zero ajustada & $\log$ & $\log$ & $\operatorname{logito}$ \\
\hline
\end{tabular}

Tabela 3.1: Funções de ligação utilizadas nos modelos GAMLSS.

\subsubsection{Estimação dos parâmetros do modelo}

As estimativas dos vetores paramétricos $\boldsymbol{\beta}_{k}$ e de efeitos aleatórios $\gamma_{j k}$ para $j=1,2, \ldots, J_{k}$ e $k=1,2,3,4$ são obtidas através da maximização da função de verossimilhança penalizada $\ell_{p}$, presente na equação (3.17), e considerando que os valores dos hiper-parâmetros suavizados $\lambda_{j k}$ são fixos. A função de verossimilhança maximizada é dada por

$$
\ell_{p}=\ell-\frac{1}{2} \sum_{k=1}^{p} \sum_{j=1}^{J_{k}} \lambda_{j k} \gamma_{j k}^{\prime} \boldsymbol{G}_{j k} \gamma_{j k}
$$

em que $\ell=\sum_{i=1}^{n} \log f\left(y_{i} \mid \boldsymbol{\theta}^{i}\right)$ é o log da função de verossimilhança.

Como a abordagem deste trabalho abrange apenas as funções paramétricas do GAMLSS, a equação (3.17) será reduzida para $\ell$, e os vetores $\boldsymbol{\beta}_{k}$ serão estimados pela maximização desta função. Dessa maneira, o processo de estimação será equivalente ao apresentado na Subseção 3.1.3 para os modelos GLM.

No trabalho de Rigby e Stasinopoulos (2005) são apresentados dois algoritmos para o ajuste dos modelos GAMLSS. O algoritmo denominado CG utiliza a derivada de primeira ordem e os valores esperados das derivadas de segunda ordem e cruzada da função de verossimilhança em relação aos parâmetros da distribuição. Entretanto, para diversas distribuições, a derivada cruzada é nula devido à ortogonalidade dos parâmetros, tornando o algoritmo ineficaz. Para isso, aplica-se o método RS que não considera esta última derivada. Ambos os métodos utilizam o procedimentos de Newton-Raphson/escore de Fisher, citados previamente. 
A função de verossimilhança apresenta uma certa particularidade quando trabalhada sob as distribuições discretas-contínuas, como a ZAGA ou ZAIG consideradas neste trabalho. Conforme detalhado no trabalho de Mills (2013), a função de verossimilhança pode ser fatorada em duas partes, uma referente ao estimador da probabilidade da observação ser nula e outro referente ao estimador da média da variável resposta, considerando somente seus valores positivos.

Para ilustrar esta situação, a equação (2.2) que define a função de probabilidade discretacontínua mista é reescrita da seguinte forma

$$
f(y)=(1-\pi) I_{y=0}+(\pi g(y)) I_{y>0},
$$

em que para $y=0, I_{y=0}=1$, caso contrário, se $y>0$ tem-se $I_{y=0}=0$, analogamente para $I_{y>0}$.

Desta forma, a função de verossimilhança pode ser escrita como

$$
\begin{aligned}
L(\boldsymbol{\theta}) & =\prod_{i=1}^{n} f\left(y_{i}\right) \\
& =\prod_{i=1}^{n}\left[(1-\pi) I_{y=0}+(\pi g(y)) I_{y>0}\right] \\
& =\prod_{y_{i}=0}[1-\pi] \prod_{y_{i}>0}[\pi g(y)] \\
& =\left[\prod_{y_{i}=0}(1-\pi) \prod_{y_{i}>0} \pi\right]\left[\prod_{y_{i}>0} g(y)\right] .
\end{aligned}
$$

E por fim, a log-verossimilhança será definida por

$$
\begin{aligned}
l & =\log \left[\prod_{y_{i}=0}(1-\pi) \prod_{y_{i}>0} \pi\right]\left[\prod_{y_{i}>0} g(y)\right] \\
& =\log \left[\prod_{y_{i}=0}(1-\pi) \prod_{y_{i}>0} \pi\right]+\log \left[\prod_{y_{i}>0} g(y)\right] .
\end{aligned}
$$

A função de forma fatorada permite que esta seja maximizada separadamente para os modelos de probabilidades e de média, independentemente das covariáveis presentes em cada modelo. Dessa forma, os coeficientes $\boldsymbol{\beta}_{k}^{T}$ referentes aos parâmetros da distribuição atribuída aos dados serão estimados de forma independente.

\subsubsection{Técnicas de diagnóstico}

Devido à diversidade de distribuições dos modelos GAMLSS, os resíduos brutos, definidos pela diferença entre o valor observado e o valor ajustado e representados por $r_{i}=y_{i}-\hat{y}_{i}$ para $i=$ $1,2, \ldots, n$, se tornam inadequados para estes modelos. Isso ocorre pois o comportamento esperado destes resíduos seria condizente com uma variável de distribuição normal. Como alternativa, as análises de diagnóstico desta classe de modelos se baseiam nos resíduos quantílicos aleatorizados propostos por Dunn e Smyth (1996).

Os resíduos são definidos da seguinte forma

$$
r_{q, i}=\Phi^{-1}\left(F\left(y_{i} ; \hat{\boldsymbol{\theta}}^{i}\right)\right), i=1,2, \ldots, n,
$$

em que:

- $y_{i}$ corresponde à $i$-ésima observação da variável resposta; 
- $F\left(y_{i} ; \hat{\boldsymbol{\theta}}^{i}\right)$ é a distribuição acumulada da função de probabilidade assumida no modelo;

- $\hat{\boldsymbol{\theta}}^{i}=\left(\hat{\mu}_{i}, \hat{\sigma}_{i}, \hat{\nu}_{i}, \hat{\tau}_{i}\right)$ são as estimativas dos parâmetros do modelo;

- $\Phi^{-1}($.$) é a função de distribuição acumulada normal padrão.$

Esta definição se aplica para modelos derivados de uma distribuição contínua, podendo ser denominados simplesmente como resíduos quantílicos.

Para distribuições discretas ou discretas-contínuas, como a ZAGA e a ZAIG, torna-se necessária a definição de uma nova variável aleatória, $u_{i}$, de distribuição uniforme no intervalo $\left(a_{i}, b_{i}\right]$, para $a_{i}$ e $b_{i}$ obtidos por

$$
a_{i}=F\left(y_{i}-1 \mid \hat{\boldsymbol{\theta}}^{i}\right), \quad b_{i}=F\left(y_{i} \mid \hat{\boldsymbol{\theta}}^{i}\right) .
$$

Sua introdução nos resíduos $r_{q, i}$, possibilita a geração de resíduos aleatórios contínuos, definidos por

$$
r_{q, i}=\Phi^{-1}\left(u_{i}\right) .
$$

Este procedimento tem por finalidade evitar massas de pontos na distribuição dos resíduos, e retoma o nome resíduos quantílicos aleatorizados (chamados apenas de resíduos subsequentemente).

Considerando que o modelo foi especificado corretamente, estes resíduos terão distribuição normal padrão. Isto posto, diversas técnicas de diagnóstico usuais podem ser realizadas para verificação do modelo.

Devido ao fator de aleatoriedade aplicado aos dados para o caso (3.23), Dunn e Smyth (1996) recomendam que os resíduos sejam produzidos quatro vezes para sua validação. Para esta finalidade, Stasinopoulos et al. (2008) apresentam a função rqres.plot que gera diversas vezes os resíduos para um mesmo modelo e produz a mesma quantidade de gráficos QQ para ratificação do comportamento destes.

A saída padrão de diagnóstico nos modelos GAMLSS é composta pelos quatro gráficos definidos abaixo, acrescidas das medidas descritivas do resíduo.

- Resíduos versus valores ajustados;

- Resíduos versus um índice ou uma variável explicativa;

- Densidade estimada de Kernel dos resíduos;

- Gráfico quantil-quantil normal (QQ-plot) dos resíduos.

O esperado é que a média destes resíduos seja aproximadamente zero, com desvio padrão próximo de um e as medidas de assimetria e curtose em torno de zero e três, respectivamente, características correspondentes à uma variável com distribuição normal padrão. Para os gráficos, esperam-se comportamentos típicos de resíduos com distribuição normal, conforme apresentado por Montgomery e Peck (1992).

\subsubsection{Seleção do modelo}

Os modelos GAMLSS apresentam diferentes funções para a seleção de variáveis explicativas. A função considerada nesta dissertação é construída com base no critério de informação Akaike generalizado (Generalized Akaike Information Criterion - GAIC) (Rigby e Stasinopoulos, 2005), definido por

$$
G A I C(\#)=G D+\# d f
$$


em que $G D$ é a deviance global dada por $-2 \ell, d f$ os graus de liberdade utilizados no modelo e \# uma penalidade aplicada a cada grau de liberdade utilizado no modelo.

Esta generalização consiste na mudança da penalização utilizada no critério de informação de Akaike (Akaike Information Criterion - AIC) em que \# = 2. Dessa forma, o AIC é considerado um caso especial do GAIC. Assim como no critério AIC, o modelo sugerido será aquele com menor valor para o GAIC, considerando o método backward que subtrai gradativamente as variáveis do modelo completo. Esta medida mantém a propriedade de parcimônia do critério AIC, dado que os modelos com menos parâmetros terão penalidades menores e consequentemente valores mais baixos para o GAIC.

Este critério de seleção de variáveis explicativas pode ser aplicado para todos os parâmetros da distribuição considerada no modelo. Após a seleção das variáveis para o modelo de médias $\mu$, aplica-se o mesmo processo para o modelo do parâmetro de escala, $\sigma$, e assim sucessivamente para todos os parâmetros da distribuição.

\subsubsection{Intervalo de confiança para o indivíduo}

Assim como no GLM, a partir das estimativas de máxima verossimilhança do vetor de parâmetros, resultante do modelo de médias, a estimativa para uma determinada unidade amostral será dada por:

$$
\hat{Y}_{i}=\hat{\mu}_{i}=g^{-1}\left(\hat{\eta}_{i}\right)=g^{-1}\left(x_{i}^{T} \hat{\boldsymbol{\beta}}\right)
$$

O intervalo de confiança (IC) para esta unidade poderá ser obtido através de quantis da distribuição atribuída aos dados, o mesmo procedimento detalhado no item 3.1.6.

O diferencial para os modelos GAMLSS será devido à maior quantidade de parâmetros da distribuição modelados. Enquanto nos modelos GLM o parâmetro de escala é fixo, para o GAMLSS este poderá variar de acordo com grupos de observações. Para as distribuições ZAGA e ZAIG, acrescentam-se ainda as estimativas do ajuste do parâmetro de probabilidade, $\nu$. 


\section{Capítulo 4}

\section{Aplicação}

A motivação para este trabalho surgiu a partir de um estudo da doença atresia biliar (AB), um distúrbio raro caracterizado pela obstrução das vias biliares e identificada durante o período neonatal. Esta doença é a principal indicação de transplante hepático na faixa etária pediátrica (Silva et al., 2011).

O primeiro tratamento recomendado para estas crianças é o procedimento cirúrgico chamado portoenterostomia de Kasai que consiste em uma drenagem da bílis. Este procedimento possibilita o adiamento do transplante, um fator de grande importância considerando a faixa etária das crianças acometidas pela doença. Vale ressaltar que, em alguns casos, este é suficiente para a recuperação do paciente (Chardot, 2006). Entretanto, caso seja necessário o transplante de fígado após este primeiro tratamento, os pacientes têm apresentado maiores riscos de complicações cirúrgicas, como por exemplo, sangramentos durante e após a cirurgia.

Considerando que o sangramento é uma das principais complicações durante a cirurgia de transplante e dificilmente mensurável, a variável resposta do estudo será definida com base no volume de sangue recebido pelo paciente. A partir desta variável serão realizadas análises para mensurar a viabilidade do procedimento de Kasai, levando em consideração também o índice de debilidade do fígado (Pediatric End-Stage Liver Disease - PELD) no momento do transplante.

Esses dados foram analisados previamente pela pesquisadora Ana Luiza Bierrenbach, que questionou o ajuste de modelos usuais para dados positivos dado que tal conjunto de dados apresentou uma relevante proporção de zeros para a variável resposta. Isso motivou a proposta de diferentes modelos e sua comparação nessa dissertação.

\subsection{Análise descritiva}

A base de dados utilizada neste estudo é formada por 310 pacientes que foram submetidos ao transplante de fígado no período de 1995 a 2013 no Hospital Sírio-Libanês, um dos maiores centros de transplantes hepáticos pediátricos da América do Sul. Entre as diversas variáveis coletadas antes, durante e após a cirurgia, apenas a transfusão de sangue, a realização do procedimento de Kasai e o nível de debilidade do fígado foram consideradas relevantes para o estudo das complicações, morbidade e mortalidade do transplante de fígado.

Estas variáveis serão denominadas da seguinte forma:

1. transfpeso: transfusão de sangue em relação ao peso do paciente (percentual);

2. Kasai: variável binária que assume valor 1 quando o paciente foi submetido ao procedimento de Kasai e 0 caso contrário;

3. PELD: variável com quatro níveis correspondente aos quartis da medida PELD.

A variável PELD consiste na categorização em quartis do escore PELD atribuído aos pacientes. Optou-se por este tipo de categorização de forma a criar níveis progressivos da debilidade do fígado 
que se diferenciassem, assim como mensurar uma possível relação com a variável resposta. Essa opção segue a proposta e análise prévia da pesquisadora Ana Luiza Bierrenbach e seus colaboradores. A notação adotada para essa variável é $P E L D(1)$ igual a 1 se o indivíduo tem escore PELD menor ou igual ao primeiro quartil de PELD. De modo semelhante são definidas as variáveis indicadoras PELD(2), PELD(3) e PELD(4), se os valores estão em cada quartil do escore PELD.

O gráfico exposto na Figura 4.1, correspondente ao percentual de transfusão de sangue em relação ao peso do paciente, revela o comportamento de uma variável contínua com assimetria à direita. Trabalhar com este percentual permite uma mesma escala para todas as crianças, dado que o sangue a ser recebido depende também do seu peso. Pelo gráfico é possível observar uma grande amplitude nos dados, sendo observado um mínimo de 0 e um máximo superior a 19, porém com uma média de 3\%. Os valores nulos, aproximadamente $7 \%$ da amostra, identificam os casos em que o indivíduo não precisou receber transfusão de sangue durante o transplante; não obstante, este individuo presumivelmente teve sangramento durante o procedimento.

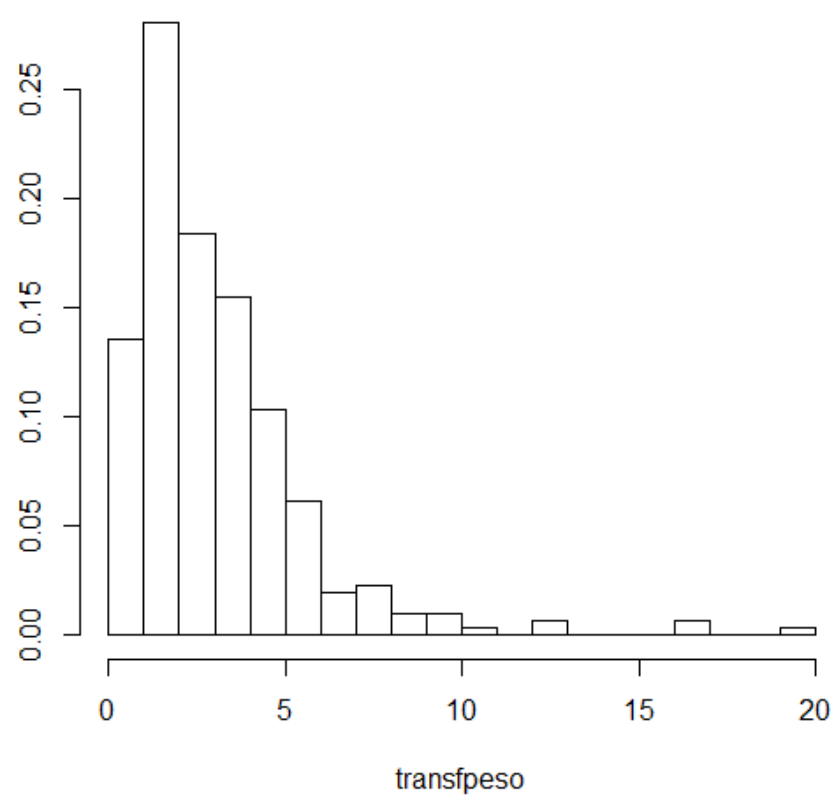

Figura 4.1: Histograma da variável de transfusão de sangue por peso do paciente.

Para o estudo descritivo das variáveis explicativas a base de dados foi analisada de duas formas distintas. A base A é composta por 288 observações, correspondente aos pacientes que receberam transfusão de sangue, adequando a base ao suporte das distribuições gama, log-normal e normal inversa. A base B mantém-se com as 310 observações, entretanto a variável resposta do estudo é a ocorrência ou não de transfusão de sangue, ou seja, consiste em variável binária.

\subsubsection{Base de dados $\mathrm{A}$}

Para o estudo da variável Kasai foi considerada sua interação com a transfusão de sangue por peso. Entre os indivíduos que receberam transfusão, $57 \%$ foram submetidos ao procedimento de Kasai antes do transplante de fígado. Para estes indivíduos, a média de transfusão de sangue recebido é significativamente maior, $c o m$ valor- $\mathrm{p}=0,001$ para o teste não paramétrico de Wilcoxon. A utilização deste teste se justifica pelo comportamento da variável transfpeso, distante da distribuição normal. Na Tabela 4.1 estão presentes as estatísticas descritivas da variável resposta transfusão de sangue por peso para os dois grupos de pacientes.

Os boxplots da Figura 4.2 realçam a diferença de comportamento entre os dois grupos em relação 


\begin{tabular}{rcccccc}
\hline Kasai & $\mathrm{N}$ & Média & Mediana & Desv. Padrão & Mínimo & Máximo \\
\hline Não (0) & 125 & 2,63 & 2,36 & 1,55 & 0,85 & 9,60 \\
Sim (1) & 163 & 3,71 & 3,09 & 2,95 & 0,49 & 19,16 \\
\hline Total & 288 & 3,24 & 2,66 & 2,50 & 0,49 & 19,16 \\
\hline
\end{tabular}

Tabela 4.1: Medidas descritivas da transfusão de sangue por peso segundo Kasai.

à variabilidade. Estes apontam ainda que os pacientes que receberam mais que $10 \%$ do seu peso em transfusão de sangue realizaram a pré-cirurgia de Kasai.

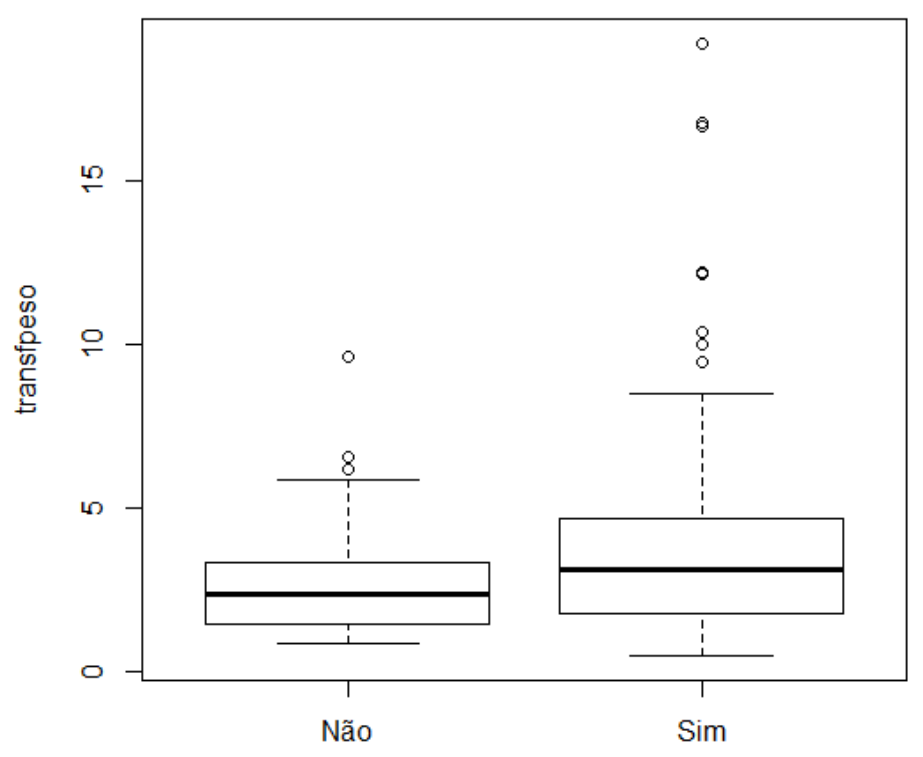

Figura 4.2: Boxplot da transfusão de sangue por peso do paciente segundo Kasai.

A relação entre a variável PELD e o percentual de transfusão de sangue por peso pode ser avaliada na Tabela 4.2, que indica uma forte relação entre as variáveis, dado o aumento progressivo da média de transfusão recebida quanto maior o PELD. Como a codificação da variável foi realizada na base de 310 casos, sua redução acarretou em um pequeno desequilíbrio nas quantidades de observações entre os quartis. O primeiro nível foi mais afetado por conter a maior parte dos indivíduos que não receberam transfusão de sangue. Entretanto, os tamanhos das amostras dos grupos são relativamente próximos e grandes, desta forma, considerados adequados para o estudo.

\begin{tabular}{ccccccc}
\hline PELD & N & Média & Mediana & Desv. Padrão & Mínimo & Máximo \\
\hline PELD $(1)$ & 63 & 2,51 & 2,01 & 1,68 & 0,49 & 7,70 \\
PELD $(2)$ & 75 & 2,92 & 2,36 & 2,21 & 0,64 & 12,12 \\
PELD $(3)$ & 75 & 3,31 & 2,94 & 2,23 & 0,97 & 16,74 \\
PELD $(4)$ & 75 & 4,12 & 3,38 & 3,26 & 0,83 & 19,16 \\
\hline Total & 288 & 3,24 & 2,66 & 2,50 & 0,49 & 19,16 \\
\hline
\end{tabular}

Tabela 4.2: Medidas descritivas da transfusão de sangue por peso segundo PELD.

A desigualdade entre os gráficos da Figura 4.3 demonstram ainda que além da média, a varia- 
bilidade da transfusão de sangue aumenta conforme a debilidade do fígado do indivíduo, ou seja, existe correlação positiva entre o percentual de sangue recebido pelo paciente e o índice PELD; pacientes com maior debilidade tendem a receber mais sangue.

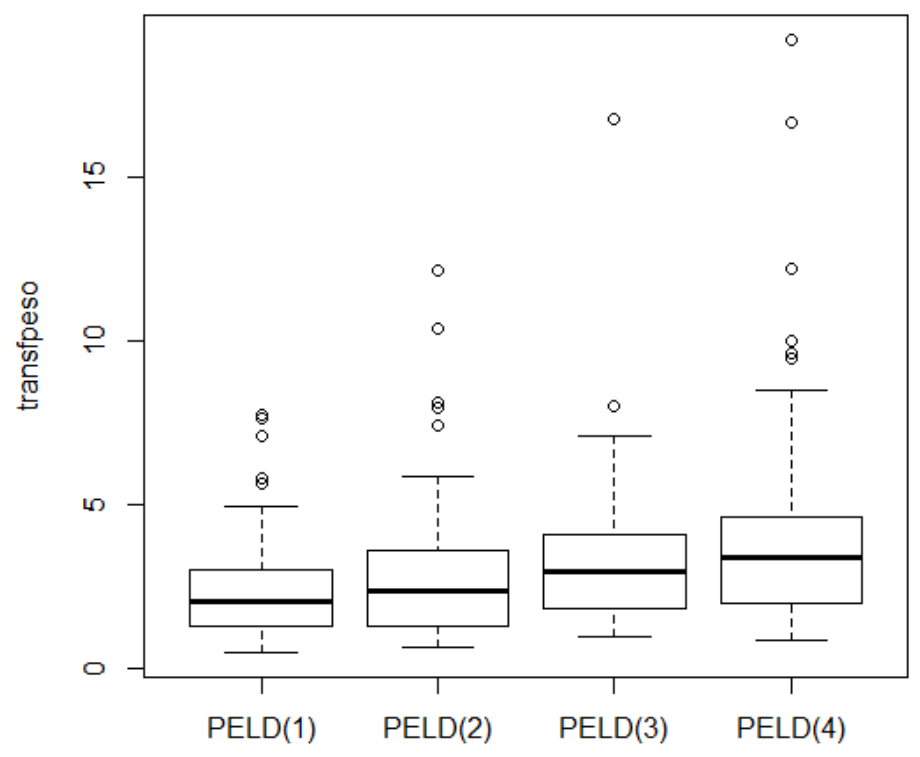

Figura 4.3: Boxplot da transfusão de sangue por peso segundo PELD.

A média e o desvio padrão da tranfusão de sangue por peso aumentam mais para os pacientes de Kasai, quanto maior o PELD. Isso indica efeito de interação entre Kasai e PELD não só sobre a média, mas também sobre a variabilidade da transfusão de sangue por peso. Tal efeito fica bem evidente na Figura 4.4.

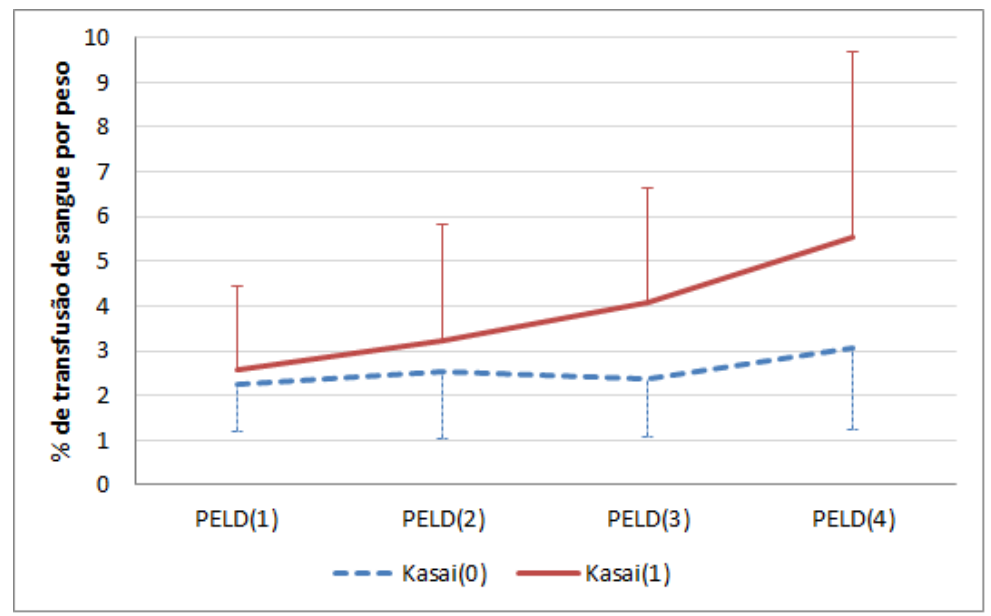

Figura 4.4: Perfis médios da transfusão de sangue por peso segundo Kasai e PELD.

Um fato usual para muitas variáveis positivas é observar que quanto maior é a média, maior é o desvio padrão. Muitas distribuições de probabilidade levam em conta esse comportamento. Em vários casos, o coeficiente de variação (desvio padrão dividido pela média) é constante. Para o conjunto de dados analisado, temos que o coeficiente de variação não parece constante e apresenta maiores valores para os pacientes de Kasai, conforme Tabela 4.3. 


\begin{tabular}{rrcccc}
\hline Kasai & Estatística & PELD $(1)$ & PELD(2) & PELD(3) & PELD(4) \\
\hline Não (0) & Número de casos & 16 & 32 & 34 & 43 \\
& Média & 2,26 & 2,52 & 2,36 & 3,07 \\
& Desvio Padrão & 1,07 & 1,50 & 1,31 & 1,84 \\
& Coeficiente de Variação & $47 \%$ & $60 \%$ & $55 \%$ & $60 \%$ \\
\hline Sim (1) & Número de casos & 47 & 43 & 41 & 32 \\
& Média & 2,59 & 3,22 & 4,09 & 5,52 \\
& Desvio Padrão & 1,84 & 2,60 & 2,53 & 4,15 \\
& Coeficiente de Variação & $71 \%$ & $81 \%$ & $62 \%$ & $75 \%$ \\
\hline
\end{tabular}

Tabela 4.3: Coeficiente de variação de transfpeso segundo Kasai e PELD.

\subsubsection{Base de dados $\mathrm{B}$}

Para a base $B$, com todas as observações, a variável resposta foi trabalhada de forma qualitativa, ou seja, de acordo com a ocorrência ou não de transfusão. Este processo se torna necessário para a modelagem de todas as observações, incluindo os valores nulos de transfusão de sangue, conforme as distribuições apresentadas no Capitulo 2, ZAGA e ZAIG. As próximas tabelas exibem seu comportamento em relação às variáveis explicativas.

Como apresentado na Tabela 4.4, 7\% dos pacientes não precisaram de transfusão de sangue. A proporção de pacientes que precisou de transfusão é muito semelhante para os pacientes que fizeram e não fizeram o Kasai. Essa proporção é bem diferente para diferentes níveis de PELD, já que $19 \%$ dos pacientes com menores valores de PELD $(P E L D(1))$, visto na Tabela 4.5, não receberam transfusão e esse percentual cai para em torno de $3 \%$ a $4 \%$ para quem tem maiores valores de PELD. Logo, há efeito da variável PELD sobre a probabilidade de receber transfusão.

\begin{tabular}{rccccc}
\hline & \multicolumn{2}{c}{ Com transfusão } & \multicolumn{2}{c}{ Sem transfusão } & Total \\
\hline Kasai & $\mathrm{N}$ & $\%$ & $\mathrm{~N}$ & $\%$ & $\mathrm{~N}$ \\
\hline Não (0) & 125 & $94 \%$ & 8 & $6 \%$ & 133 \\
Sim (1) & 163 & $92 \%$ & 14 & $8 \%$ & 177 \\
\hline Total & 288 & $93 \%$ & 22 & $7 \%$ & 310 \\
\hline
\end{tabular}

Tabela 4.4: Frequência da ocorrência de transfusão segundo Kasai.

\begin{tabular}{rrrrrr}
\hline PELD & \multicolumn{2}{c}{ Com transfusão } & \multicolumn{2}{c}{ Sem transfusão } & Total \\
& $\mathrm{N}$ & $\%$ & $\mathrm{~N}$ & $\%$ & $\mathrm{~N}$ \\
\hline PELD(1) & 63 & $81 \%$ & 15 & $19 \%$ & 78 \\
PELD(2) & 75 & $96 \%$ & 3 & $4 \%$ & 78 \\
PELD(3) & 75 & $97 \%$ & 2 & $3 \%$ & 77 \\
PELD(4) & 75 & $97 \%$ & 2 & $3 \%$ & 77 \\
\hline Total & 288 & $93 \%$ & 22 & $7 \%$ & 310 \\
\hline
\end{tabular}

Tabela 4.5: Frequência da ocorrência de transfusão segundo PELD.

\subsection{Análise inferencial}

Para avaliar o efeito das variáveis explicativas Kasai e PELD na distribuição da transfusão de sangue por peso, primeiro foram ajustados os modelos lineares generalizados para variáveis positivas com as distribuições gama, log-normal e normal inversa. Tais modelos se aplicam somente 
a variáveis positivas e todos os valores iguais a zero são simplesmente descartados, ou seja, isso equivale a utilizar somente o conjunto de dados da base $A$. Uma alternativa seria substituir todos os valores por um pequeno valor positivo para ajustar tais modelos e até considerar diferentes valores para avaliar o efeito da escolha de tal valor. Não foi adotada essa abordagem nesse trabalho já que há modelos que permitem considerar a presença de zeros de modo mais prático e adequado.

De acordo com a avaliação dos ajustes de modelos e também de acordo com a análise descritiva, observou-se que o desvio padrão dos modelos propostos não é necessariamente proporcional à média, portanto tornou-se necessário propor um modelo para melhor se ajustar à variabilidade dos dados segundo as variáveis explicativas. Para tal foram considerados os modelos GAMLSS, utilizando modelos lineares para o logaritmo da média e do parâmetro de escala, ou seja, sem a parte não paramétrica que diz respeito ao modelo aditivo. Para ajustar tais modelos também consideraram-se as distribuições gama, log-normal e normal inversa que, portanto, requerem que a variável resposta seja positiva. Assim também foram levados em conta somente os pacientes que receberam transfusão na base $A$.

Por fim, também utilizando uma versão dos modelos GAMLSS, ajustou-se modelos com distribuição ZAIG e ZAGA (2.1.1 e 2.3.1), em que a variável resposta é uma mistura de zeros e de uma distribuição para valores positivos. É interessante ressaltar que o modelo ZAGA só foi implementado no R em 2014 (Stasinopoulos et al. (2014)). Tais modelos permitem considerar todos os dados observados da base $B$, e avaliar o efeito das variáveis explicativas sobre a probabilidade do paciente receber transfusão, como foi analisado descritivamente na Subseção 4.1.2.

Os ajustes dos modelos de regressão apresentados no Capítulo 3 serão expostos da seguinte forma:

1. Modelo linear generalizado (GLM) com distribuições gama, log-normal e normal inversa, com ajuste para a média $(\mu)$;

2. Modelo aditivo generalizado para posição, escala e forma (GAMLSS) com distribuições gama, log-normal e normal inversa, com ajuste para os parâmetros de posição e escala $(\mu, \sigma)$;

3. Modelo aditivo generalizado para posição, escala e forma (GAMLSS) com distribuições gama zero ajustada e normal inversa zero ajustada, com ajuste para os parâmetros de posição, escala e probabilidade $(\mu, \sigma, \nu)$.

Para as distribuições gama e normal inversa, foi adotada a função de ligação logaritmo, de modo que o logaritmo da média da variável resposta é uma função linear dos parâmetros e variáveis explicativas $(\eta=\log (\mu))$. Já a análise com a distribuição log-normal demanda que a transformação logarítmica seja realizada nas observações, sendo assim, seu parâmetro de posição terá a ligação identidade, $\eta=\mu$. Apesar dessa diferença, os resultados são comparáveis e os efeitos das variáveis explicativas são multiplicativos sobre a média.

Para a modelagem do parâmetro de escala $\sigma$ nos modelos GAMLSS, foi aplicada a função de ligação padrão do software, que para todas as distribuições é $\eta=\log (\sigma)$. Já a probabilidade de não receber transfusão de sangue, representada por $\nu$, recebeu a ligação logito, dada por $\eta=\log \left(\frac{\nu}{1-\nu}\right)$; já que essa é a função de ligação mais usual para variáveis binárias.

Para todas as ligações logarítmicas trabalhadas na dissertação, considerou-se o logaritmo neperiano (ou natural), função inversa da função exponencial.

\subsubsection{GLM com distribuições gama, log-normal e normal inversa}

Nos modelos GLM será avaliada a adequabilidade das distribuições sugeridas neste trabalho para a modelagem do parâmetro de média. Para efeito de comparação, todos os modelos irão contar com as duas variáveis explicativas consideradas no estudo, assim como sua interação. Estes serão representados pela equação (4.1) 


$$
\begin{aligned}
\log \left(\mu_{i}\right) & =\beta_{0}+\beta_{1} \operatorname{Kasai}(1)+\beta_{2} P E L D(2)+\beta_{3} P E L D(3)+\beta_{4} P E L D(4) \\
& +\beta_{5} \operatorname{Kasai}(1) P E L D(2)+\beta_{6} \operatorname{Kasai}(1) P E L D(3)+\beta_{7} \operatorname{Kasai}(1) P E L D(4)
\end{aligned}
$$

em que:

- o índice $i$ referencia o indivíduo, $i=1, \ldots, 288$;

- $\mu$ corresponde à média da transfusão de sangue por peso;

- $\beta_{j}$ para $j=0, \ldots, 7$ são os coeficientes do modelo para cada nível das variáveis explicativas.

Na Tabela 4.6 estão presentes as estimativas dos coeficientes do modelo de médias e do parâmetro de dispersão para cada distribuição atribuída, assim como seus respectivos erros padrões e níveis descritivos.

É notável que as estimativas dos efeitos da média são iguais para as distribuições gama e normal inversa, mas os erros padrões são diferentes.

As estimativas dos efeitos de interação entre as variáveis Kasai e PELD se mostram significantes para todas as distribuições se considerado o nível de significância de $10 \%$. Entretanto, apenas a distribuição log-normal mantém essa mesma conclusão se adotado o nível de significância deste estudo de $5 \%$.

\begin{tabular}{rrccc}
\hline Coeficiente & Distribuição & Estimativa & Erro padrão & p-valor \\
\hline Intercepto & Gama & 0,814 & 0,166 & $<0,001$ \\
& Log-Normal & 0,705 & 0,152 & $<0,001$ \\
& Normal Inversa & 0,814 & 0,141 & $<0,001$ \\
Kasai(1) & Gama & 0,138 & 0,192 & 0,4729 \\
& Log-Normal & 0,021 & 0,176 & 0,9073 \\
& Normal Inversa & 0,138 & 0,166 & 0,4077 \\
PELD(2) & Gama & 0,109 & 0,203 & 0,5909 \\
& Log-Normal & 0,049 & 0,186 & 0,7929 \\
& Normal Inversa & 0,109 & 0,176 & 0,5354 \\
PELD(3) & Gama & 0,046 & 0,201 & 0,8187 \\
& Log-Normal & 0,028 & 0,184 & 0,8806 \\
& Normal Inversa & 0,046 & 0,172 & 0,7891 \\
PELD(4) & Gama & 0,308 & 0,194 & 0,1141 \\
& Log-Normal & 0,256 & 0,178 & 0,1522 \\
& Normal Inversa & 0,308 & 0,173 & 0,0765 \\
Kasai(1)*PELD(2) & Gama & 0,108 & 0,246 & 0,6620 \\
& Log-Normal & 0,138 & 0,226 & 0,5431 \\
& Normal Inversa & 0,108 & 0,222 & 0,6274 \\
Kasai(1)*PELD(3) & Gama & 0,410 & 0,246 & 0,0962 \\
& Log-Normal & 0,532 & 0,226 & 0,0192 \\
& Normal Inversa & 0,410 & 0,227 & 0,0716 \\
Kasai(1)*PELD(4) & Gama & 0,449 & 0,246 & 0,0693 \\
& Log-Normal & 0,499 & 0,226 & 0,0283 \\
& Normal Inversa & 0,449 & 0,249 & 0,0723 \\
$\phi^{-1}$ & Gama & 0,439 & - & - \\
& Log-Normal & 0,370 & - & - \\
& Normal Inversa & 0,141 & - & - \\
\hline
\end{tabular}

Tabela 4.6: Estimativas dos modelos GLM.

Para avaliar a distribuição que acomoda de melhor forma os dados, utilizaram-se os gráficos presentes na Figura 4.5. No gráfico normal de probabilidades, a distribuição atribuída aos dados é adequada se os resíduos do modelo estiverem acomodados dentro das bandas de confiança. A 
distribuição gama se apresenta claramente fora do padrão desejado, dado que os limites definidos não suportam a assimetria dos dados. As outras duas distribuições ajustam razoavelmente bem os resíduos, sendo levadas para maiores diagnósticos.
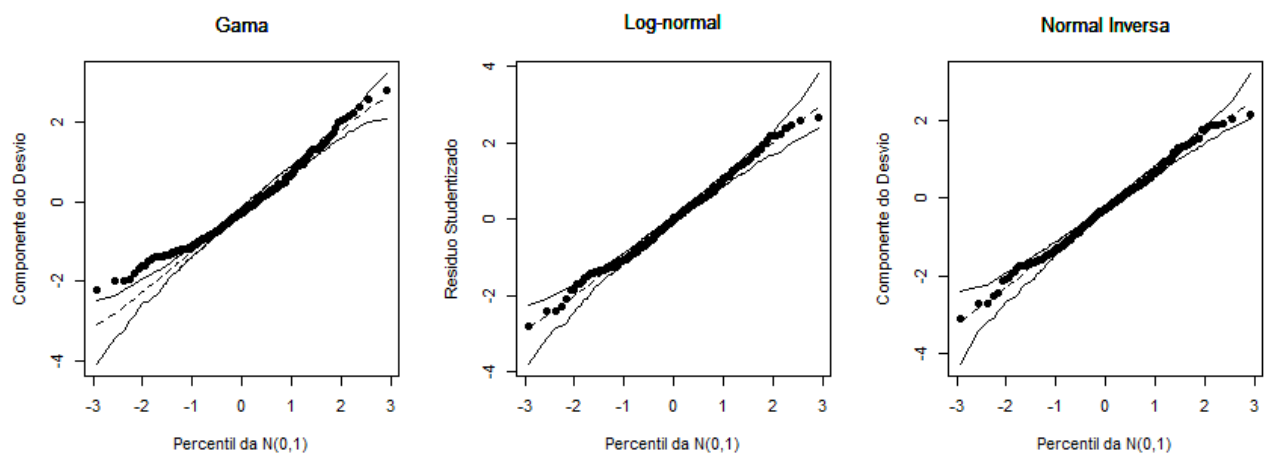

Figura 4.5: Gráfico de envelope para os modelos GLM.

Os gráficos da Figura 4.6 revelam indícios de heterocedasticidade dos resíduos, não ajustada de forma satisfatória para os modelos com distribuição log-normal e normal inversa. Esta constatação se respalda nas diferentes variabilidades dos resíduos entre os níveis dos valores ajustados, indicando a necessidade do ajuste do parâmetro de dispersão pelas variáveis explicativas. Para a distribuição normal inversa foi considerado o resíduo componente do desvio, enquanto na distribuição log-normal utilizou-se o resíduo padronizado, posto que por ser resultante de um modelo com distribuição normal, este seguiria a mesma.

Log-Normal

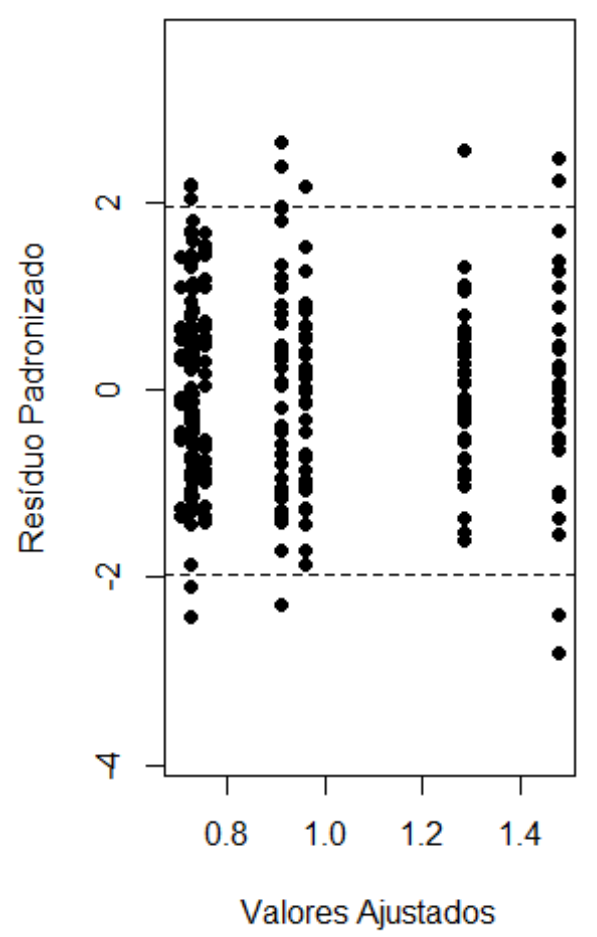

Normal Inversa

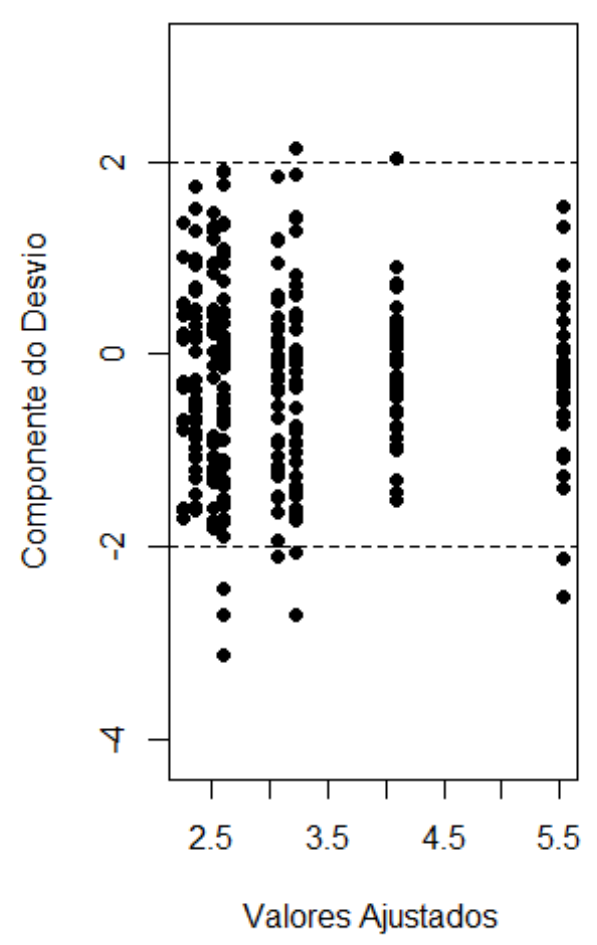

Figura 4.6: Gráficos de resíduos padronizados para os modelos GLM. 


\subsubsection{GAMLSS com distribuições gama, log-normal e normal inversa}

Ratificada a necessidade de modelar o parâmetro de dispersão da distribuição, devido à má qualidade dos ajustes dos modelos apresentados na subseção anterior, a próxima abordagem será baseada no ajuste dos modelos GAMLSS.

Conforme apresentado na Seção 3.2, nesta classe tem-se como resultado o ajuste de dois modelos, um para a média e outro para o parâmetro de escala, que podem ser distintos em relação ao grupo de variáveis explicativas. Entretanto, para viabilizar a comparação entre as distribuições gama, log-normal e normal inversa será adotado o mesmo procedimento do item anterior; a matriz de planejamento irá contar com as duas variáveis explicativas do estudo e sua interação. As equações destes modelos são representadas por

$$
\begin{aligned}
\log \left(\mu_{i}\right) & =\beta_{0}+\beta_{1} \operatorname{Kasai}(1)+\beta_{2} P E L D(2)+\beta_{3} P E L D(3)+\beta_{4} P E L D(4) \\
& +\beta_{5} \text { Kasai }(1) P E L D(2)+\beta_{6} \text { Kasai }(1) P E L D(3)+\beta_{7} \text { Kasai }(1) P E L D(4), \\
\log \left(\sigma_{i}\right) & =\alpha_{0}+\alpha_{1} \operatorname{Kasai}(1)+\alpha_{2} P E L D(2)+\alpha_{3} P E L D(3)+\alpha_{4} P E L D(4) \\
& +\alpha_{5} \text { Kasai }(1) P E L D(2)+\alpha_{6} \text { Kasai }(1) P E L D(3)+\alpha_{7} \text { Kasai }(1) P E L D(4),
\end{aligned}
$$

em que:

- o índice $i$ referencia o indivíduo, com $i=1, \ldots, 288$;

- $\mu$ é o parâmetro de locação;

- $\sigma$ é o parâmetro de escala;

- $\beta_{j}$ para $j=0, \ldots, 7$ são os coeficientes do modelo para cada nível das variáveis explicativas associadas ao parâmetro $\mu$.

- $\alpha_{j}$ para $j=0, \ldots, 7$ são os coeficientes do modelo para cada nível das variáveis explicativas associadas ao parâmetro $\sigma$.

As estimativas dos parâmetros, assim como seus desvios padrões e valores-p estão presentes nas Tabelas 4.7 e 4.8, respectivamente para os parâmetros $\mu$ e $\sigma$. Os resultados são apresentados conjuntamente para as três distribuições em estudo, permitindo comparação direta das variáveis com efeitos significativos no modelo.

Diferentemente do resultado apresentado na seção anterior, em que apenas no uso da distribuição log-normal o efeito da interação entre as variáveis Kasai e PELD foi significante para o modelo, ao ajustar o parâmetro de escala a interação se torna significante para a média em todas as distribuições e para diferentes níveis da interação.

Ademais, o nível mais alto da variável PELD é significantemente diferente do nível mais baixo, se considerada a distribuição gama. Por ser uma estimativa positiva, esta informação corrobora o fato de que quem tem maior debilidade no figado precisou receber um volume maior de transfusão de sangue em relação à quem está menos debilitado, classificado no primeiro quartil da variável PELD, mesmo para quem não realizou a pré-cirurgia de Kasai.

No modelo para o parâmetro de escala é possível verificar se entre os níveis das variáveis Kasai e PELD o percentual de sangue recebido oscila de forma distinta, e, caso isso seja significativo, quantificar esta diferença.

Para o modelo em que a distribuição normal inversa foi atribuída aos dados, a interação entre as variáveis explicativas se mostrou altamente significante para a variabilidade de quem foi submetido à pré-cirurgia Kasai e concomitantemente foi classificado no terceiro nível da variável PELD. A oscilação entre os coeficientes de variação, avaliados na análise descritiva da Tabela 4.3 já indicava um comportamento relevante para a interação das variáveis. Embora somente um nível da interação apresente valor-p menor que 5\%, a significância da relação entre as variáveis pode ser ainda 


\begin{tabular}{rrccc}
\hline Coeficiente & Distribuição & Estimativa & Erro padrão & p-valor \\
\hline Intercepto & Gama & 0,814 & 0,115 & $<0,001$ \\
& Log-Normal & 0,705 & 0,120 & $<0,001$ \\
& Normal Inversa & 0,814 & 0,126 & $<0,001$ \\
Kasai(1) & Gama & 0,138 & 0,149 & 0,3562 \\
& Log-Normal & 0,021 & 0,155 & 0,8949 \\
PELD(2) & Normal Inversa & 0,138 & 0,167 & 0,4089 \\
& Gama & 0,109 & 0,153 & 0,4750 \\
& Log-Normal & 0,049 & 0,158 & 0,7567 \\
PELD(3) & Normal Inversa & 0,109 & 0,167 & 0,5137 \\
& Gama & 0,046 & 0,143 & 0,7474 \\
& Log-Normal & 0,028 & 0,146 & 0,8499 \\
PELD(4) & Normal Inversa & 0,046 & 0,154 & 0,7648 \\
& Gama & 0,308 & 0,143 & 0,0320 \\
& Log-Normal & 0,256 & 0,148 & 0,0849 \\
Kasai(1)*PELD(2) & Normal Inversa & 0,308 & 0,157 & 0,0505 \\
& Gama & 0,108 & 0,208 & 0,6052 \\
& Log-Normal & 0,138 & 0,215 & 0,5216 \\
& Normal Inversa & 0,108 & 0,233 & 0,6434 \\
Kasai(1)*PELD(3) & Gama & 0,410 & 0,188 & 0,0298 \\
& Log-Normal & 0,532 & 0,192 & 0,0059 \\
& Normal Inversa & 0,410 & 0,205 & 0,0464 \\
Kasai(1)*PELD(4) & Gama & 0,449 & 0,207 & 0,0307 \\
& Log-Normal & 0,499 & 0,215 & 0,0212 \\
& Normal Inversa & 0,449 & 0,236 & 0,0574 \\
\hline
\end{tabular}

Tabela 4.7: Estimativas dos modelos GAMLSS para o parâmetro de posição $\mu$.

\begin{tabular}{rrccc}
\hline Coeficiente & Distribuição & Estimativa & Erro padrão & p-valor \\
\hline Intercepto & Gama & $-0,776$ & 0,171 & $<0,001$ \\
& Log-Normal & $-0,738$ & 0,177 & $<0,001$ \\
Kasai(1) & Normal Inversa & $-1,096$ & 0,177 & $<0,001$ \\
& Gama & 0,348 & 0,196 & 0,0777 \\
& Log-Normal & 0,347 & 0,205 & 0,0909 \\
NELmal Inversa & 0,333 & 0,205 & 0,1046 \\
& Gama & 0,210 & 0,208 & 0,3130 \\
& Log-Normal & 0,197 & 0,217 & 0,3627 \\
& Normal Inversa & 0,160 & 0,217 & 0,4609 \\
PELD(3) & Gama & 0,075 & 0,207 & 0,7177 \\
& Log-Normal & 0,029 & 0,214 & 0,8929 \\
& Normal Inversa & 0,011 & 0,214 & 0,9608 \\
Kasai(1)*PELD(2) & Gama & 0,186 & 0,199 & 0,3506 \\
& Log-Normal & 0,176 & 0,207 & 0,3961 \\
& Normal Inversa & 0,046 & 0,207 & 0,8239 \\
& Gama & $-0,152$ & 0,251 & 0,5459 \\
& Log-Normal & $-0,164$ & 0,263 & 0,5327 \\
& Normal Inversa & $-0,227$ & 0,263 & 0,3887 \\
Kasai(1)*PELD(3) & Gama & $-0,362$ & 0,252 & 0,1514 \\
& Log-Normal & $-0,384$ & 0,262 & 0,1445 \\
& Normal Inversa & $-0,628$ & 0,262 & 0,0174 \\
Kasai(1)*PELD(4) & Gama & $-0,181$ & 0,251 & 0,4708 \\
& Log-Normal & $-0,165$ & 0,263 & 0,5316 \\
& Normal Inversa & $-0,390$ & 0,263 & 0,1395 \\
\hline & & &
\end{tabular}

Tabela 4.8: Estimativas dos modelos GAMLSS para o parâmetro de escala $\sigma$. 
confirmada por meio do critério de informação de Akaike generalizado (GAIC), que apresentou um valor menor para o modelo completo em relação ao modelo sem a interação.

A validação das distribuições sugeridas nos modelos será realizada por meio dos gráficos de diagnóstico dos modelos GAMLSS, baseados em resíduos quantílicos - neste caso sem a componente aleatória por tratar-se de variável resposta contínua.

Na Figura 4.7, a análise do gráfico quantil-quantil sugere que a distribuição gama se mantém inadequada para o ajuste dos dados, dado o distanciamento de diversos resíduos do entorno da reta. As caudas pesadas sugeridas por este gráfico são confirmadas pelo formato da densidade estimada de Kernel dos resíduos, assim como as medidas de assimetria e curtose presentes na Tabela 4.9, distantes dos valores esperados de zero e três, respectivamente.

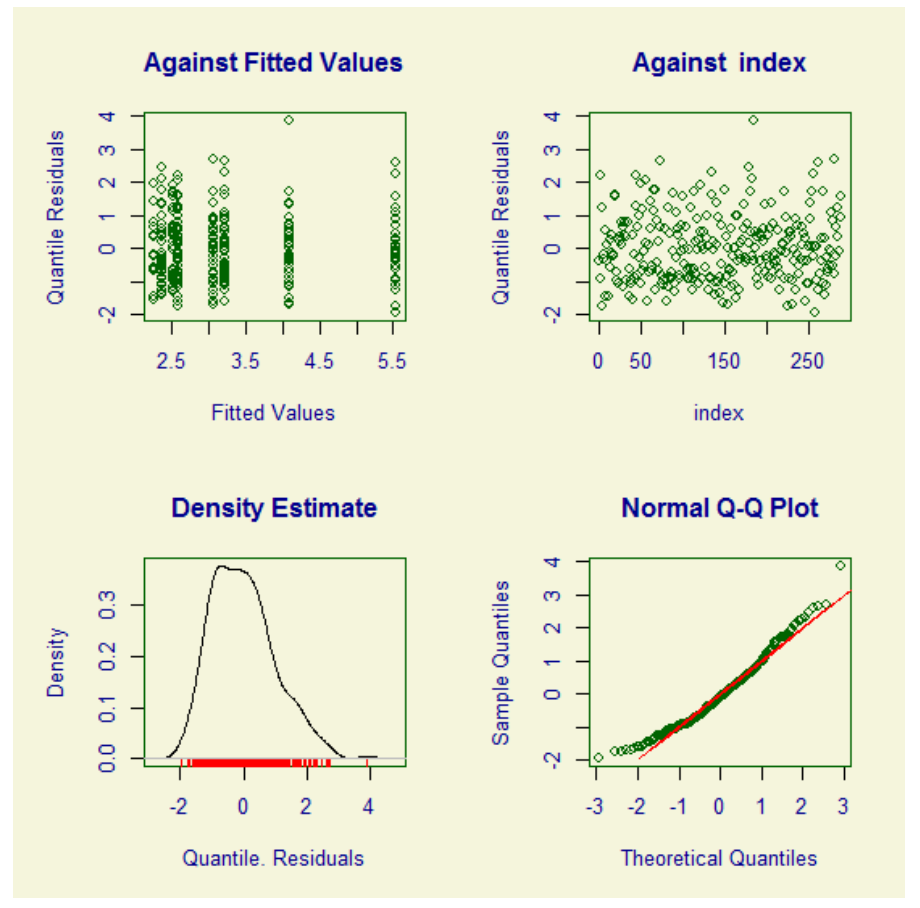

Figura 4.7: Gráficos para diagnóstico do ajuste do modelo considerando a distribuição gama para os dados.

\begin{tabular}{rrrr}
\hline Medidas resumo & Gama & Log-Normal & Normal Inversa \\
\hline Média & $-0,006$ & 0,000 & $-0,004$ \\
Variância & 1,000 & 1,003 & 1,002 \\
Coeficiente de assimetria & 0,652 & 0,189 & 0,138 \\
Coeficiente de curtose & 3,265 & 2,618 & 2,747 \\
\hline
\end{tabular}

Tabela 4.9: Medidas resumo do resíduo quantílico para os modelos GAMLSS.

Para a distribuição log-normal estes tipos de desvios são relativamente menores, de forma mais clara em relação à assimetria dos resíduos. No gráfico quantil-quantil da Figura 4.8 nota-se uma quantidade menor de pontos distantes da reta diagonal, compreendendo-se que a distribuição lognormal acomoda dados com assimetrias mais acentuadas do que a distribuição gama. O coeficiente de assimetria confirma esta análise devido à sua forte queda em direção ao valor zero, conforme as medidas apresentadas na Tabela 4.9.

Por fim, apresentam-se as medidas para diagnóstico do modelo GAMLSS com distribuição normal inversa na Figura 4.9. Similar à análise do gráfico anterior, pode-se inferir que a distribuição normal inversa resulta em uma qualidade de ajuste consideravelmente superior em relação à gama. De forma moderada, inclusive parece ser mais adequada do que a distribuição log-normal. A visualização desta afirmação é dada pelos gráficos quantil-quantil, em que uma quantidade ainda menor de pontos se distancia da reta diagonal. 


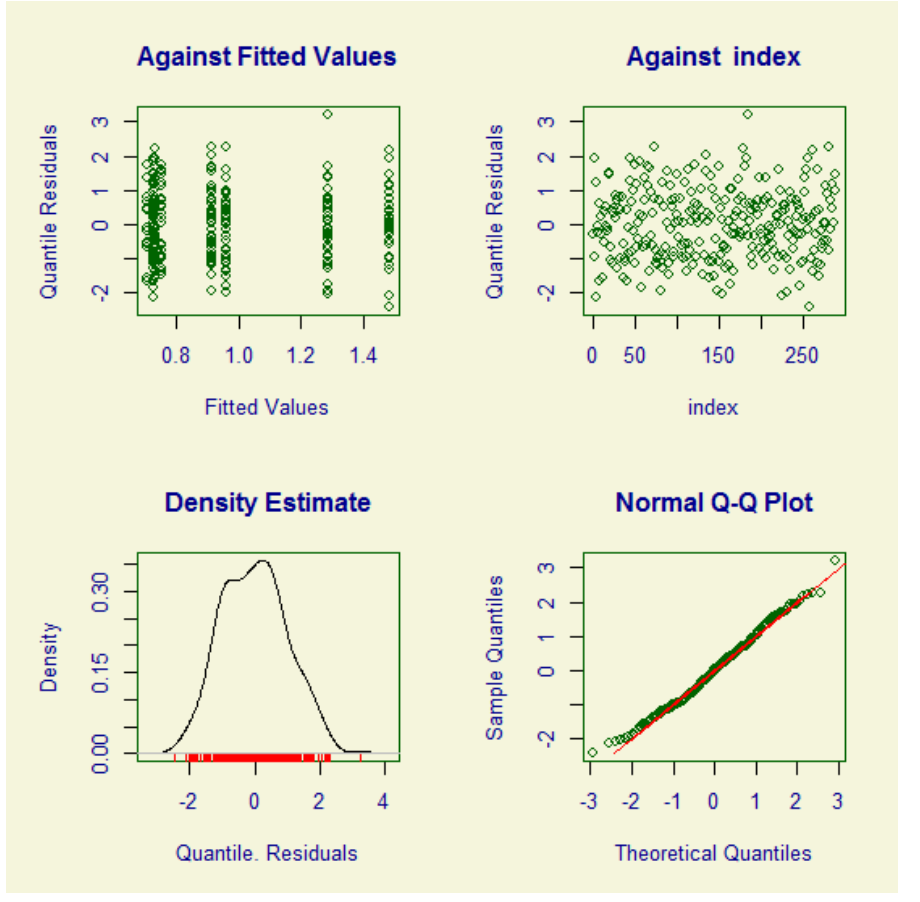

Figura 4.8: Gráficos para diagnóstico do ajuste do modelo considerando a distribuição log-normal para os dados.

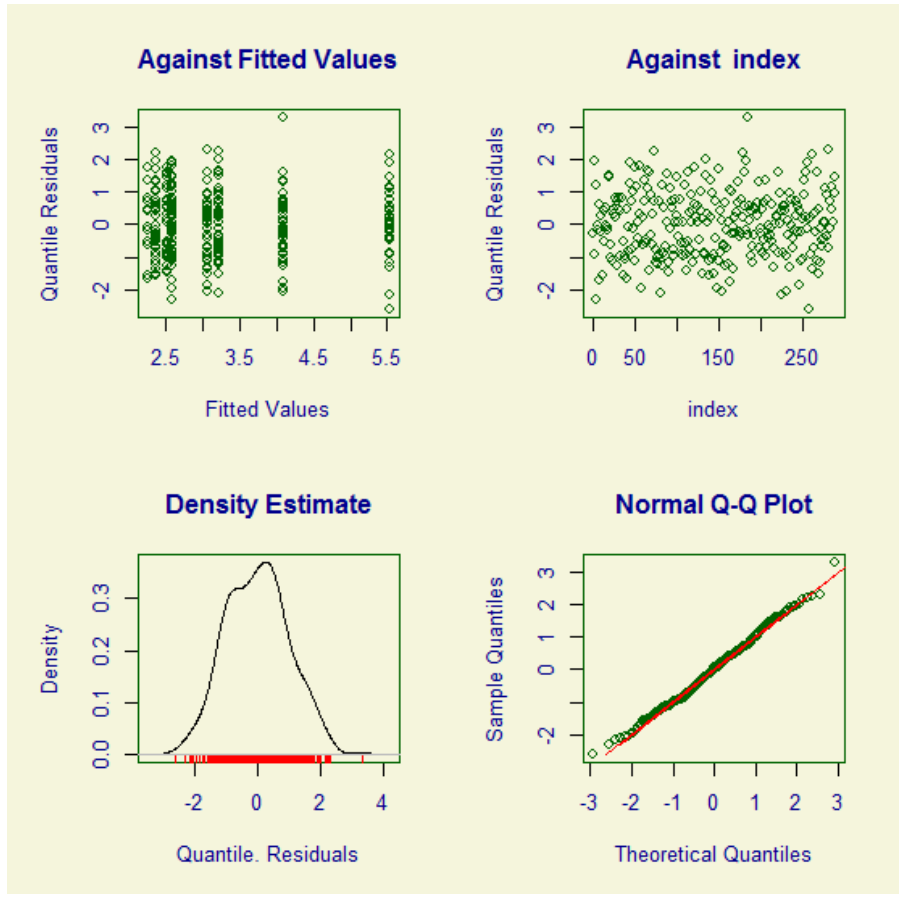

Figura 4.9: Gráficos para diagnóstico do ajuste do modelo considerando a distribuição normal inversa para os dados.

Homologando as discussões anteriores, as medidas da distribuição do resíduo quantílico do modelo com distribuição normal inversa, presentes na Tabela 4.9, são mais próximas às medidas de uma curva normal padrão, particularmente se tomadas as medidas de forma: assimetria e curtose. 


\subsubsection{GAMLSS com distribuições gama zero ajustada e normal inversa zero ajustada}

Na última categoria de modelos a serem ajustados será utilizada por fim a base completa de dados, visto que as distribuições ZAGA e ZAIG comportam as observações nulas da variável resposta. Dessa forma, os indivíduos que não precisaram de transfusão de sangue passam a ser incorporados na modelagem e uma possível relação com as variáveis Kasai e PELD poderá ser investigada. O parâmetro $\nu$ será ajustado por um modelo logístico, considerando que este trata a variável transfpeso categorizada de forma binária, conforme descrito na análise descritiva (4.1.2). Isso significa que esse parâmetro $\nu$ corresponde à probabilidade do indivíduo não receber transfusão.

Assim como nos modelos apresentados na subseção anterior, o parâmetro de escala também será ajustado, dado que este faz parte das distribuições abordadas neste item e por ter se mostrado necessário para controle de heterocedasticidade dos dados. Mantem-se nestes ajustes a matriz de planejamento, com as variáveis Kasai e PELD, além de sua interação para a comparação dos modelos com as duas distribuições.

As equações que representam o ajuste dos modelos com distribuição ZAGA e ZAIG são dadas por

$$
\begin{aligned}
& \log \left(\mu_{i}\right)=\beta_{0}+\beta_{1} \operatorname{Kasai}(1)+\beta_{2} P E L D(2)+\beta_{3} P E L D(3)+\beta_{4} P E L D(4) \\
& +\beta_{5} \text { Kasai(1)PELD(2)+ } \beta_{6} \text { Kasai(1)PELD(3) }+\beta_{7} \text { Kasai(1)PELD(4), } \\
& \log \left(\sigma_{i}\right)=\alpha_{0}+\alpha_{1} \operatorname{Kasai}(1)+\alpha_{2} P E L D(2)+\alpha_{3} P E L D(3)+\alpha_{4} P E L D(4) \\
& +\alpha_{5} \text { Kasai(1)PELD(2) }+\alpha_{6} \text { Kasai(1)PELD(3) }+\alpha_{7} \text { Kasai }(1) P E L D(4) \text {, } \\
& \log \left(\frac{\nu_{i}}{1-\nu_{i}}\right)=\gamma_{0}+\gamma_{1} \operatorname{Kasai}(1)+\gamma_{2} P E L D(2)+\gamma_{3} P E L D(3)+\gamma_{4} P E L D(4) \\
& +\gamma_{5} \operatorname{Kasai}(1) P E L D(2)+\gamma_{6} \operatorname{Kasai}(1) P E L D(3)+\gamma_{7} \operatorname{Kasai}(1) P E L D(4),
\end{aligned}
$$

em que:

- o índice $i$ referencia o indivíduo, com $i=1, \ldots, 310$;

- $\mu$ é o parâmetro de locação;

- $\sigma$ é o parâmetro de escala;

- $\nu$ é o parâmetro de forma, no caso identificado como a probabilidade de não receber transfusão;

- $\beta_{j}$ para $j=0, \ldots, 7$ são os coeficientes do modelo para cada nível das variáveis explicativas associadas ao parâmetro $\mu$.

- $\alpha_{j}$ para $j=0, \ldots, 7$ são os coeficientes do modelo para cada nível das variáveis explicativas associadas ao parâmetro $\sigma$.

- $\gamma_{j}$ para $j=0, \ldots, 7$ são os coeficientes do modelo para cada nível das variáveis explicativas associadas ao parâmetro $\nu$.

As estimativas dos modelos e suas estatísticas estão presentes nas Tabelas 4.10, 4.11 e 4.12, para os parâmetros de posição, escala e forma, respectivamente.

Devido à ortogonalidade assintótica entre os parâmetros da distribuição $(\mu, \sigma, \nu)$, os estimadores dos coeficientes de seus modelos serão por consequência independentes. Dessa forma, os valores e inferências apresentados para os parâmetros $\mu$ e $\sigma$ serão análogas às apresentadas na seção anterior, considerando a equivalência das distribuições referentes à parte contínua dos dados. Com isso, mantém-se a significância da interação entre as variáveis explicativas para os modelos dos parâmetros de locação e escala, ou seja, tanto a média quanto a variância da variável resposta são afetadas de forma significativa pela interação entre os níveis do $P E L D$ e a realização da pré-cirurgia de Kasai. 


\begin{tabular}{rrccc}
\hline Coeficiente & Distribuição & Estimativa & Erro padrão & p-valor \\
\hline Intercepto & ZAGA & 0,814 & 0,115 & $<0,001$ \\
& ZAIG & 0,814 & 0,126 & $<0,001$ \\
Kasai(1) & ZAGA & 0,138 & 0,149 & 0,3562 \\
& ZAIG & 0,138 & 0,167 & 0,4088 \\
PELD(2) & ZAGA & 0,109 & 0,153 & 0,4750 \\
& ZAIG & 0,109 & 0,167 & 0,5137 \\
PELD(3) & ZAGA & 0,046 & 0,143 & 0,7474 \\
& ZAIG & 0,046 & 0,154 & 0,7648 \\
PELD(4) & ZAGA & 0,308 & 0,143 & 0,0320 \\
& ZAIG & 0,308 & 0,157 & 0,0505 \\
Kasai(1)*PELD(2) & ZAGA & 0,108 & 0,208 & 0,6052 \\
& ZAIG & 0,108 & 0,233 & 0,6433 \\
Kasai(1)*PELD(3) & ZAGA & 0,410 & 0,188 & 0,0298 \\
& ZAIG & 0,410 & 0,205 & 0,0463 \\
Kasai(1)*PELD(4) & ZAGA & 0,449 & 0,207 & 0,0307 \\
& ZAIG & 0,449 & 0,236 & 0,0574 \\
\hline
\end{tabular}

Tabela 4.10: Estimativas dos modelos GAMLSS para o parâmetro de posição $\mu$.

\begin{tabular}{rrccc}
\hline Coeficiente & Distribuição & Estimativa & Erro padrão & p-valor \\
\hline Intercepto & ZAGA & $-0,776$ & 0,171 & $<0,001$ \\
& ZAIG & $-1,096$ & 0,177 & $<0,001$ \\
Kasai(1) & ZAGA & 0,348 & 0,196 & 0,0777 \\
& ZAIG & 0,333 & 0,205 & 0,1045 \\
PELD(2) & ZAGA & 0,210 & 0,208 & 0,3129 \\
& ZAIG & 0,160 & 0,217 & 0,4609 \\
PELD(3) & ZAGA & 0,075 & 0,207 & 0,7177 \\
& ZAIG & 0,011 & 0,214 & 0,9608 \\
PELD(4) & ZAGA & 0,186 & 0,199 & 0,3505 \\
& ZAIG & 0,046 & 0,207 & 0,8239 \\
Kasai(1)*PELD(2) & ZAGA & $-0,152$ & 0,251 & 0,5459 \\
& ZAIG & $-0,227$ & 0,263 & 0,3887 \\
Kasai(1)*PELD(3) & ZAGA & $-0,362$ & 0,252 & 0,1513 \\
& ZAIG & $-0,628$ & 0,262 & 0,0174 \\
Kasai(1)*PELD(4) & ZAGA & $-0,181$ & 0,251 & 0,4708 \\
& ZAIG & $-0,390$ & 0,263 & 0,1395 \\
\hline
\end{tabular}

Tabela 4.11: Estimativas dos modelos GAMLSS para o parâmetro de escala $\sigma$.

As estimativas na Tabela 4.12 correspondem aos efeitos das variáveis explicativas na probabilidade do indivíduo não receber transfusão de sangue. Tanto para a distribuição gama (ZAGA), quanto para a normal inversa (ZAIG), os efeitos das probabilidades são iguais, já que o modelo de mistura com zeros é equivalente ao ajuste de modelo logístico para a probabilidade de não ocorrência de transfusão.

A interação entre as variáveis Kasai e PELD não foi significante, entretanto, para validação dos modelos esta será mantida. A variável PELD por sua vez mostra que pessoas classificadas no nível de maior debilidade tem menor probabilidade de não receber transfusão de sangue em relação à quem está classificado no primeiro quartil, significativamente. Também parece não haver efeito de Kasai sobre a probabilidade de transfusão.

A análise de diagnóstico dos modelos será baseada nos resíduos quantílicos aleatorizados devido à característica discreta-contínua das distribuições ZAGA e ZAIG. A Figura 4.10 traz os gráficos de diagnóstico para a distribuição ZAGA. Apesar da evolução na bondade do ajuste em relação ao primeiro modelo com distribuição gama na Subseção 4.2.1, estes resíduos ainda apresentam desvios 


\begin{tabular}{rccc}
\hline Coeficiente & Estimativa & Erro padrão & $\mathrm{p}$-valor \\
\hline Intercepto & $-1,386$ & 0,559 & 0,0137 \\
Kasai $(1)$ & $-0,066$ & 0,652 & 0,9195 \\
$\operatorname{PELD}(2)$ & $-2,079$ & 1,159 & 0,0739 \\
$\operatorname{PELD}(3)$ & $-1,447$ & 0,918 & 0,1159 \\
$\operatorname{PELD}(4)$ & $-2,375$ & 1,156 & 0,0408 \\
Kasai(1)*PELD $(2)$ & 0,464 & 1,407 & 0,7420 \\
Kasai(1)*PELD $(3)$ & $-10,304$ & 114,971 & 0,9287 \\
Kasai(1)*PELD $(4)$ & 0,361 & 1,575 & 0,8186 \\
\hline
\end{tabular}

Tabela 4.12: Estimativas dos modelos GAMLSS para a probabilidade de não receber transfusão $\nu$.

do comportamento esperado de uma distribuição normal. Os pontos distantes da reta diagonal no gráfico quantil-quantil levam à inadequação da distribuição e esta conclusão é reforçada pela densidade estimada dos resíduos que apresenta uma curvatura distante da normal, especialmente em relação à cauda à direita da distribuição.

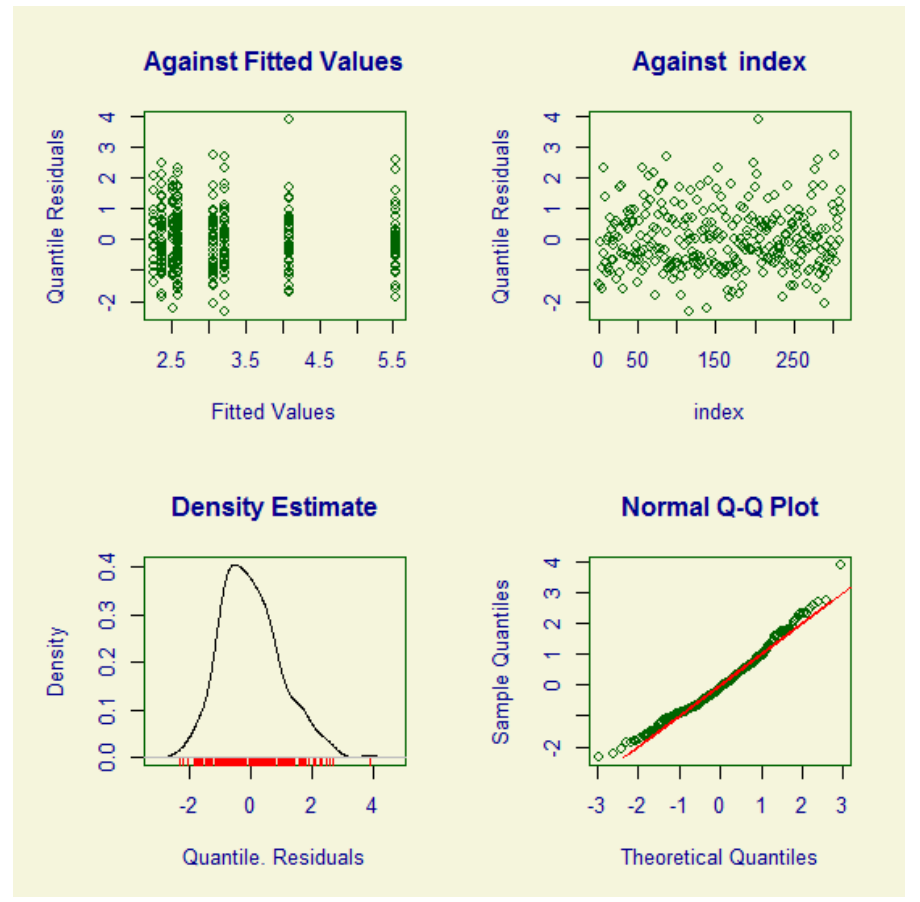

Figura 4.10: Gráficos para diagnóstico do ajuste do modelo considerando a distribuição ZAGA para os dados.

Ainda que as medidas de média e variância dos resíduos da Tabela 4.13 se apresentem condizentes com a normal padrão, as medidas relativas à forma da distribuição se afastam consideravelmente do valor esperado. Em particular, o coeficiente de assimetria que deveria ser aproximadamente zero, apresentou um valor de 0,563 , o que indica uma certa assimetria positiva nos resíduos, não ajustada pelo modelo com distribuição gama.

De forma positiva, os resíduos graficamente apresentados versus os valores ajustados ou um índice indicam que o ajuste da heterocedasticidade foi realizado com sucesso, dado que sua distribuição ocorre em torno no zero e sua amplitude não tem grandes variações.

Por fim, o modelo que adota a distribuição ZAIG para os dados, apresenta um diagnóstico no qual as pequenas deficiências apresentadas anteriormente são minimizadas. No gráfico quantilquantil presente na Figura 4.11 uma quantidade muito reduzida de pontos se distância da reta diagonal. A maior diferença em relação à distribuição ZAGA é vista pela aproximação da simetria dos resíduos, tanto na análise gráfica quanto pelas medidas descritivas do resíduo na Tabela 4.13. 


\begin{tabular}{rrr}
\hline Medidas resumo & ZAGA & ZAIG \\
\hline Média & $-0,002$ & $-0,011$ \\
Variância & 0,999 & 1,028 \\
Coeficiente de assimetria & 0,563 & 0,073 \\
Coeficiente de curtose & 3,383 & 2,822 \\
\hline
\end{tabular}

Tabela 4.13: Medidas do resíduo quantílico aleatorizado para os modelos com distribuição ZAGA e ZAIG.

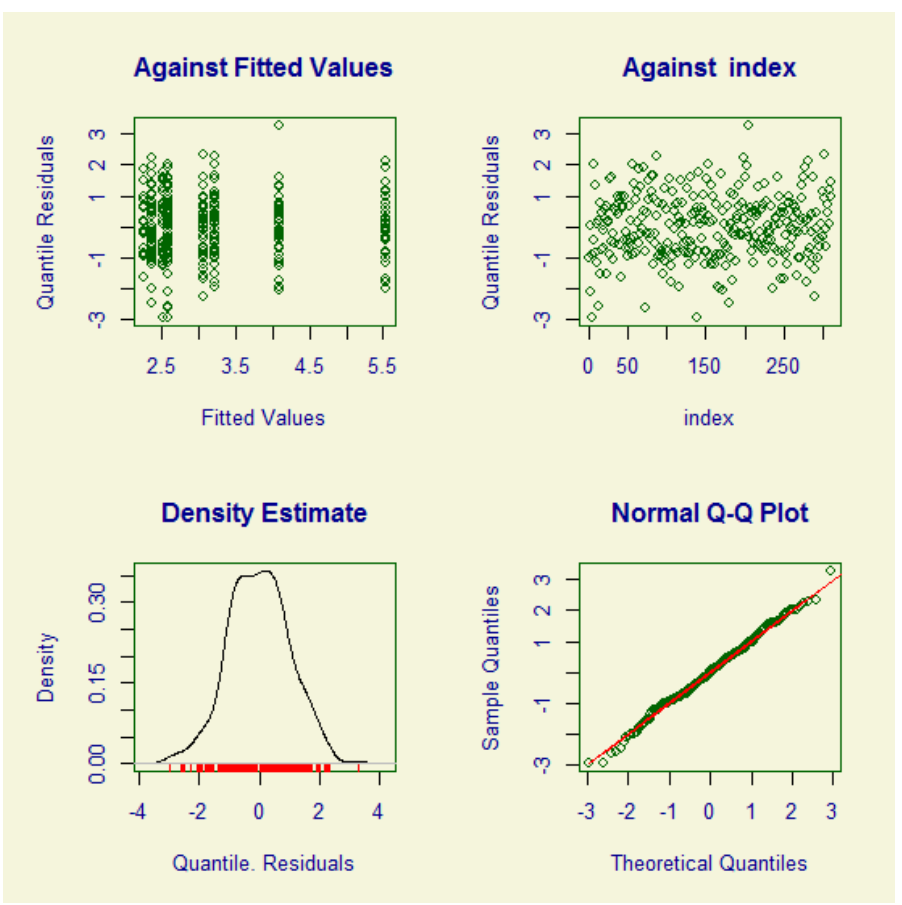

Figura 4.11: Gráficos para diagnóstico do ajuste do modelo considerando a distribuição ZAIG para os dados.

\subsection{Seleção do Modelo}

Ao longo da exposição dos modelos propostos para ajuste dos dados foi possível verificar que a distribuição gama apresentou os ajustes mais deficientes. Mesmo após o acréscimo do parâmetro de escala no modelo, a assimetria dos dados não foi modelada de forma efetiva, refletindo claramente no comportamento dos resíduos apresentados em gráficos normais de probabilidade, ou gráficos quantil-quantil nas Figuras 4.5, 4.7 e 4.10.

A distribuição log-normal já acomodou de forma mais eficiente a assimetria dos dados, visualizados também pelos gráficos quantil-quantil nas Figuras 4.5 e 4.8. O coeficiente de assimetria dos resíduos no modelo GAMLSS para os parâmetros $\mu$ e $\sigma$ confirma este comportamento ao se mostrar substancialmente reduzido em relação ao modelo com distribuição gama, comparáveis na Tabela 4.9, além de se aproximar do coeficiente de assimetria da distribuição normal, esperada para estes resíduos.

Por fim, a distribuição normal inversa pode ser considerada para as várias abordagens a mais adequada para o ajuste da base de dados em estudo. Conforme apontado ao final do Capítulo 2, esta distribuição apresenta predileção na modelagem de dados com forte assimetria, o que se mostrou uma propriedade da variável transfpeso. Os resíduos quantílicos resultantes da modelagem pela classe GAMLSS podem ser considerados os mais próximos da distribuição normal padrão, baseando-se nos gráficos de diagnóstico e seus valores de média, variância e coeficientes de assimetria e curtose.

Entre as classes de modelos propostas, os modelos GLM ajustam de forma mais precária os dados, devido à sua incapacidade de acomodar os pacientes que não receberam transfusão de sangue juntamente com os outros. Outra deficiência desta abordagem consiste no fato de considerar o 
parâmetro de dispersão $\phi$ constante para as variáveis explicativas. Os gráficos do componente do desvio em função dos valores ajustados confirmam a necessidade do ajuste deste parâmetro da distribuição.

A evolução para os modelos GAMLSS permitiu o ajuste da média simultaneamente com o parâmetro de escala, em que as variáveis Kasai e PELD se mostraram influentes de forma significativa para a variabilidade da transfusão de sangue por peso, assim como sua interação. Consequentemente, o problema de heterocedasticidade nos resíduos foi eliminado, uma vez que os modelos GAMLSS comprovaram o aumento na qualidade do ajuste dos dados.

Finalmente, os modelos GAMLSS considerando as distribuições discreta-contínuas ZAGA e ZAIG carregam a propriedade de modelar os três parâmetros necessários para um ajuste adequado e completo da base de dados. A partir desta abordagem, as informações dos pacientes que não receberam transfusão de sangue puderam ser incluídas no modelo, enriquecendo os resultados. Por mais que estes pacientes não tivessem necessitado de reposição sanguínea, ainda assim, inevitavelmente, eles tiveram sangramento durante a cirurgia, tornando-se valiosos para o estudo. Por serem extensões das distribuições contínuas gama e normal inversa, a modelagem dos parâmetros $\mu$ e $\sigma$ simultaneamente foi mantida, controlando também a heterocedasticidade dos resíduos.

Após todas as ponderações, conclui-se que a classe de modelos GAMLSS é a mais adequada para ajuste dos dados das crianças com atresia biliar, atribuindo uma distribuição normal inversa zero ajustada à variável resposta transfpeso. Posto isto, serão verificadas as variáveis significativas para o modelo, para cada parâmetro da distribuição atribuída.

Conforme recomendado pela metodologia dos modelos GAMLSS, a seleção de variáveis no modelo final foi realizada por meio da medida GAIC. O processo teve início pelo ajuste do parâmetro de locação, e, considerando o método backward, em cada etapa foi retirada uma variável do modelo e seu valor GAIC calculado. Estes procedimentos foram aplicados até que o menor GAIC fosse encontrado. Para os outros parâmetros repetiu-se o mesmo processo, considerando-se sempre o modelo selecionado na etapa anterior.

Para os parâmetros $\mu$ e $\sigma$ não houve modificação nos modelos já especificados na equação 4.3; o menor GAIC foi obtido no modelo com a interação das variáveis explicativas nos dois casos, o que é coerente já que os efeitos de interação foram significativos. Contudo, para a probabilidade de não receber transfusão de sangue, não somente a interação deixa de ser importante para o modelo, como a variável Kasai também deixa de ser necessária, indicando que a probabilidade não sofre influência do procedimento pré-cirurgico. Tais resultados estão de acordo com os apresentados na Tabela 4.12, já que os efeitos de interação e de Kasai não eram significativos. A Tabela 4.14 apresenta os valores de cada etapa do processo. Cabe ressaltar que como o modelo completo apresenta um GAIC menor do que o modelo sem interação, não se faz necessário testar a retirada de outras variáveis.

\begin{tabular}{rrrr}
\hline & \multicolumn{3}{c}{ Parâmetro } \\
\hline Modelo & $\mu$ & $\sigma$ & $\nu$ \\
\hline Kasai+PELD+Kasai*PELD & 1239,86 & 1239,86 & 1239,86 \\
Kasai+PELD & 1240,00 & 1239,90 & 1236,96 \\
PELD & - & - & 1235,12 \\
Kasai & - & - & 1250,60 \\
Intercepto & - & - & 1249,00 \\
\hline
\end{tabular}

Tabela 4.14: Valores do critério GAIC para seleção de variáveis nos ajustes dos parâmetros da distribuição.

Por fim, a equação final do modelo para ajuste dos dados após a seleção de variáveis é dada por 


$$
\begin{aligned}
\log \left(\mu_{i}\right) & =\beta_{0}+\beta_{1} \operatorname{Kasai}(1)+\beta_{2} P E L D(2)+\beta_{3} P E L D(3)+\beta_{4} P E L D(4) \\
& +\beta_{5} \operatorname{Kasai}(1) P E L D(2)+\beta_{6} \operatorname{Kasai}(1) P E L D(3)+\beta_{7} \operatorname{Kasai}(1) P E L D(4), \\
\log \left(\sigma_{i}\right) & =\alpha_{0}+\alpha_{1} \operatorname{Kasai}(1)+\alpha_{2} P E L D(2)+\alpha_{3} P E L D(3)+\alpha_{4} P E L D(4) \\
& +\alpha_{5} \operatorname{Kasai}(1) P E L D(2)+\alpha_{6} \operatorname{Kasai}(1) P E L D(3)+\alpha_{7} \operatorname{Kasai}(1) P E L D(4), \\
\log \left(\frac{\nu_{i}}{1-\nu_{i}}\right) & =\gamma_{0}+\gamma_{1} P E L D(2)+\gamma_{2} P E L D(3)+\gamma_{3} P E L D(4),
\end{aligned}
$$

em que:

- O índice $i$ referencia o indivíduo, com $i=1, \ldots, 310$;

- $\mu$ é o parâmetro de locação;

- $\sigma$ é o parâmetro de escala;

- $\nu$ é o parâmetro de forma;

- $\beta_{j}$ para $j=0, \ldots, 7$ são os coeficientes do modelo para cada nível das variáveis explicativas associadas ao parâmetro $\mu$.

- $\alpha_{j}$ para $j=0, \ldots, 7$ são os coeficientes do modelo para cada nível das variáveis explicativas associadas ao parâmetro $\sigma$.

- $\gamma_{j}$ para $j=0, \ldots, 3$ são os coeficientes do modelo para cada nível das variáveis explicativas associadas ao parâmetro $\nu$.

Na Tabela 4.15 estão presentes as estimativas do modelo final. Conforme apresentado já na Subseção 4.2.2, a significância da interação entre as variáveis explicativas mostra que ter sido submetido à pré-cirurgia de Kasai e estar classificado entre os níveis de maior debilidade do fígado aumentam consideravelmente o volume de sangue recebido, ou seja, o paciente perde mais sangue durante a cirurgia de transplante. Além disso, esta concomitância de características é responsável por uma maior variabilidade no sangramento do paciente, indicada pela significância da interação no modelo para o parâmetro de escala, o que qualifica os pacientes com maiores volumes de transfusão de sangue nestes grupos. Esses achados estão de acordo com o gráfico de perfis médios apresentado na etapa de análise descritiva na Figura 4.4.

Ao se tratar da probabilidade de não receber transfusão de sangue, a fragilidade do fígado mantém sua influência de forma significativa, mostrando que os pacientes classificados no primeiro nível da variável PELD apresentam maior chance de não precisar receber transfusão. Contudo, a realização do procedimento de Kasai já não afeta mais a variável resposta; não foi detectada diferença na probabilidade de receber transfusão entre os pacientes que não fizeram a pré-cirurgia e os que fizeram.

Os gráficos da Figura 4.12 confirmam a boa qualidade do ajuste do modelo já obtida no modelo completo, com resíduos notavelmente próximos da distribuição normal padrão. Os dois primeiros gráficos ilustram que a heterocedasticidade dos dados foi controlada devido ao padrão nulo da nuvem de pontos e a amplitude regular dos resíduos. As medidas na Tabela 4.16 confirmam essa proximidade das características da distribuição referência.

Para finalizar o diagnóstico, a análise dos gráficos na Figura 4.13 trazem a confirmação de que estes resíduos se comportam de forma adequada, pois em razão de sua aleatoriedade, quando resultantes de uma distribuição discreta ou discreta-contínua, recomenda-se que sejam gerados diversas vezes pelo mesmo modelo. Em todos os casos, a reta diagonal está coberta quase completamente pelos resíduos, com ocorrências praticamente desprezíveis de pontos distantes da reta.

Uma abordagem muito comum para a interpretação das estimativas resultantes do modelo, especialmente na área médica, é verificar o efeito em termos percentuais sobre a resposta média 


\begin{tabular}{rcccccc}
\hline & \multicolumn{2}{c}{$\sigma$} & \multicolumn{2}{c}{$\nu$} \\
\hline Coeficiente & Estimativa (EP) & p-valor & Estimativa (EP) & p-valor & Estimativa (EP) & p-valor \\
\hline Intercepto & $0,814(0,126)$ & $<0,001$ & $-1,096(0,177)$ & $<0,001$ & $-1,435(0,287)$ & $<0,001$ \\
Kasai(1) & $0,138(0,167)$ & 0,4088 & $0,333(0,205)$ & 0,1045 & - & - \\
PELD(2) & $0,109(0,167)$ & 0,5137 & $0,160(0,217)$ & 0,4609 & $-1,784(0,655)$ & 0,0069 \\
PELD(3) & $0,046(0,154)$ & 0,7648 & $0,011(0,214)$ & 0,9608 & $-2,189(0,772)$ & 0,0049 \\
PELD(4) & $0,308(0,157)$ & 0,0505 & $0,046(0,207)$ & 0,8239 & $-2,189(0,772)$ & 0,0049 \\
Kasai(1)*PELD(2) & $0,108(0,233)$ & 0,6433 & $-0,227(0,263)$ & 0,3886 & - & - \\
Kasai(1)*PELD(3) & $0,410(0,205)$ & 0,0463 & $-0,628(0,262)$ & 0,0174 & - & - \\
Kasai(1)*PELD(4) & $0,449(0,236)$ & 0,0574 & $-0,390(0,263)$ & 0,1395 & - & - \\
\hline
\end{tabular}

Tabela 4.15: Estimativas do modelo selecionado.

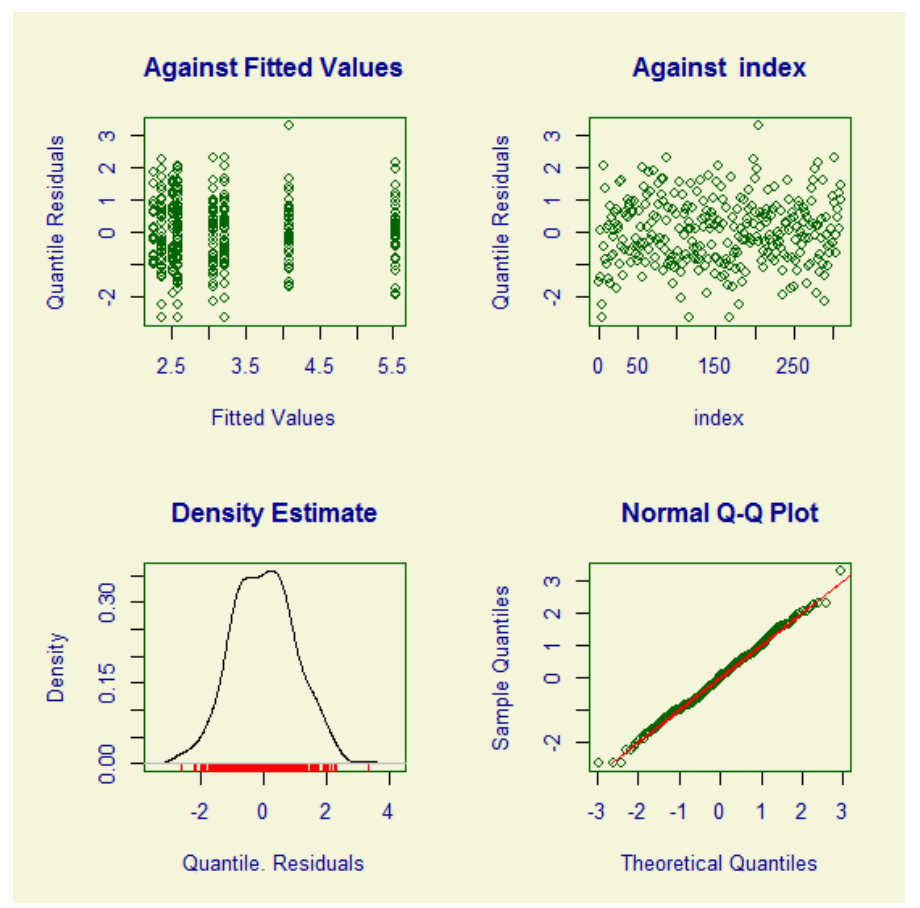

Figura 4.12: Gráficos para diagnóstico do ajuste do modelo selecionado.

\begin{tabular}{rc}
\hline Média & $-0,005$ \\
Variância & 1,013 \\
Coeficiente de assimetria & 0,079 \\
Coeficiente de curtose & 2,892 \\
\hline
\end{tabular}

Tabela 4.16: Medidas do resíduo quantílico aleatorizado para o modelo selecionado.

da unidade amostral. Desta forma, a interpretação dos coeficientes estimados é realizada para sua transformação, caso tenha sido utilizada uma função de ligação para o parâmetro do modelo, equivalente neste caso à efeito $=\exp \left(\hat{\beta}_{j}\right)$, para $j=1,2, \ldots, 7$.

Devido à codificação das variáveis explicativas, tem-se como referência no modelo os pacientes que não foram submetidos ao Kasai e quem está classificado no primeiro quartil da variável PELD. Assim, é possível verificar por exemplo que o se o paciente fez a pré-cirurgia Kasai, a quantidade de sangue recebido aumenta em média 14,8\% com relação a um paciente que não fez. Os resultados estão presentes na Tabela 4.17.

Entre os pacientes que não foram submetidos ao procedimento, a quantidade de sangue recebido aumenta em média 36\%, se ele está classificado no PELD(4) com relação a um paciente no PELD(1); e não há aumento significativo na quantidade média de sangue recebido entre os pacientes com 


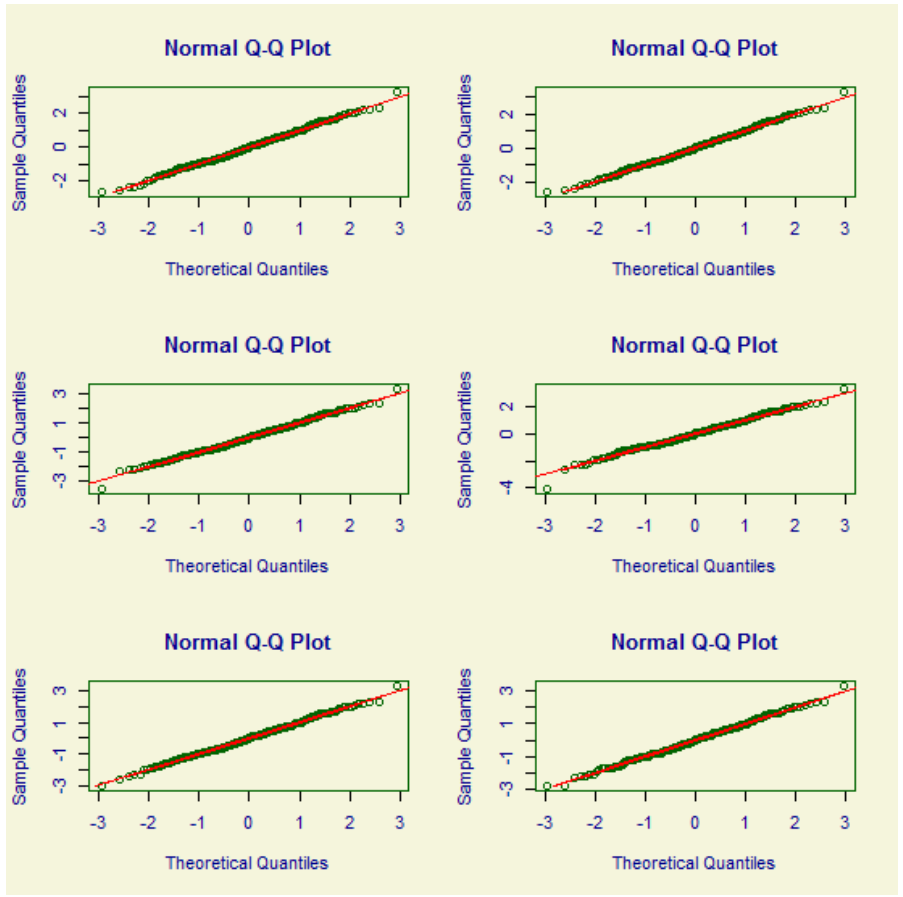

Figura 4.13: Gráficos para diagnóstico dos resíduos do modelo selecionado.

PELD respectivamente igual a $2(\mathrm{p}=0,5137)$ ou $3(\mathrm{p}=0,7648)$ em relação à categoria de referência, $\operatorname{PELD}(1)$.

Entre os pacientes que fizeram a pré-cirurgia Kasai, o volume de sangue em relação ao peso recebido aumenta em média $57,8 \%(1,047 * 1,507), 113 \%(1,36 * 1,567)$ se ele está classificado, respectivamente, nos níveis da PELD iguais a 3 ou 4 com relação a um paciente no PELD(1). Conforme citado na Subseção 3.1.2, os efeitos das variáveis explicativas são multiplicativos, então para a avaliação da interação entre duas variáveis, se faz necessário multiplicar o efeito calculado, chegando ao percentual real de acréscimo na média.

\begin{tabular}{rclcc}
\hline Coeficiente & Estimativa & \multicolumn{2}{l}{ Intervalo de confiança } & p-valor \\
\hline Kasai(1) & 1,148 & 0,828 & 1,591 & 0,4088 \\
PELD(2) & 1,115 & 0,804 & 1,547 & 0,5137 \\
PELD(3) & 1,047 & 0,774 & 1,416 & 0,7648 \\
PELD(4) & 1,360 & 1,001 & 1,849 & 0,0505 \\
Kasai(1)*PELD $(2)$ & 1,114 & 0,706 & 1,758 & 0,6433 \\
Kasai(1)*PELD $(3)$ & 1,507 & 1,009 & 2,253 & 0,0463 \\
Kasai(1)*PELD $(4)$ & 1,567 & 0,988 & 2,487 & 0,0574 \\
\hline
\end{tabular}

Tabela 4.17: Efeitos estimados com intervalo de confiança e valor-p para o ajuste do parâmetro $\mu$.

Um possível resultado obtido a partir do modelo ajustado é o intervalo de confiança para o indivíduo. Nesse estudo o nível de confiança adotado foi de $95 \%$. Uma vez que todos os níveis da variável PELD têm ocorrência de pacientes que não precisaram de transfusão de sangue, o limite inferior do intervalo com este nível de confiança será sempre o valor zero. Na Tabela 4.18 apresentamse também as estimativas para a unidade amostral, que revelam o comportamento distinto verificado no modelo.

Através da comparação do resultado em um mesmo nível da variável PELD, quem foi submetido ao procedimento de Kasai sempre apresenta uma estimativa maior para o percentual de transfusão de sangue recebido. A amplitude desta diferença aumenta consideravelmente após o segundo quartil da variável $P E L D$, chegando a pouco mais de dois pontos no último quartil.

O mesmo padrão de comportamento pode ser observado nos valores dos limites superiores, em 
que o valor mais alto observado nos pacientes que não fizeram o Kasai, referente ao $P E L D(4)$, é ligeiramente superior ao valor mais baixo dos pacientes que fizeram o procedimento, obtido no $\operatorname{PELD}(1)$.

\begin{tabular}{lrrrrr}
\hline & & PELD(1) & PELD(2) & PELD(3) & PELD(4) \\
\hline Kasai(0) & $\hat{Y}_{i}$ & 1,82 & 2,42 & 2,30 & 2,99 \\
& Limite inferior & 0,00 & 0,00 & 0,00 & 0,00 \\
& Limite superior & 4,92 & 6,56 & 5,46 & 7,94 \\
Kasai(1) & $\hat{Y}_{i}$ & 2,09 & 3,10 & 3,98 & 5,38 \\
& Limite inferior & 0,00 & 0,00 & 0,00 & 0,00 \\
& Limite superior & 7,37 & 9,92 & 9,33 & 17,00 \\
\hline
\end{tabular}

Tabela 4.18: Intervalo de confiança para a transfusão de sangue por peso.

O gráfico da Figura 4.14 permite a visualização do efeito de interação entre as variáveis Kasai e PELD. A resposta média do indivíduo aumenta consideravelmente para aqueles que fizeram o procedimento de Kasai conforme o índice PELD aumenta, enquanto o aumento para os pacientes que não passaram pelo procedimento ocorre de forma mais suave.

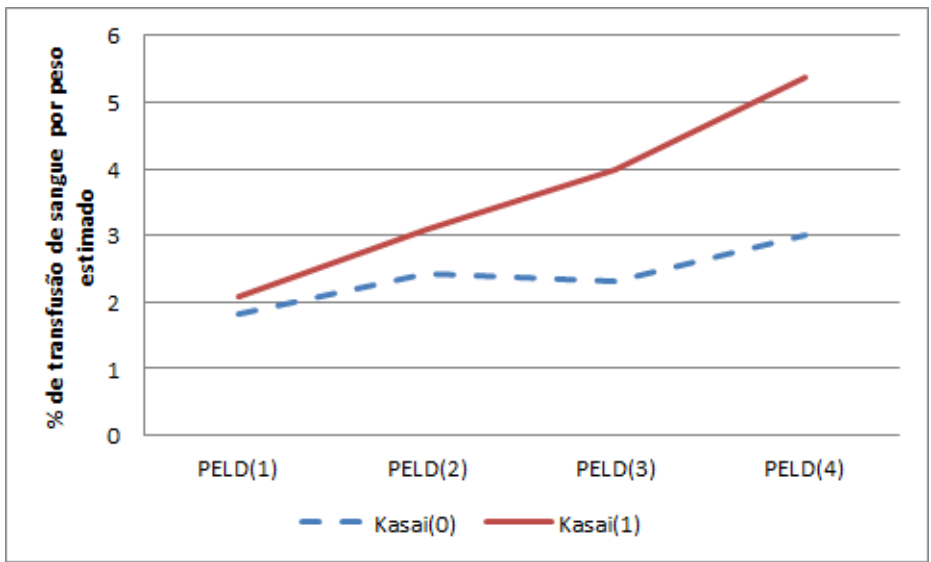

Figura 4.14: Perfis médios estimados pelo modelo final da transfusão de sangue por peso segundo Kasai $e$ PELD. 


\section{Capítulo 5}

\section{Estudo bootstrap}

Os estudos de simulação na área estatística são geralmente ligados à estimação de parâmetros desconhecidos. O desenvolvimento de computadores com mais memória e processamento nos últimos anos permitiu que esses estudos auxiliassem bastante a análise de dados. A técnica bootstrap consiste em uma reamostragem dos dados, formando novas amostras para avaliação do parâmetro de interesse. Este procedimento é de grande utilidade para casos em que as técnicas de análise estatística tradicionais não podem ser aplicadas ou são muito complicadas.

O trabalho de Efron e Tibshirani (1986) apresenta diversos métodos para estimação de desvios padrões e intervalos de confiança, considerando técnicas paramétricas e não paramétricas. Dessa forma, estas estatísticas podem ser calculadas mesmo que a distribuição do estimador do parâmetro seja desconhecida, o que vem a ser uma grande vantagem dos estudos de simulação computacional.

O método pode ser descrito da seguinte forma: considera-se uma amostra aleatória com $n$ observações, denotada por $\boldsymbol{y}=\left(x_{1}, x_{2}, \ldots, x_{n}\right)$, e com uma certa distribuição de probabilidade $F$. Para o estudo de uma estatística de interesse $\hat{\theta}$ adota-se o seguinte algoritmo:

1. Utilizando um gerador de números aleatórios, seleciona-se de forma independente uma quantidade $B$ de amostras de tamanho $n$, independentes e com distribuição $F$, representadas por $\boldsymbol{y}^{*}(1), \boldsymbol{y}^{*}(2), \ldots, \boldsymbol{y}^{*}(B)$

2. Para cada amostra selecionada na etapa anterior, calcula-se a estatística de interesse $\hat{\theta}^{*}(b)$, para $b=1,2, \ldots, B$

3. As medidas de desvio padrão e média amostrais, por exemplo, de $\hat{\theta}^{*}$ serão dadas respectivamente por

$$
\hat{\sigma}_{B}=\left[\frac{\sum_{b=1}^{B}\left\{\hat{\theta}^{*}(b)-\hat{\theta}^{*}(.)\right\}^{2}}{B-1}\right]^{1 / 2}, \quad \hat{\theta}^{*}(.)=\frac{\sum_{b=1}^{B} \hat{\theta}^{*}(b)}{B} .
$$

Caso a distribuição $F$ seja conhecida, a abordagem do estudo se torna paramétrica. Entretanto, em muitos casos $F$ é desconhecido, ou ainda, deseja-se testar sua veracidade, e por este motivo o tratamento não paramétrico se torna necessário. Neste caso, as amostras bootstrap na primeira etapa do algoritmo são caracterizadas por amostras aleatórias de tamanho $n$, com reposição, da amostra original $\boldsymbol{y}=\left(x_{1}, x_{2}, \ldots, x_{n}\right)$.

Como resultado tem-se a distribuição de probabilidades bootstrap, $\hat{G}(s)$ para $\hat{\theta}^{*}$. Ao tomar os percentis $100 * a / 2$ e $100 *(1-a / 2)$ desta distribuição, em que $a$ é o nível de significância atribuído ao estudo, um intervalo de confiança para $\theta$ seria dado por

$$
I C_{p}=\left[\hat{G}(a / 2)^{-1} ; \hat{G}(1-a / 2)^{-1}\right],
$$

chamado então de intervalo de confiança bootstrap percentil. Conforme ressaltado por Singh e Xie (2010), esta técnica exige a simetria da distribuição amostral do parâmetro $\hat{\theta}$ em torno de $\theta$. 
Como esta condição nem sempre é válida, uma opção é trabalhar com o método percentil centrado, que toma como suposição que a distribuição de $\hat{\theta}-\theta$ pode ser aproximada pela distribuição bootstrap de $\hat{\theta}^{*}-\hat{\theta}$. Considerando os percentis definidos anteriormente, tem-se que a quantidade $\hat{\theta}-\theta$ se encontra dentro do intervalo $\left[\hat{G}(a / 2)^{-1}-\hat{\theta}, \hat{G}(1-a / 2)^{-1}-\hat{\theta}\right]$, com uma probabilidade aproximada de $100 *(1-a) \%$. Ao trabalhar algebricamente com estas quantidades, o intervalo de confiança bootstrap percentil centrado para $\theta$ será dado por

$$
I C_{c}=\left[2 \hat{\theta}-\hat{G}(1-a / 2)^{-1}, 2 \hat{\theta}-\hat{G}(a / 2)^{-1}\right] .
$$

\section{$5.1 \quad$ Objetivo}

Neste estudo, a aplicação de técnicas bootstrap permite avaliar a distribuição dos estimadores dos coeficientes do modelo de regressão. Na metodologia apresentada no Capítulo 3, a distribuição assintótica destes estimadores é considerada normal. Contudo, nem sempre esta suposição se mantém válida, por exemplo ao tratar de dados com distribuições de características distantes da distribuição normal.

Em geral, os programas de modelagem de dados têm como saída padrão testes estatísticos para avaliação das variáveis explicativas significativas para o modelo. Estes testes consideram a suposição descrita acima, e portanto sua hipótese nula de que o coeficiente é igual a zero é testada sob a distribuição normal. Além do critério GAIC, estes testes também foram levados em consideração para a seleção de variáveis explicativas do modelo final (4.4). Por esse motivo, este estudo se torna adequado para validação dos procedimentos tomados.

Para esta finalidade, algumas estatísticas serão construídas para os coeficientes $\beta_{j}, \alpha_{j}$ e $\gamma_{j}$, com $j=0,1, \ldots, 7$, resultantes do modelo GAMLSS com distribuição ZAIG definido na equação (4.3), assim como para seu modelo reduzido (4.4). As etapas descritas anteriormente serão realizados da seguinte forma:

1. Utilizando um gerador de números aleatórios, seleciona-se de forma independente uma quantidade $B$ de amostras de tamanho 310 , independentes e com reposição a partir da amostra original, representadas por $\boldsymbol{y}^{*}(1), \boldsymbol{y}^{*}(2), \ldots, \boldsymbol{y}^{*}(B)$;

2. Para cada amostra selecionada na etapa anterior, ajusta-se um modelo de regressão GAMLSS com distribuição ZAIG, conforme (4.3) (ou (4.4)), e memorizam-se seus coeficientes estimados $\hat{\beta}_{j}, \hat{\alpha_{j}}$ e $\hat{\gamma}_{j}$;

3. As seguintes medidas são calculadas para a amostra bootstrap de cada coeficiente: média, mediana, desvio padrão e os percentis de $2,5 \%$ e $97,5 \%$.

Com estas estatísticas, avalia-se se a significância assumida para as variáveis explicativas pode ser ratificada. A partir dos percentis calculados, determinam-se os intervalos de confiança para o coeficiente, e sua significância será comprovada caso o valor zero não esteja contido nestes intervalos.

Optou-se por trabalhar com uma quantidade $B=10.000$ de amostras bootstrap, um tamanho relativamente grande e que ainda permite um tempo computacional reduzido.

\subsection{Resultados}

A terminologia utilizada na apresentação dos resultados será identificada da seguinte forma:

- $\hat{\beta}_{j}$ : Estimativas dos coeficientes resultantes do modelo (4.3) para a amostra original;

- $\hat{\beta}_{j}^{*}$ : Estimativas dos coeficientes resultantes do modelo (4.3) de cada amostra bootstrap;

- $\hat{\mu}\left(\hat{\beta}_{j}^{*}\right)$ : Média amostral das estimativas $\hat{\beta}_{j}^{*}$; 
- $\hat{M}\left(\hat{\beta}_{j}^{*}\right)$ : Mediana amostral das estimativas $\hat{\beta}_{j}^{*}$;

- $\hat{\sigma}\left(\hat{\beta}_{j}^{*}\right)$ : Desvio padrão amostral das estimativas $\hat{\beta}_{j}^{*}$;

- $L I_{p}$ : Limite inferior para o intervalo de confiança percentil para $\beta_{j}$, conforme (5.2);

- $L S_{p}$ : Limite superior para o intervalo de confiança percentil para $\beta_{j}$, conforme (5.2);

- $L I_{c}$ : Limite inferior para o intervalo de confiança percentil centrado para $\beta_{j}$, conforme (5.3);

- $L S_{c}$ : Limite superior para o intervalo de confiança percentil centrado para $\beta_{j}$, conforme (5.3);

Esta notação aplica-se também para os coeficientes $\alpha$ e $\gamma$, resultantes dos modelos para os parâmetros $\sigma$ e $\nu$, respectivamente.

Após a realização das etapas descritas na seção anterior, a avaliação do comportamento dos coeficientes estimados nas amostras bootstrap foi iniciada por gráficos do tipo histograma e quantilquantil, facilitando visualmente sua comparação com a distribuição normal.

Os gráficos da Figura 5.1 ilustram o comportamento dos coeficientes estimados para o modelo do parâmetro $\mu$ por meio de histogramas. Para todos estes, observa-se um formato aproximado de sino, sugerindo que sua distribuição é próxima da normal.
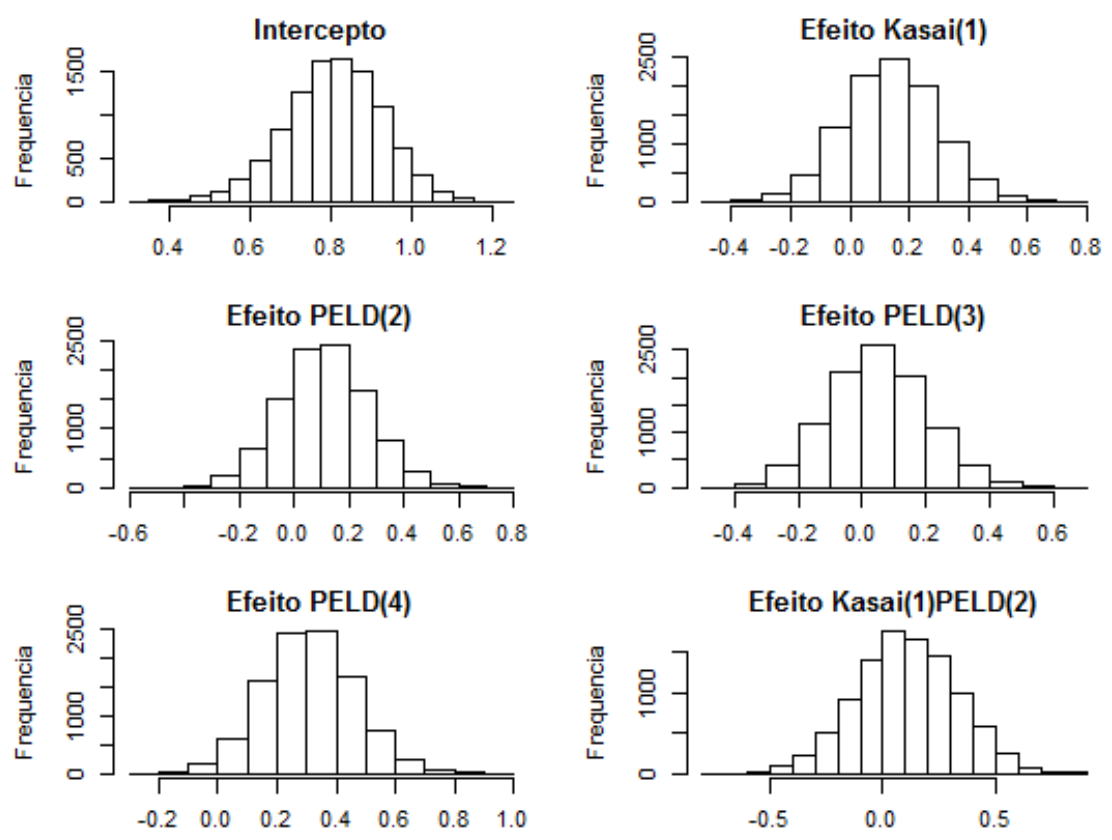

Efeito Kasai(1)PELD(3)
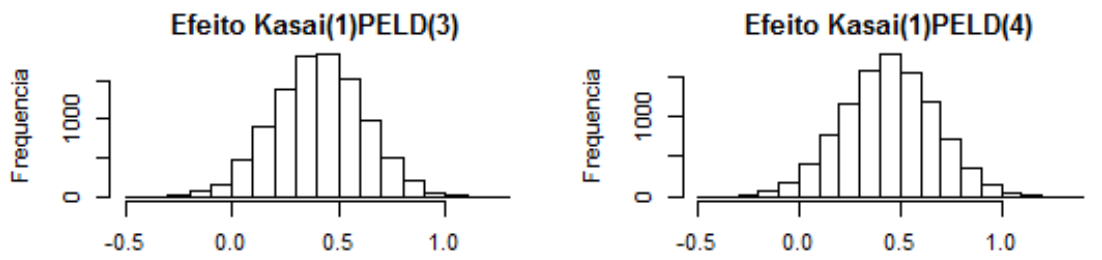

Figura 5.1: Histograma das estimativas para cada $\hat{\beta}_{j}^{*}$ derivados do ajuste do parâmetro $\mu$.

Por mais que o formato observado nos histogramas se assemelhe à distribuição normal, os gráficos quantil-quantil na Figura 5.2 revelam pequenos desvios desta suposição para alguns coeficientes. Especificamente para o intercepto, o efeito de Kasai(1) e os efeitos de PELD(2), PELD(3) e $P E L D(4)$ é possível verificar pontos fora das bandas de confiança, mas não há indícios de violação da suposição de normalidade.

As distribuições dos coeficientes referentes ao parâmetro de escala $\sigma$ se distanciam mais claramente da distribuição normal, pois em todos os casos é possível observar assimetria nos histogramas 

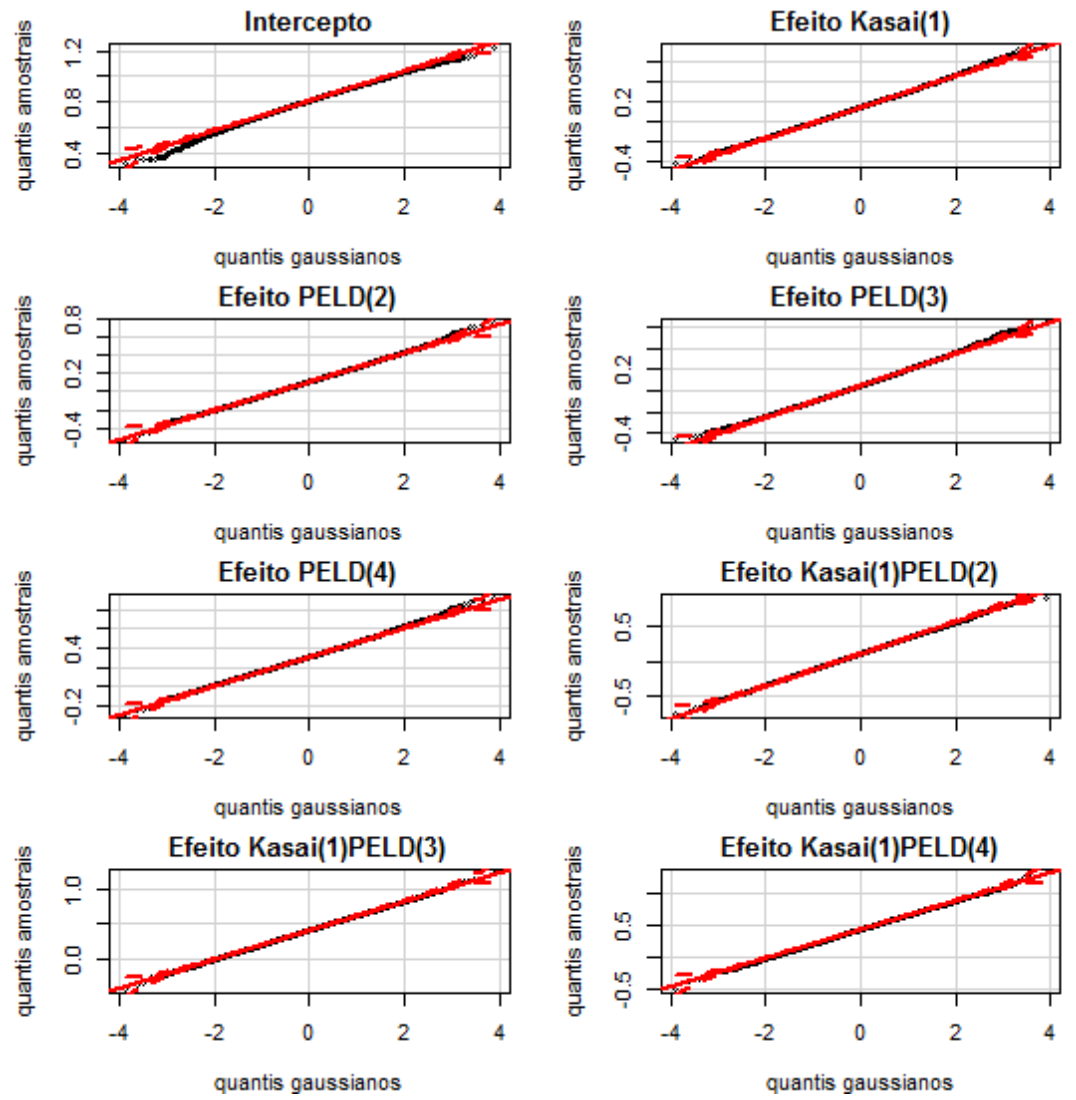

Figura 5.2: Gráfico quantil-quantil das estimativas para cada $\hat{\beta}_{j}^{*}$ derivados do ajuste do parâmetro $\mu$.

apresentados na Figura 5.3. Para os efeitos de Kasai e os níveis do PELD essa assimetria está à direita, enquanto o intercepto e os níveis de interação, apresentam assimetria à esquerda. Os gráficos quantil-quantil na Figura 5.4 corroboram o afastamento da distribuição normal dos coeficientes estimados para o parâmetro de escala. Para todos, é possível observar caudas pesadas fora das bandas de confiança.

Ao analisar os gráficos da Figura 5.5, conclui-se que as estimativas dos coeficientes do ajuste do parâmetro de probabilidade $\nu$ violam claramente a suposição de normalidade assintótica. Notavelmente, para todos os coeficientes que envolvem a variável PELD, seu histograma apresenta uma mistura de distribuições. Esse tipo de comportamento é resultado da quantidade reduzida de casos classificados nestas categorias e que não receberam transfusão de sangue, exposto na Tabela 4.5.

Ao sortear aleatoriamente amostras da amostra original, possivelmente algumas categorias não foram preenchidas, e por isso a estimativa do parâmetro representa a probabilidade aproximadamente nula deste evento ocorrer, equivalente aos valores negativos em torno de -10 nos gráficos. Os valores próximos ao zero seriam resultantes de amostras de características semelhantes à original, devido à proximidade dos coeficientes estimados a partir desta. Por fim, o grupo que se concentra próximo ao valor 10 representa amostras bootstrap em que a probabilidade do indivíduo apresentar a referente categorização e não ter recebido transfusão de sangue é aproximadamente um. Um exemplo deste tipo de amostra com coeficientes extremos pode ser definido da seguinte forma: para pacientes que não receberam transfusão de sangue, no segundo nível da variável PELD foram sorteados apenas indivíduos que foram submetidos ao procedimento de Kasai. Dessa forma, o coeficiente referente à esta interação terá valor próximo de 10 que equivale a probabilidade próxima de um, enquanto o coeficiente PELD(2), que é formado pelos indivíduos que não fizeram o procedimento, terá um valor em torno do -10, equivalente à probabilidade complementar e próxima de zero.

Nos gráficos quantil-quantil da Figura 5.6 comprova-se que estes coeficientes não são distribuídos conforme a normal. Os quantis amostrais chegam a se distribuir em até quatro grupos ao longo dos quantis gaussianos, em alguns casos totalmente distantes da reta diagonal e suas bandas de 

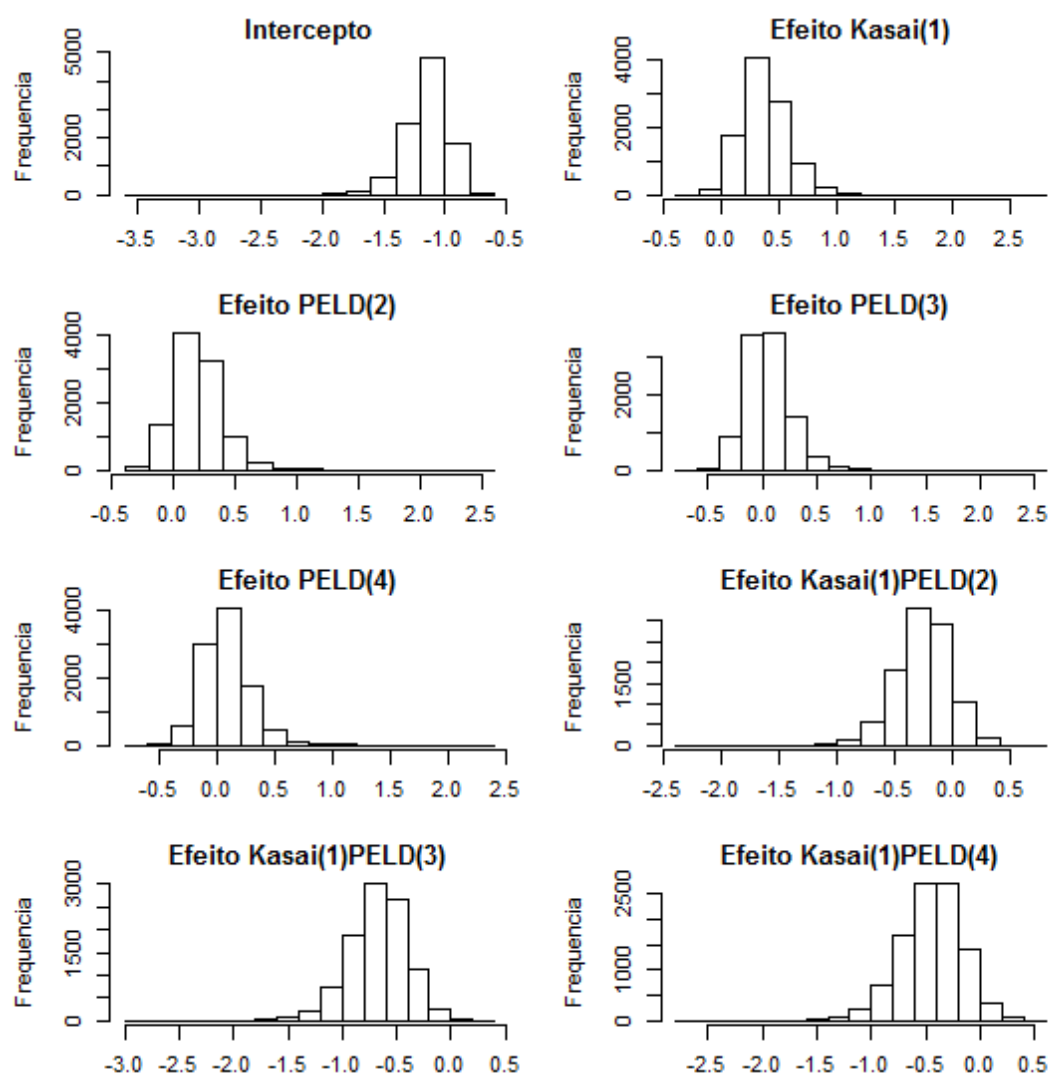

Figura 5.3: Histograma das estimativas para cada $\hat{\alpha}_{j}^{*}$ derivados do ajuste do parâmetro $\sigma$.
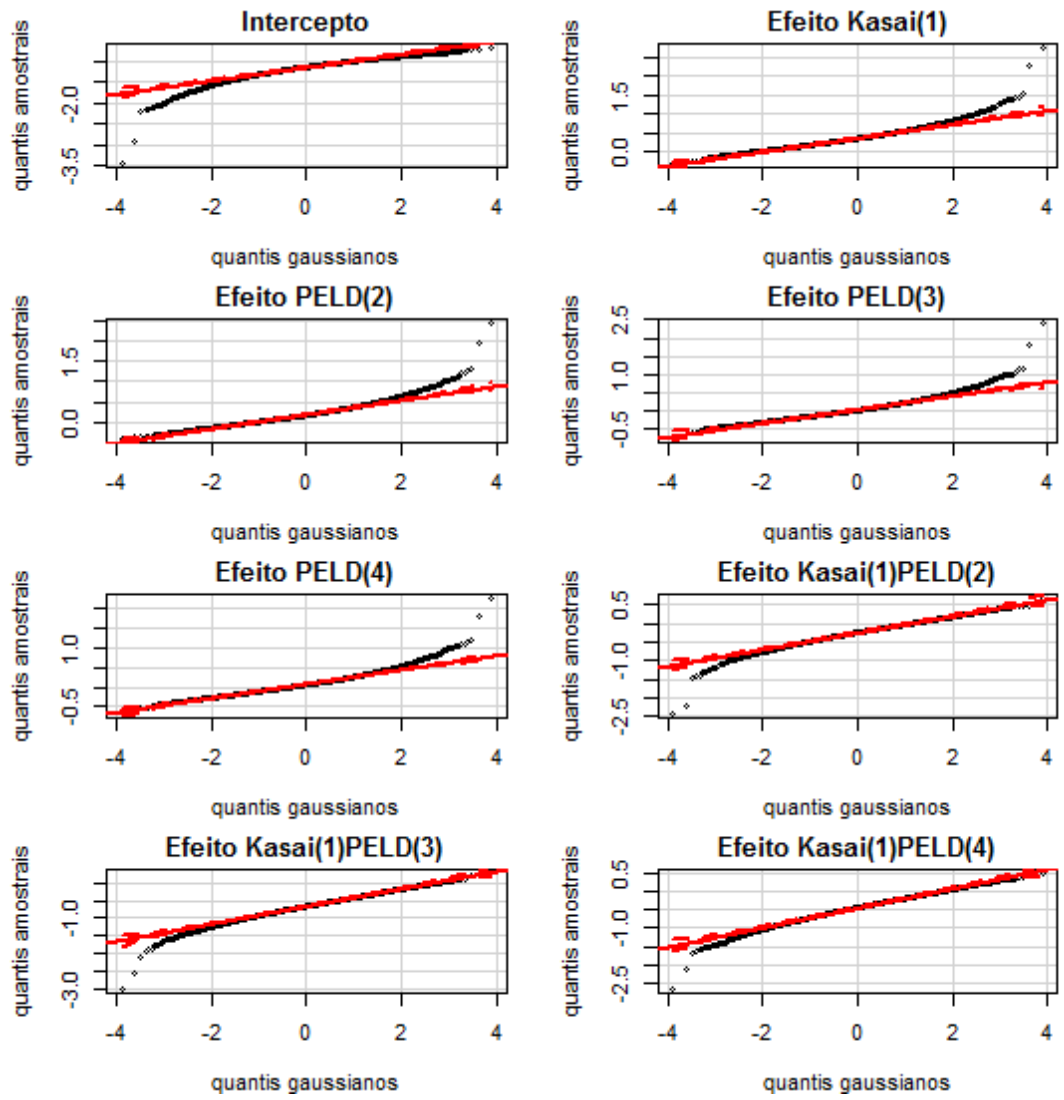

Figura 5.4: Gráfico quantil-quantil das estimativas para cada $\hat{\alpha}_{j}^{*}$ derivados do ajuste do parâmetro $\sigma$. 

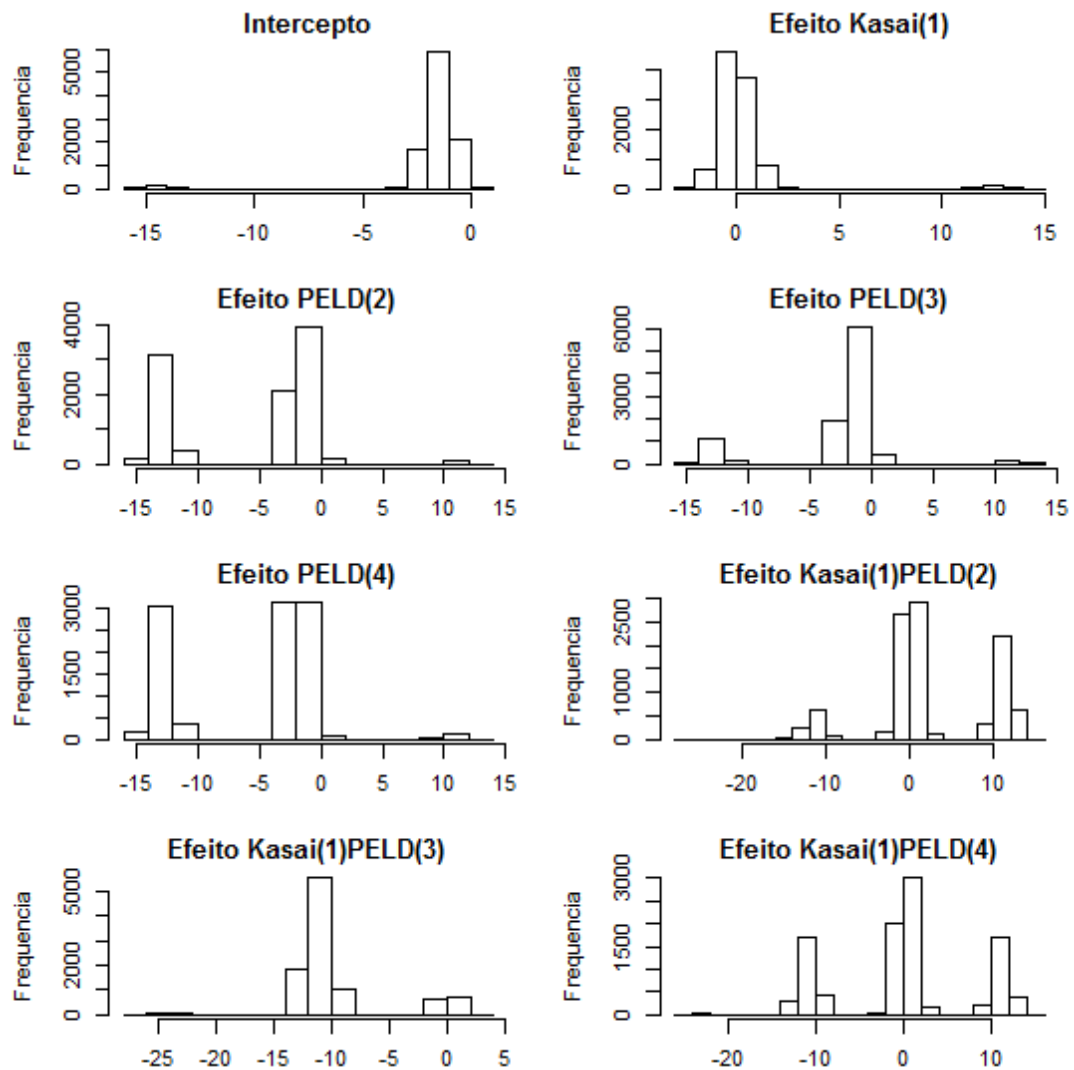

Figura 5.5: Histograma das estimativas para cada $\hat{\gamma}_{j}^{*}$ derivados do ajuste do parâmetro $\nu$.

confiança.

Seguindo a etapa 3 do algoritmo definido no estudo, a Tabela 5.1 apresenta as medidas para avaliação dos coeficientes do modelo para o parâmetro de locação $\mu$, conforme terminologias descritas no início da seção. Os valores em negrito identificam os coeficientes significativos para o modelo. Os testes de significância para os coeficientes da primeira coluna podem ser verificados na Tabela 4.10 .

Ao comparar os valores das estimativas dos coeficientes $\hat{\beta}_{j}$, resultantes do modelo com a base original com a média e mediana de suas respectivas amostras bootstrap, vê-se que estes estão muito próximos, com diferenças menores do que 0,01. Este fato salienta a proximidade da distribuição normal para os estimadores $\hat{\beta}_{j}$, validando os testes padrões do modelo GAMLSS.

Os intervalos de confiança bootstrap percentil e percentil centrado mantém a mesma inferência em relação à obtida pelos testes citados acima. Apesar de alguns coeficientes passarem a ser significativos para o modelo, mantém-se a interação entre Kasai e PELD e, consequentemente, as variáveis isoladamente.

\begin{tabular}{rcccccccc}
\hline & $\hat{\beta}_{j}$ & $\hat{\mu}\left(\hat{\beta}_{j}^{*}\right)$ & $\hat{M}\left(\hat{\beta}_{j}^{*}\right)$ & $\hat{\sigma}\left(\hat{\beta}_{j}^{*}\right)$ & $L I_{p}$ & $L S_{p}$ & $L I_{c}$ & $L S_{c}$ \\
\hline Intercepto & $\mathbf{0 , 8 1 4}$ & 0,806 & 0,810 & 0,119 & $\mathbf{0 , 5 5 9}$ & $\mathbf{1 , 0 3 0}$ & $\mathbf{0 , 5 9 8}$ & $\mathbf{1 , 0 6 9}$ \\
Kasai(1) & 0,138 & 0,141 & 0,139 & 0,158 & $-0,161$ & 0,456 & $-0,180$ & 0,437 \\
PELD(2) & 0,109 & 0,110 & 0,110 & 0,158 & $-0,199$ & 0,423 & $-0,205$ & 0,418 \\
PELD(3) & 0,046 & 0,050 & 0,049 & 0,152 & $-0,243$ & 0,353 & $-0,261$ & 0,336 \\
PELD(4) & 0,308 & 0,310 & 0,307 & 0,151 & $\mathbf{0 , 0 2 0}$ & $\mathbf{0 , 6 1 9}$ & $-0,003$ & 0,596 \\
Kasai(1)*PELD(2) & 0,108 & 0,105 & 0,103 & 0,222 & $-0,331$ & 0,533 & $-0,317$ & 0,547 \\
Kasai(1)*PELD(3) & $\mathbf{0 , 4 1 0}$ & 0,407 & 0,409 & 0,208 & $\mathbf{0 , 0 0 1}$ & $\mathbf{0 , 8 1 2}$ & $\mathbf{0 , 0 0 9}$ & $\mathbf{0 , 8 1 9}$ \\
Kasai(1)*PELD(4) & 0,449 & 0,443 & 0,446 & 0,227 & $-0,006$ & 0,879 & $\mathbf{0 , 0 2 0}$ & $\mathbf{0 , 9 0 4}$ \\
\hline
\end{tabular}

Tabela 5.1: Medidas descritivas dos coeficientes $\hat{\beta}_{j}^{*}$ para as amostras bootstrap do modelo ZAIG. 

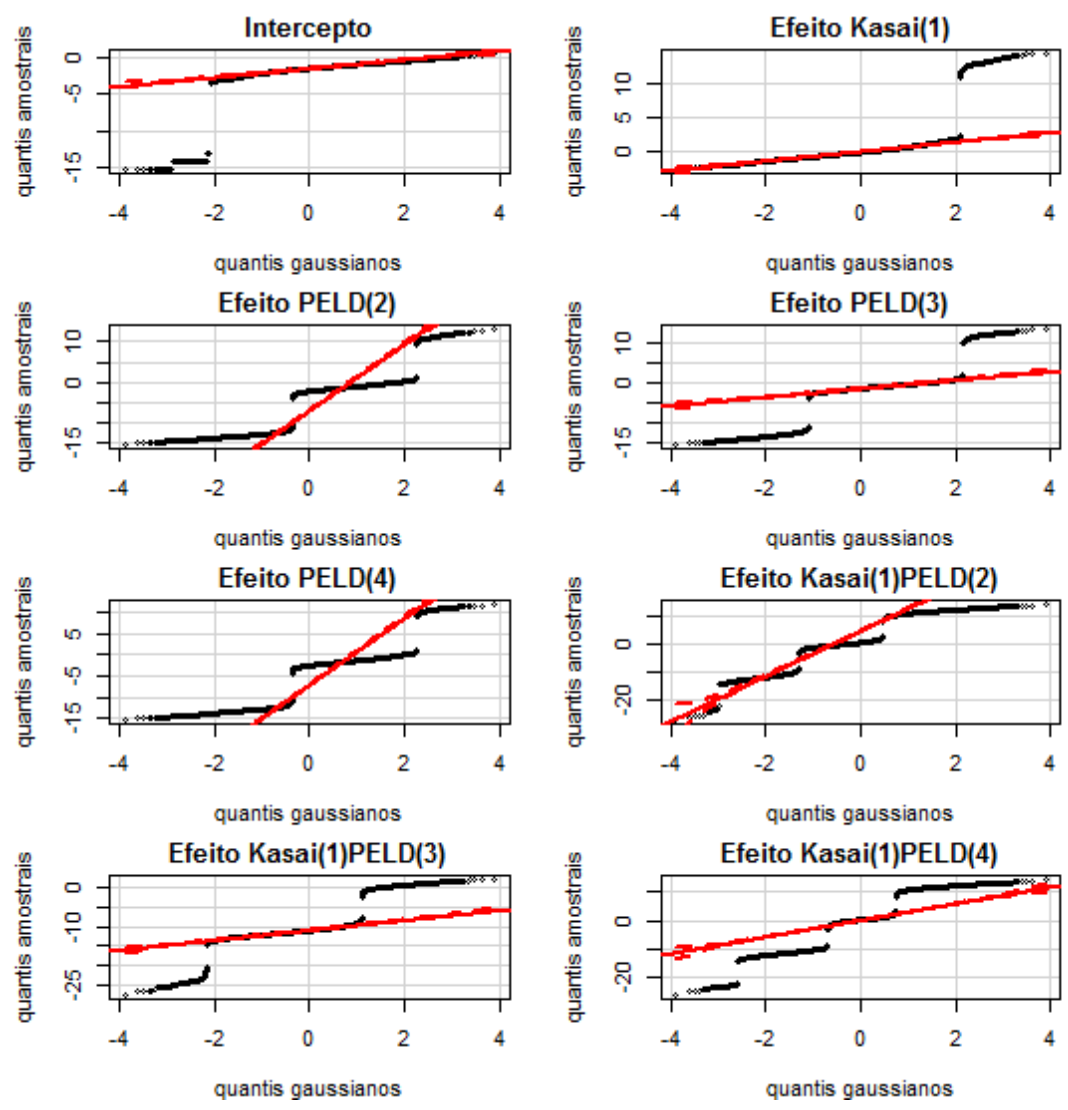

Figura 5.6: Gráfico quantil-quantil das estimativas para cada $\hat{\gamma}_{j}^{*}$ derivados do ajuste do parâmetro $\nu$.

A Tabela 5.2 apresenta as medidas dos coeficientes relativos ao parâmetro de escala $\sigma$. Neste caso, os valores das estimativas dos coeficientes $\hat{\alpha}_{j}$, resultantes do modelo com a base original e os valores para a média e mediana de suas respectivas amostras bootstrap se distanciam um pouco mais, com a maior diferença na ordem de 0,06. Este fato ratifica o afastamento da normalidade dos parâmetros já observada nas Figuras 5.3 e 5.4.

Entretanto, a significância resultante dos testes padrões do modelo GAMLSS são equiparáveis aos resultados obtidos pelos intervalos de confiança bootstrap, ou seja, a interação entre Kasai e PELD continua significante para a variabilidade da transfusão de sangue ao considerar ambos os intervalos, percentil e percentil centrado.

\begin{tabular}{rcccccccc}
\hline & $\hat{\alpha}_{j}$ & $\hat{\mu}\left(\hat{\alpha}_{j}^{*}\right)$ & $\hat{M}\left(\hat{\alpha}_{j}^{*}\right)$ & $\hat{\sigma}\left(\hat{\alpha}_{j}^{*}\right)$ & $L I_{p}$ & $L S_{p}$ & $L I_{c}$ & $L S_{c}$ \\
\hline Intercepto & $\mathbf{- 1 , 0 9 6}$ & $-1,151$ & $-1,128$ & 0,177 & $-1,559$ & $-0,879$ & $\mathbf{- 1 , 3 1 2}$ & $\mathbf{- 0 , 6 3 2}$ \\
Kasai(1) & 0,333 & 0,369 & 0,353 & 0,203 & $\mathbf{0 , 0 2 4}$ & $\mathbf{0 , 8 2 0}$ & $-0,153$ & 0,642 \\
PELD(2) & 0,160 & 0,194 & 0,176 & 0,194 & $-0,134$ & 0,629 & $-0,309$ & 0,454 \\
PELD(3) & 0,011 & 0,040 & 0,023 & 0,201 & $-0,299$ & 0,484 & $-0,463$ & 0,320 \\
PELD(4) & 0,046 & 0,078 & 0,064 & 0,201 & $-0,270$ & 0,523 & $-0,430$ & 0,363 \\
Kasai(1)*PELD(2) & $-0,227$ & $-0,262$ & $-0,249$ & 0,235 & $-0,759$ & 0,161 & $-0,615$ & 0,305 \\
Kasai(1)*PELD(3) & $\mathbf{- 0 , 6 2 8}$ & $-0,671$ & $-0,659$ & 0,263 & $\mathbf{- 1 , 2 2 9}$ & $\mathbf{- 0 , 1 8 3}$ & $\mathbf{- 1 , 0 7 2}$ & $\mathbf{- 0 , 0 2 7}$ \\
Kasai(1)*PELD(4) & $-0,390$ & $-0,445$ & $-0,430$ & 0,277 & $-1,034$ & 0,060 & $-0,839$ & 0,254 \\
\hline
\end{tabular}

Tabela 5.2: Medidas descritivas dos coeficientes $\hat{\alpha}_{j}^{*}$ para as amostras bootstrap do modelo ZAIG.

Nitidamente os valores da Tabela 5.3 confirmam que os coeficientes derivados da modelagem do parâmetro de probabilidade $\nu$ não seguem uma distribuição normal. Ao comparar as estimativas $\hat{\gamma}_{j}$ às médias dos respectivos coeficientes obtidos nas amostras bootstrap a diferença chega a ser de 3,5 pontos para o efeito do $P E L D(2)$. Em termos de probabilidade, isto indica que a modelagem da amostra original resulta em uma probabilidade consideravelmente maior do indivíduo que não 
recebeu transfusão de sangue estar classificado neste nível do índice de debilidade do fígado.

Ao avaliar o intervalo de confiança bootstrap percentil a inferência sobre o modelo se mantém, de forma que a interação entre as variáveis explicativas pode ser desconsiderada do modelo. Entretanto, o segundo intervalo proposto na metodologia resulta em conclusão diferente, indicando que a interação é significativa para a probabilidade de não receber transfusão de sangue.

\begin{tabular}{rcccccccc}
\hline & $\hat{\gamma}_{j}$ & $\hat{\mu}\left(\hat{\gamma}_{j}^{*}\right)$ & $\hat{M}\left(\hat{\gamma}_{j}^{*}\right)$ & $\hat{\sigma}\left(\hat{\gamma}_{j}^{*}\right)$ & $L I_{p}$ & $L S_{p}$ & $L I_{c}$ & $L S_{c}$ \\
\hline Intercepto & $\mathbf{- 1 , 3 8 6}$ & $-1,698$ & $-1,435$ & 1,804 & $-3,045$ & $-0,442$ & $-2,331$ & 0,272 \\
Kasai(1) & $-0,066$ & 0,210 & $-0,045$ & 1,832 & $-1,312$ & 1,816 & $-1,948$ & 1,180 \\
PELD(2) & $-2,079$ & $-5,570$ & $-2,256$ & 5,734 & $-13,817$ & 0,105 & $-4,264$ & 9,658 \\
PELD(3) & $-1,447$ & $-2,709$ & $-1,511$ & 4,412 & $-13,510$ & 0,636 & $-3,530$ & 10,616 \\
PELD(4) & $\mathbf{- 2 , 3 7 5}$ & $-5,659$ & $-2,538$ & 5,571 & $\mathbf{- 1 3 , 8 1 7}$ & $\mathbf{- 0 , 0 1 9}$ & $-4,731$ & 9,067 \\
Kasai(1)*PELD(2) & 0,464 & 2,457 & 0,547 & 6,912 & $-12,005$ & 12,505 & $-11,577$ & 12,932 \\
Kasai(1)*PELD(3) & $-10,304$ & $-9,863$ & $-11,015$ & 4,348 & $-13,502$ & 0,634 & $\mathbf{- 2 1 , 2 4 1}$ & $\mathbf{- 7 , 1 0 6}$ \\
Kasai(1)*PELD(4) & 0,361 & $-0,033$ & 0,223 & 7,779 & $-12,214$ & 12,237 & $-11,514$ & 12,937 \\
\hline
\end{tabular}

Tabela 5.3: Medidas descritivas dos coeficientes $\hat{\gamma}_{j}^{*}$ para as amostras bootstrap do modelo ZAIG.

O intervalo de confiança bootstrap percentil possui vasta aplicação na literatura, e por isso seus resultados foram considerados para a confirmação dos métodos de seleção utilizados no capítulo anterior. Com isso, o algoritmo definido no início da seção foi aplicado novamente para o modelo reduzido, seguindo a equação (4.4).

Conforme esperado, as análises para os ajustes dos parâmetros $\mu$ e $\sigma$ não se alteram, já que estes não sofreram redução de variáveis e a ortogonalidade dos parâmetros da distribuição implica em coeficientes independentes entre seus modelos. Seus resultados podem ser observados nas tabelas e gráficos apresentados acima.

Os gráficos na Figura 5.7 mantém as características observadas na modelagem do parâmetro de probabilidades para o modelo completo, em que possivelmente os coeficientes relativos à variável $P E L D$ são derivados de uma mistura de distribuições. Neste caso porém, observam-se valores extremos apenas para a probabilidade nula de ocorrência de indivíduos que não receberam transfusão de sangue e são classificados nos quartis dois, três e quatro do PELD.

Ao comparar os quantis amostrais com os quantis gaussianos na Figura 5.8, a fuga da normalidade continua evidente, mesmo para o intercepto, que passou a ter apenas um grupo de dados no gráfico, porém com muitos pontos fora das bandas de confiança. Para os níveis da variavel PELD, os dados ainda se apresentam em dois grupos distintos, da mesma forma que foi avaliado nos histogramas da Figura 5.7.

Ao avaliar as medidas da Tabela 5.4, verifica-se uma proximidade consideravelmente maior entre as estimativas dos coeficientes $\hat{\gamma}_{j}$ e a média e mediana amostrais bootstrap de seus respectivos coeficientes. O intervalo de confiança percentil obtém exatamente o mesmo resultado em termos de significância das variáveis explicativas para o modelo; todos os níveis da PELD tem efeito diferente de zero no modelo, e conforme a escala de debilidade aumenta, a probabilidade do paciente não receber transfusão de sangue é reduzida.

Já o intervalo de confiança percentil centrado mantém o resultado apresentado na Tabela 5.3 para o modelo completo, indicando que a variável PELD não é significante para o modelo de probabilidades.

\begin{tabular}{rcccccccc}
\hline & $\hat{\gamma}_{j}$ & $\hat{\mu}\left(\hat{\gamma}_{j}^{*}\right)$ & $\hat{M}\left(\hat{\gamma}_{j}^{*}\right)$ & $\hat{\sigma}\left(\hat{\gamma}_{j}^{*}\right)$ & $L I_{p}$ & $L S_{p}$ & $L I_{c}$ & $L S_{c}$ \\
\hline Intercepto & $\mathbf{- 1 , 4 3 5}$ & $-1,461$ & $-1,435$ & 0,302 & $\mathbf{- 2 , 1 1 0}$ & $\mathbf{- 0 , 9 2 7}$ & $\mathbf{- 1 , 9 4 3}$ & $\mathbf{- 0 , 7 6 0}$ \\
PELD$(2)$ & $\mathbf{- 1 , 7 8 4}$ & $-2,408$ & $-1,843$ & 2,495 & $\mathbf{- 1 2 , 8 3 5}$ & $\mathbf{- 0 , 6 6 4}$ & $-2,904$ & 9,267 \\
PELD(3) & $\mathbf{- 2 , 1 8 9}$ & $-3,620$ & $-2,276$ & 3,721 & $\mathbf{- 1 3 , 0 5 3}$ & $\mathbf{- 0 , 9 8 3}$ & $-3,395$ & 8,675 \\
PELD(4) & $\mathbf{- 2 , 1 8 9}$ & $-3,537$ & $-2,277$ & 3,614 & $\mathbf{- 1 2 , 9 9 9}$ & $\mathbf{- 0 , 9 9 3}$ & $-3,385$ & 8,621 \\
\hline
\end{tabular}

Tabela 5.4: Medidas descritivas dos coeficientes $\hat{\gamma}_{j}^{*}$ para as amostras bootstrap do modelo ZAIG reduzido. 

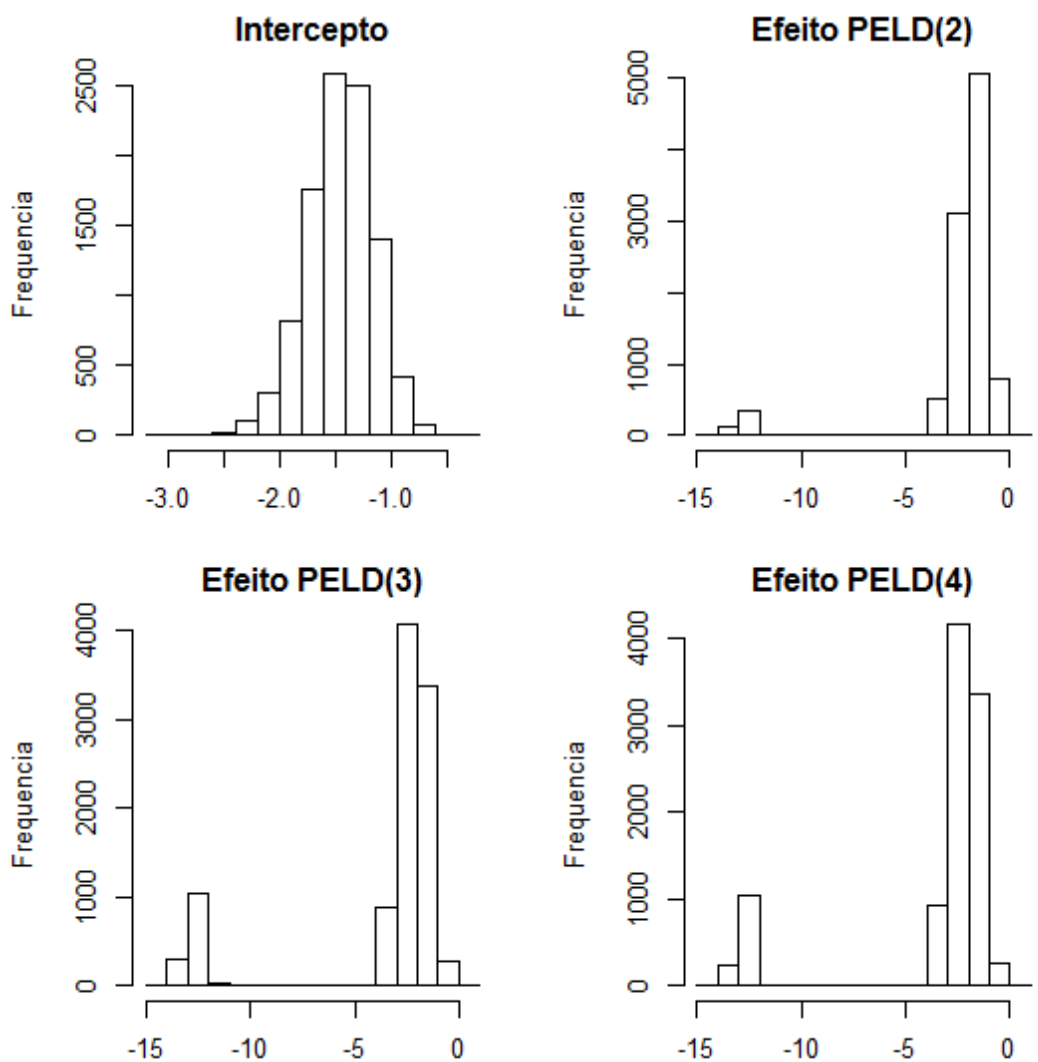

Figura 5.7: Histograma das estimativas para cada $\hat{\gamma}_{j}^{*}$ derivados do ajuste do parâmetro $\nu$ no modelo reduzido.

Se considerado o intervalo de confiança bootstrap percentil centrado, o modelo adotado para o parâmetro de probabilidades poderia ser diferente, devido à significância que este entrega a interação entre Kasai e PELD. Entretanto, devido à base extremamente reduzida neste cruzamento, entendese que a sensibilidade do teste deve ser avaliada com cautela, levando em consideração todo o conjunto de informações disponíveis ao longo da análise dos dados. Como a interação entre as variáveis provoca de forma significativa o aumento da média de transfusão de sangue recebida pelo paciente, é plausível supor que esta mesma interação não iria aumentar a probabilidade de não receber transfusão.

Portanto, o estudo bootstrap neste capítulo revela que os resultados apresentados no capítulo anterior ao considerar testes padrões do modelos GAMLSS e o critério GAIC podem ser considerados válidos. 

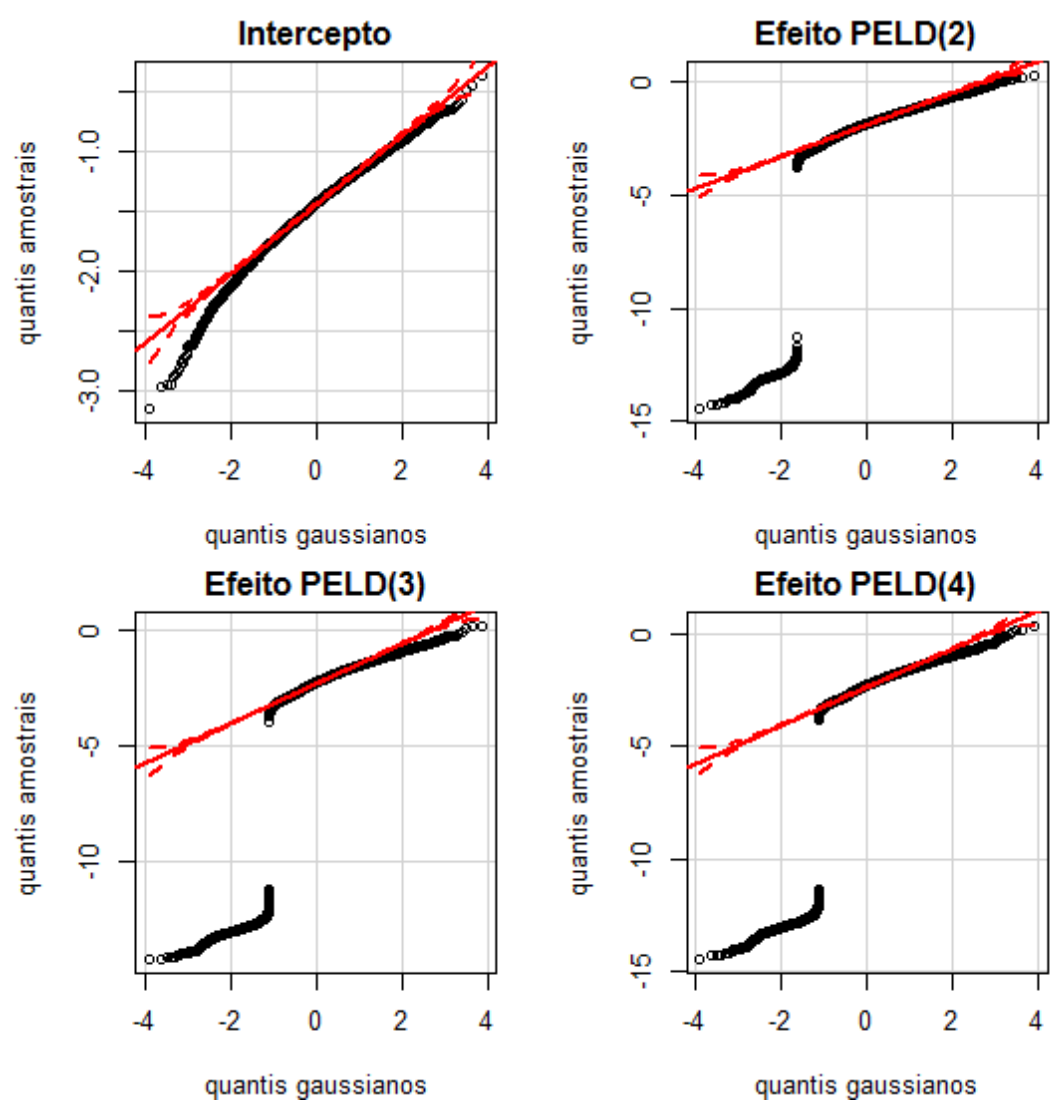

Figura 5.8: Gráfico quantil-quantil das estimativas para cada $\hat{\gamma}_{j}^{*}$ derivados do ajuste do parâmetro $\nu$ no modelo reduzido. 


\section{Capítulo 6}

\section{Conclusões e sugestões}

Neste capítulo será apresentada uma síntese do conteúdo desenvolvido e discutido ao longo da dissertação, possibilitando comparações e sugestões de métodos para análise de dados assimétricos, assim como metodologias similares investigadas mas que não apresentaram vantagens suficientes para desenvolvimento neste trabalho.

Em termos de distribuição amostral, a informação do Capítulo 2 de que em geral as distribuições gama e log-normal produzem resultados semelhantes e, consequentemente, a mesma inferência para o modelo, mostrou-se válida também para a distribuição normal inversa, especificamente para os coeficientes do modelo de médias. A grande diferença entre as distribuições reside na estimação do parâmetro de dispersão, visto que a variabilidade de cada distribuição apresenta diferentes funções da média. Por este motivo, a distribuição normal inversa, que leva em consideração uma função cúbica da média, mostrou-se vantajosa neste trabalho, em que a assimetria dos dados é mais acentuada.

A proximidade das distribuições para o parâmetro de média resultou ainda em estimativas iguais nos coeficientes do modelo para $\mu$, se consideradas as distribuições gama e normal inversa com ligação logarítmica para o parâmetro, o que deve ocorrer já que a média amostral é o estimador de máxima verossimilhança em ambos os casos. A distribuição log-normal pede que a transformação logarítmica seja aplicada aos dados previamente à modelagem, de forma que as estimativas dos coeficientes sejam construídas a partir de médias geométricas, enquanto para as outras distribuições as estimativas são obtidas através de médias aritméticas, e por isso não se apresentem iguais.

Entre os diversos softwares estatísticos e suas múltiplas funções para modelagem de dados, foram investigados para esta dissertação o SAS e o R.

No software SAS, a função PROC FMM, correspondente aos modelos de misturas finitas (Finite Mixture Models - FMM), permite a modelagem da base completa de dados por comportar o ajuste de valores nulos da variável resposta para qualquer distribuição (SAS Institute Inc., 2013). Suas aplicações geralmente são ilustradas em dados inflacionados de zero para distribuições de contagem, como a Poisson ou Binomial Negativa, considerando que os dados são provenientes de uma mistura de distribuições univariadas. Neste caso, supõe-se que as observações são geradas por dois processos com funções de distribuição distintas, uma para gerar valores iguais a zero e outra para valores no suporte da distribuição. Dessa forma, a modelagem dos dados resulta em dois ajustes, um para a média da variável resposta e outro para a probabilidade desta ser igual a zero, e assim como nos modelos GAMLSS, as variáveis explicativas podem ser testadas em ambos ajustes. Entretanto, esta abordagem não permite a modelagem do parâmetro de escala em função das variáveis explicativas do estudo, o que se mostrou essencial para o conjunto de dados deste estudo.

O trabalho de Mills (2013) trouxe grande contribuição para o entendimento do processo de modelagem da mistura de distribuições discreta-contínua, já que esta apresenta o desenvolvimento de modelos gama e log-normal inflacionados de zero, assim como testes para comparações de grupos de unidades amostrais. Os dados são ajustados a partir de modelos de duas partes, uma para os dados positivos por meio de uma regressão gama com função de ligação logarítmica (ou uma regressão lognormal) e outra para a probabilidade da observação ser positiva em uma regressão logística. A tese 
considera ainda o acréscimo de variáveis explicativas binárias ou contínuas no modelo, entretanto a variável PELD, com quatro níveis e de grande significância para este estudo, não seria comportada por sua metodologia, resultando na necessidade de complemento em seus algoritmos. Assim como nos modelos FMM, o parâmetro de escala seria estimado como uma constante, sem possibilidade de testar a significância do efeito das variáveis explicativas sobre a variabilidade.

A solução para modelagem do parâmetro de dispersão foi testada também por meio dos modelos DGLM, citados no Capítulo 3. Nesta metodologia o parâmetro de média é ajustado simultaneamente ao de escala, portanto se apresenta equivalente ao modelo GAMLSS quando ajustado para estes mesmos parâmetros. Entretanto para diagnóstico do modelo, avalia-se separadamente a qualidade do ajuste de cada parâmetro, uma desvantagem em relação ao modelo GAMLSS que produz os resíduos quantílicos (aleatorizados) para uma avaliação completa do modelo. Esta categoria de modelos foi descartada ainda por não comportar as observações nulas da variável resposta, ou seja, não modela a probabilidade do indivíduo não receber transfusão de sangue.

Após avaliar estas metodologias, que ora comportam a modelagem do parâmetro de escala, ora a probabilidade de não receber transfusão de sangue (além da média), somada às estimativas constantes dos coeficientes dos parâmetros $\mu$ e $\sigma$ para os modelos GAMLSS com distribuição normal inversa ou ZAIG, foi possível concluir que modelar a variável binária com um modelo logístico e separadamente os valores positivos da variável resposta com uma distribuição adequada para esses dados é equivalente a modelar conjuntamente. Isso ocorre pelo fato de que no modelo completo a verossimilhança é fatorada, de modo que os coeficientes do modelo logístico ficam em um fator e os coeficientes relativos à parte positiva ficam em outro. Entre as vantagens de se ajustar um modelo completo, estão o diagnóstico por meio da análise de resíduos e escolha de modelos utilizando medidas como o GAIC, unificado para todos os dados.

Para este trabalho, essa abordagem de modelo logístico desassociado do modelo para dados positivos seria aplicável para a distribuição log-normal. Todavia, não foi necessário considerar a análise com a distribuição log-normal inflada de zeros, pois o ajuste do modelo na Subseção 4.2.2 foi considerado inapropriado para modelar a quantidade de sangue por peso para os pacientes que receberam transfusão.

Outra vantagem do modelo completo com base nas distribuições ZAGA e ZAIG, suportadas pelos modelos GAMLSS, reside na construção de valores preditos pelo modelo, bem como intervalos de confiança para a resposta do indivíduo, alvo desta dissertação. Ao trabalhar com a distribuição ZAIG, os limites do intervalo puderam ser obtidos por seus quantis, considerando os parâmetros $\mu$, $\sigma$ e $\nu$ estimados no modelo como verdadeiros para a população.

Caso o tratamento dos dados seja de forma independente para as observações da variável resposta positivas e nulas, a construção do intervalo de confiança ainda é possível, entretanto o nível de confiança precisa ser ajustado. Com os resultados obtidos no modelo de médias, a metodologia de quantis da Subseção 3.1.6 pode ser aplicada para distribuições usuais, geralmente implementadas nos softwares estatísticos. A diferença estará no percentil aplicado, que deverá ser ajustado de acordo com a probabilidade da observação ser igual a zero, estimada no modelo logístico.

O estudo bootstrap do modelo GAMLSS se mostrou importante para a confirmação das metodologias utilizadas na análise da seleção de variáveis explicativas. A primeira verificação importante foi em relação à distribuição assintótica dos estimadores dos coeficientes para cada parâmetro modelado. Em relação ao parâmetro de média, a suposição de normalidade assintótica pode ser ratificada, entretanto, para os coeficientes dos ajustes dos parâmetros $\sigma$ e $\nu$, esta suposição é violada explicitamente.

Ainda assim, a construção do intervalo de confiança bootstrap percentil confirmou a seleção das variáveis explicativas realizada pelos testes padrões do modelo GAMLSS e o critério GAIC para os ajustes dos três parâmetros da distribuição ZAIG, $\mu, \sigma$ e $\nu$. Um segundo intervalo de confiança bootstrap, denominado percentil centrado, também foi considerado na análise, porém apresentou resultados distintos para os coeficientes relativos ao modelo de probabilidades. Devido à característica dos dados, assim como a uniformidade dos outros métodos, este resultado não provocou maiores questionamentos na validade do modelo final selecionado para avaliação da relação entre a 
transfusão de sangue por peso recebida pelos pacientes com atresia biliar e suas características de debilidade do fígado, PELD, e participação na pré-cirurgia de Kasai. 


\section{Referências Bibliográficas}

Akantziliotou et al. (2002) C. Akantziliotou, R. A. Rigby e D. M. Stasinopoulos. The r implementation of generalized additive models for location, scale and shape. Em M. In Stasinopoulos e G. (eds.) Touloumi, editors, Statistical Modelling in Society: Proceedings of the 17th International Workshop on Statistical Modelling, páginas 75-83. Citado na pág. 2, 12

Chardot (2006) C. Chardot. Biliary atresia. Orphanet Journal of Rare Diseases, 1(1):28. Citado na pág. 23

Dunn e Smyth (1996) P. K. Dunn e G. K. Smyth. Randomized quantile residuals. Journal of Computational and Graphical Statistics, 5(3):236-244. Citado na pág. 20, 21

Efron e Tibshirani (1986) B. Efron e R. Tibshirani. Bootstrap methods for standard errors, confidence intervals, and other measures of statistical accuracy. Statistical Science, 1:54-75. Citado na pág. 45

Firth (1988) D. Firth. Multiplicative errors: log-normal or gamma? Journal of the Royal Statistical Society. Series B (Methodological), páginas 266-268. Citado na pág. 10

Giner e Smyth (2014) G. Giner e G. K. Smyth. A monotonically convergent Newton iteration for the quantiles of any unimodal distribution, with application to the inverse gaussian distribution. Citado na pág. 17

Hastie e Tibshirani (1990) T. J. Hastie e R. J. Tibshirani. Generalized Additive Models, volume 43. CRC Press. Citado na pág. 12

Heller et al. (2006) G. Heller, D. M. Stasinopoulos e R. A. Rigby. The zero-adjusted inverse gaussian distribution as a model for insurance claims. Em Proceedings of the 21th International Workshop on Statistical Modelling, páginas 226-233. Citado na pág. 5, 10

Jorgensen (1987) B. Jorgensen. Exponential dispersion models (with discussion). Journal of the Royal Statistical Society B, 49:127-162. Citado na pág. 9

McCullagh e Nelder (1989) P. McCullagh e J. A. Nelder. Generalized Linear Models. London: Chapman and Hall, second ed. Citado na pág. 10

Mills (2013) E. D. Mills. Adjusting for covariates in zero-inflated gamma and zero-inflated lognormal models for semicontinuous data. Tese de Doutorado, Universidade de Iowa, Estados Unidos. Citado na pág. 20, 55

Montgomery e Peck (1992) D. C. Montgomery e E. A Peck. Introduction to Linear Regression Analysis. John Wiley \& Sons. Citado na pág. 11, 21

Mood (1950) A. M. Mood. Introduction to the Theory of Statistics. McGraw-hill. Citado na pág. 14

Nelder e Wedderburn (1972) J. A. Nelder e R. W. M. Wedderburn. Generalized linear models. Journal of the Royal Statistical Society. Series A, páginas 370-384. Citado na pág. 2, 11, 12

Paula (2013) G. A. Paula. Modelos de Regressão: com apoio computacional. IME-USP São Paulo. Citado na pág. 5, 9, 11, 12, 15

R Core Team (2014) R Core Team. R: A Language and Environment for Statistical Computing. R Foundation for Statistical Computing, Vienna, Austria, 2014. URL http://www.R-project.org/. Citado na pág. 12

Rigby e Stasinopoulos (2001) R. A. Rigby e D. M. Stasinopoulos. The gamlss project: a flexible approach to statistical modelling. Em B. In Klein e L. (eds.) Korsholm, editors, New Trends in Statistical Modelling: Proceedings of the 16th International Workshop on Statistical Modelling, páginas 249-256. Citado na pág. 2, 12 
Rigby e Stasinopoulos (2005) R. A. Rigby e D. M. Stasinopoulos. Generalized additive models for location, scale and shape. Applied Statistics, 54:507-554. Citado na pág. 2, 12, 17, 19, 21

SAS Institute Inc. (2013) SAS Institute Inc. SAS/STAT® 13.1 User's Guide. SAS Institute Inc., Cary, NC, USA, 2013. Citado na pág. 55

Silva et al. (2011) E. S. Silva, M. Medina, P. Rocha, B. Bonet, J. A. F. de Sousa e C. Enes. Atrésia das vias biliares extrahepáticas: estudo clínico retrospectivo. Nascer e Crescer - Revista do Hospital de Crianças Maria Pia, 20:9 - 15. ISSN 0872-0754. URL http://www.scielo.gpeari. mctes.pt/scielo.php?script=sci_arttext\&pid=S0872-07542011000100002\&nrm=iso. Citado na pág. 23

Singh e Xie (2010) K. Singh e M. Xie. Bootstrap: A statistical method. 2010. URL http: //www.stat.rutgers.edu/home/mxie/RCPapers/bootstrap.pdf. Citado na pág. 45

Smyth (1989) G. K. Smyth. Generalized linear models with varying dispersion. Journal of the Royal Statistical Society. Series B (Methodological), 51(1):47-60. Citado na pág. 2, 12

Stasinopoulos et al. (2008) D. M. Stasinopoulos, R. A. Rigby e C. Akantziliotou. Instructions on how to use the gamlss package in R. Accompanying documentation in the current GAMLSS help files,(see also http://www.gamlss.com/). Citado na pág. 21

Stasinopoulos et al. (2014) D. M. Stasinopoulos, R. A. with contributions from Calliope Akantziliotou Rigby, Gillian Heller, Raydonal Ospina, Nicoletta Motpan, Fiona McElduff, Vlasios Voudouris, Majid Djennad, Marco Enea e Alexios Ghalanos. gamlss.dist: Distributions to be used for gamlss modelling. URL http://CRAN.R-project.org/package=gamlss.dist. R package version 4.3-0. Citado na pág. 5, 6, 7, 9, 12, 19, 28

Venables e Ripley (2002) W. N. Venables e B. D. Ripley. Modern Applied Statistics with S. Springer, New York, fourth ed. URL http://www.stats.ox.ac.uk/pub/MASS4. ISBN 0-38795457-0. Citado na pág. 12

Wiens (1999) B. L. Wiens. When log-normal and gamma models give different results: A case study. The American Statistician, 53(2):89-93. Citado na pág. 10 